\title{
XXVIII.
}

Aus der medicinischen Poliklinik der Universität Halle a. S. (Director: Prof. Dr. I. Mohr).

\section{Ueber den Gaswechsel verschiedener Formen von Fett- sucht und seine Beeinflussung durch Nahrungsaufnahme, Arbeit und Arzneimittel.}

Von

\section{Heinrich Haussleiter.}

(Mit 1 Abbildung in Text.)

\section{Einleitung.}

Unsere heutigen Anschauungen und Kenntnisse vom Wesen der Fettsucht sind das Product zweier an sich heterogener Begriffe, des Begriffes cines Energiewechsels des Organismus und desjenigen der chemischen Correlation der Organe auf dem Wege der inneren Secretion. Beide wurden etwa zu gleicher Zeit im Anfang der achtziger Jahre des vorigen Jahrhunderts gebildet.

Der energetischen Betrachtungsweise gelang es durch Prüfung der Energiebilanz einen T'eil der bis dahin ohne Unterschied als Fettsucht zusammengefassten Fälle restlos durch äussere Factoren verursacht zu erklären. Fin Zuviel an Nahrung oder ein Zuwonig an K̈örpermuskelarbeit konnte, gemessen an der für beide Factoren gleichen Einheit der äquivalenten Wärmemenge, mit physikalischer Genauigkeit als Ursache nachgewiesen werden. Die Mastfettsucht und die Faulheitsfettsucht schieden aus der Gruppe der eigentlichen Stoffwechselkrankheiten (trotz der vielleicht für die Fettsucht noch grösseren Bedeutung des Kraftwechsels bleibt diese Bezeichnung noch bestehen) aus.

Der Rest der Fälle liess sich nicht auf äussere Factoren zurückführen. Der Begriff der endogenen Fettsucht konnte energetisch nicht erklärt, nur umschrieben werden. Das Gesetz der Erhaltung der Energie schien für diese Formen einen sparsameren Fnergiewechsel zu fordern. Für den Grundumsatz wurde dieser in einigen Fällen nachgewiesen. Auch für den Arbeitsumsatz (sei es äussere, sei es Drüsen-Arbeit) wurde nach einer ökonomischeren Energieverwendung gefahndet. Diese liess sich jedoch bis jetzt nicht erweisen. Im Uebrigen ergab die genauc energetische Beschreibung einer Reihe solcher Fälle eine ungemeine Mannigfaltigkeit der Verhältnisse, die bis heute noch nicht erlaubt, auch nur eine bei endogenen Formen der Fettsucht vorkommende Eigenschaft des Energiewechsels auf alle diese Formen zu verallgemeinern.

Eine andere Forschungsrichtung gab nummehr Anregung zu neuer Problemstellung und Aussicht auf eine das ätiologische Bedürfnis mehr 
befriedigende Erklärung der endogenen Fettsucht. Nach den Untersuchungen über die innere Secretion kann man den Energiewechsel seiner Intensität nach normaler Weise als eine Function des polyglandulären Apparates auffassen, und so Störungen des Energiewechsels, also auch die endogene Fettsucht auf Störungen dieses Apparates zurückführen. Die zahlreichen anatomischen und funktionellen Drüsenanomalien, die sich oft mit endogener Feltsucht, wie schon früher bekannt war, vergesellschaftet fanden, gaben ein reiches Feld für Combinationen und Untersuchungen über ihren Zusammenhang mit dieser Anomalie des Energiewechsels. Der Einfluss von Schilddrüse, Zwischensubstanz der Genitaldrüsen, Hypophyse, Fpiphyse, Thymus, Pankreas worden teils im Tierexperiment, teils experimentell am Menschen durch Verabreichung entsprechender Organpräparate erforscht. Ein directer Einfluss auf den Energiewechsel des Menschen konnte bis jetzt nur bei der Schilddrüse experimentell bewiesen werden. Alles Uebrige blieb bisher Vermutung, aber ein Erfolg dieser Forschungsrichtung, der auch jetzt schon zutage tritt, war die neue Erkenntnis, dass nur die Combination von genauester klinischer Untersuchung des Fnergiewechsels einerseits in unbeeinflusstem, andererseits in experimentell-medicamentös beeinflusstem Zustand eine weitere Klärung der Fettsuchtsfrage zeitigen könne, und dass es erforderlich ist, eine möglichst grosse Reihe von Fällen nach diesen Gesichtspunkten möglichst individualisiert $z u$ untersuchen und vorläufig $z u$ sammeln, bis ein grösseres Material sichere Schlüsse erlaubt.

Die folgenden Untersuchungen wurden unter diesem Gesichtspunkt angestellt. Weiter wurde der Einfluss der Nahrungsaufnahme, der Arbeit und der Schilddrüsensubstanz auf den Gaswechsel von Fettsüchtigen geprült; ausserdem wurde jedoch noch ein zweites Medicament in die Untersuchung miteinbezogen, das um so mehr lnteresse verdient, als seine Wirksamkeit theoretisch auf ganz anderen als den eben dargelegten Anschauungen basiert ist, welche daher ebenfalls an dieser Stelle noch zu charakterisieren sind.

Es handelt sich um ein Metall der Platingruppe, bekanntlich der Gruppe der anorganischen Katalysatoren, um das Palladium. Dieses nimmt durch seine Fähigkeit, das 370 fache Volumen an Wasserstoff zu absorbieren, in der anorganischen Chemie eine Sonderstellung ein. Es wurde nun angegeben, dass es auch auf lebende Substanz als oxydationssteigender positiver Katalysator wirke, und auch auf den menschlichen Organismus, wo er eine solche Auregung bedurlte, mit Erfolg angewandt werden könne in Form der, erst seit neuster Zeit darstellbaren colloidalen Jösung des Palladiumhydroxydul $\left[\mathrm{Pd}(\mathrm{OH})_{2}\right]$. (1 $\left.{ }^{*}\right)$.

Bewahrheitete sich diese Angabe, so würde neben dem einzigen bisher beschrittenen Wege, die endogene Fettsucht organo-therapeutisch zu bekämpfen, ein zweiter einfacherer Weg gefunden sein, ohne den Umweg über den polyglandulären Regulationsapparat direct den Umsatz des lebenden Protoplasmas beeinflussend $\mathrm{zu}$ erreichen.

*) Siehe Literaturangabe: 1). 


\section{Methodik.} suche:

Folgende Punkte waren massgebend für die Wabl der Methodik unserer Ver-

1. Es waren zu erstreben bequeme Vergleichswerte verschiedener Individuen verschiedener Altersstufen, zu deren Grundlage allein der Ruheumsatz zu verwerten ist.

2. Es mussten relativ kleine $\Lambda$ bweichungen, wie sie durch $z$. T'. kurz dauernde äussere Einflüsse (Arbeit, Nahrungsaufnahme) oder Medicamente hervorgerufen werden sollten, zu prägnantem Ausdruck gebracht werden.

Es wurde daher der sogenannte kurze Respirationsversuch in der von $Z \mathbf{u} \mathbf{t z}$ bis ins einzelne kritisch ausgearbeiteten und in ihrer Bewertung abgegrenzten Anordnung gewählt $(2,3)$. Von dieser wurde in keinem wesentlichen Punkte abgewichen. An Finzelheiten sei daher nur Folgendes betont:

Der Versuchsraum befand sich im Souterrain, mit der Lage nach Norden, zeigte daher eine ziemlich gleichmässige, insbesondere während der Sommermonate nicht zu hohe T'emperatur. Die Versuchsperson lag in leichtester Kleidung auf einem horizontalen Ruhelager unter Beobachtung sog. "vorsätzlicher Muskelrube". Die Nase wurde mit federnder Klemme geschlossen. Die Atmung erfolgte durch ein Gummimundstück, zu dem ein Zuntzsches Darmventil Luft aus dem Freien zuführte, während ein anderes die Exspirationsluft zur Gasuhr abführte. Letztere bestand in einem kurz zuvor geprüften trockenen transportablen Gasmesser nach $Z$ untz mit Ablesung bis zu $10 \mathrm{ccm}$ und doppeltem Thermometer. Das abgelesene Gasvolumen wurdo - unter Annahme vollkommener Wasserdampfsättigung der Exspirationsluft - auf Trockenheit und ausserdem, wie solbstverständlich, auf 0 Grad und $760 \mathrm{~mm}$ Quecksilberdruck reduciert [unter Benutzung der physikalisch-chemischen l'abellen von Landolt und Börnstein (4)]. Der Iuftdruck wurde vor jedem Versuoh auf einem Quecksilberbarometer auf Millimeter abgelesen, auf $0,1 \mathrm{~mm}$ abgeschätzt und [nach der Tabelle von Kohlrausch, Lehrbuch der praktischen Physik (5)] auf Tomperatur 0 Grad für Ausdehnungscoëfficient der Glasskala und Quecksilbersäule corrigiert. Die Vorversuchsperiode wurde immer bis zu eingotretener gleichmässiger Atmung (erlaubte Scliwankung der abgelesenen Minutenatemvolumina $=10 \mathrm{pCt}$.) nicht unter 10 Minuten, nach Erfordernis öfters über 20 Minuten ausgedehnt. Die Dauer des Hauptversuchos schwankte in der Regel zwischen 25 und 40 Minuten. In den Versuchen $71-78$ (vgl. 'Tabelle IX) mit z. T. kürzerer Versuchsdauer, ist diese in jedem Fall besonders angegeben. Die gewöhnlich gleichzoitig in zwei Bürotten gloichmässig abgesogene Respirationsluft wurde meist sofort im Auschluss an den Versuch, zum mindesten noch am selben Tage mit einem etwas modificierten Zuntz-Geppertschen Analysenapparat unter Benutzung von Phosphor- und Natronlauge-Pipetten analysiert. Die Differenz der Doppelanalysen überschritt in der Regel nicht 0,05 pCt., als Grenze der erlaubten Abweichung wurde $0,1 \mathrm{pCl}$. festgesetzt. Zur Erlangung gleichmässiger Resultate stellte sich als wesentlich heraus, dass die beiden Messbüretten nicht nacheinander, sondern gleichmässig mit Exspirationsluft aufgefüllt wurden; und zwar wurde dazu möglichst die ganze während des Versuchs in eine der beiden Aufnahmebüretten gefüllte Luftsäulo verwendet. So wurden Fohler vermieden, dio sich sonst durch unvollkommene Mischung der in ihrer Zusammensetzung nicht ganz konstanten Exspirationsluft hätten ergeben liönnen. Die Skala der mit Rosolsäurewasser gefüllten Büretten wurde nach 5--7 Minuten während dem Absitzenlassen auf $0,1 \mathrm{ccm}$ abgelesen und auf 0,01 com geschätzt.

Zur Kontrolle der Absorptionspipetten wurde ab und zu eine Analyse der Aussenluft eingeschoben. Auf die Ausführungen der Thermo-Barometercorrectionen und die weitere Ausrechnung der in unseren 'Tabellen befindlichen Werte, welche mit 
fünfstelligen Logarithmen nach dem üblichen Schema ausgeführt wurde, einzugeben, würde zu weit fübren. Als $\mathrm{O}_{2}$-Gehalt der Luft wurde $20,92 \mathrm{pCt}$. angenommen.

Die Anordnung der Tabellen wird, so weit sie sich nicht von selbst ergibt, bei der Besprechung der einzelnen Fälle erläutert. Ebenso finden dort Abweichungen von der hier geschilderten Versucbsanordnung Erwähnung.

Das Körpergewicht wurde immer zur gleichen Tageszeit (vormittags), meist ganz nüchtern, nur vereinzelte Male nach kleinem Frübstück, festgestellt.

Der Begriff „nüchtern" wird gebraucht für den Zustand mindestens 12 Stunden nach einer nicht übermässigen Mahlzeit.

1. Fall. (Or.)

(Vgl. Tab. I [S. 423], T'ab. Ill [S. 428/429], Tab. IV [S. 433].)

Wir weichen in der Darstellung von der zeitlichen Reihenfolge der einzelnen Untersuchungen ab und beginnen mit dem zuletzt untersuchten Patienten Or. Dies hat seinen Grund darin, dass dieser Fall compliciertere Verhältnisse bietet als die übrigen und daher im besonderen Masse Anlass gibt zur Besprechung allgemein wichtiger Punkte, Wiederholungen also bei jedem weiteren Falle so am besten vermieden werden.

A. Krankengeschichte. (12.8. 1913.)

Patient: Or., früher Fleischermeister, jetzt obne Beruf, 40 Jahre alt.

Diagnose: Kombination endogener Fettsucht mit Mastfettsucht, beiderseitige Parotisschwellung, Nephritis chronica, Herzschwäche, Hyperglobulie.

Anamnese: Vor etwa vier Jahren, also im Alter von ca. 36 Jahren, will Patient in ziomlich kurzer Zeit sehr stark geworden sein. Vorher betrug sein Gewicht angeblich ca. $93 \mathrm{~kg}$. In seiner Jugend war Or. nie krank, hat beim Militär gedient (Oberjäger), hatte zu der Zeit angeblich Geschwür des Penis. Vor über vier Jahren hatte Patient einen Bandwurm. Mutter gesund, Vater an Leberkrebs gestorben. Fettsucht ist bisher in der Familie nicht rorgekommen. Patient ist verheiratet, Vater von zwei gesunden Kindern. Patient klagt seit längerer 'Zeit über Kurzatmigkeit, ist angeblich liein starker Esser (?), trinkt seit ca. 4 Jahren fast kein Bier. Er hat nach dem Fssen oft starken Durst, nimmt dann bisweilen $3 \mathrm{l}$ Wasser 20 sich. Patient klagt über grosse Mattigkeit, besonders nach dem Essen. Die Urinmenge soll relativ klein sein, zeitweise besteht Obstipation; er hat das Gefühl, als ob Wasser im Leibe wäre. Die Potenz hat seit einem Jahre stark nachgelassen.

Status praesens: Körpergrösse $170 \mathrm{~cm}$, Körpergewicht $149,2 \mathrm{~kg}$ (ohne Kleider); Halsumfang $53 \mathrm{~cm}$, mittlerer Brustumfang $138 \mathrm{~cm}$, Abdomen (in Nabelböhe) $159 \mathrm{~cm}$, 'laille $132 \mathrm{~cm}$; Schädel: Submento-occipital-Umfang $71 \mathrm{~cm}$; Oberarm (Mitte) $46 \mathrm{~cm}$, Unterarm (max.) $36 \mathrm{~cm}$; Oberschenkel (Mitte) $64 \mathrm{~cm}$, Unterschenkel (max.) $49 \mathrm{~cm}$.

Kräftiger, muskulöser, ausserordentlich fetter Mann. Die Kettablagerungen betreffen hauptsächlich Oberarme, Oberschenkel, Hals, dessen Conturen z. T. ganz verwischt sind, Doppelkinn. Fettfalten in der Lendengegend, desgl. in der Glutäalgegend.

Das Fett in der Glutäalregion ist von fast myxödenatöser Beschaffenheit; auch quer über die Regio pubica verläuft eine Fettfalte. Geringe Protrusio bulbi, kein Möbius, kein Stellwag, kein Gräfe, geringe Schwellung der 'Tränendrüsen, Cyanose an Gesicht und Lippen, Cyanose an Ï̈nden und Nates, bei geringfügiger körperlicher Anstrengung sich bedeutend verstärkend.

Fettablagerung nirgends empfindlich. Die Schilddrüse ist wegen des Fettansatzes nicht zu palpieren. Ganz geringe Oedeme an den Unterschenkeln. Am rechten Unterschenkel einige Varicen. Behaarung in der Linea alba fehlt. Geringe 
Behaarung in den Achselgruben; ziemlich normaler Bartwuchs. Penis und Hoden von normaler Grösse. Stirn tliehend, seitlich otwas zusammengedrüokt. Parotis ist klein-apfelgross beiderseits deutlich durchzupalpieren, Ohrläppchen typisch abgehoben, Sublingualis nicht vergrössert, Submaxillaris infolgo des Fettreichtums nicht zu fühlen. Zunge rissig, Zungenfollikel prominent.

I.ungen: keine Dämpfung, überall Vesiculäratmen.

Horz: perkussorisch nicht abgrenzbar, Töne rein, zweite Basaltöne etwas rerstärkt. Action regelmässig, Blutdruck palpatorisch sicher erhüht (die Riva-RocciManschette umspannt den Oberarm nicht, daher exakte Bestimmung unmöglich).

Puls: klein, etwas frequent.

Abdomen: Hängebauch. Striae. Palpation des Abdomens unmöglich. Die Leber scheint percussorisoh handbreit über dern Nabel zu stehen. Ascites nicht nachweisbar. Milz palpatorisch und percussorisch nicht als vergrössert nachzuwoisen.

Nervensystem: Patellarreflexe sind erhalten, Pupillen reagieren. Sonst keine Besonderheiten.

Urin: Zucker - Eiweiss $\frac{1}{+}++$; Essaoh $1 \frac{1}{2}$ pM.

Urin-Sediment: Hyaline Cylinder ziemlich reichlich vorhanden, einzelne granulierte Cylinder.

Blutbild: Hämoglobin $120 \mathrm{pCt}$. (Sahli), Erythrocyten 7200000 , Lenkocyten 9800 .

Blutausstrich: Neutrophile Leukocyten 70 pCt., Lymphocyten 15 pCt., grosso Iymphocyten 3 pCt., Mononucleäre und Cebergangsformen 6 pCt., Eosinophile 5 pCt., Mastzellen 1 pCt. - Wassermann negativ.

Die Röntgendurchleuchtung des Brustkorbes lässt wegen des gewaltigen l'ettpanzers keine Einzelheiten erkennen.

In horizontaler Rückenrubelage steigert sich die Kurzatmigkeit und Cyanose deo Patienten auffallend. (Es muss daher davon Abstand genommon werden, diese Lage den Respirationsversuchen zu Grunde zu legen. Als bequemste Ruhelage -. das sei hier vorweggenommen - erwies sich das Sitzen in einem Lehnsessel mit aufgelegten Unterarmen und mit Vornüberbängenlassen des Kopfes. Während einzelner, später noch zu kennzeichnender Versuche gelang es dem Patienten nicht, einzelne Bewegungen mit dem Kopfe und den Armen zu unterdrücken, eine ganze Reibe von Versuchen jedoch konnte mit ziemlich guter Muskelrube beendigt werden.)

Das psychische Verhalten des Patienten zeigt einen auch für einen Fetten ungewöhnlichen Grad rein passirer Gleichgültigkeit mit gleichmütiger Stimmung gepaart. (Dies kommt den Versuchen insofern zustatten, als er jede Versuchsanordnung geduldig über sich ergehen lässt und bei ihrer Durchführung auch wenig Störung verursacht.) Sehr auffallend ist seine Schlafsucht. In derWartezeit vor und zwischen den Versuchen schläft Pationt, wenn er sich unbeobachtet glaubt. Auch während der Versuche nickt er öfters schnell ein und hat selbst im Stehen mit dem Schlaf zu kämpfen. Dieser Zustand wird wohl durch $\mathrm{CO}_{2}$-Ceborladung der Hirngefässe erklärt; diese kommt, abgesehen von der allgemeinen Circulationsschwäche, jm besonderen wahrscheinlich dadurch zustande, dass der Abfluss des Kopfvenenblutes durch intrathorakale Fettmassen gestant wird.

Klinisch handelt es sich hier mit grosser Wahrscheinlichkeit um eine endogene Form der Fettsucht, die durch äussere Factoren noch begünstigt wurde. In ätiologischer Beziehung ergeben sich folgende Anhaltspunkte: die anamnestischen Angaben machen eine frühere luetische Infection in hohem Grade wahrscheinlich. Dass die Wassermannsche Reaction gegenwärtig negativ ausgefallen ist, nimmt dieser Tatsache nicht ihre Bedeutung. 
Nun ist bekannt, dass nicht selten . eine luetische 'Thyreoiditis zur Atrophie der Schilddrüse und hierdurch weiter zu thyreogener Fettsucht führt. In neuster Zeit hat Mohr $(6,7)$, welcher diesen Verbältnissen seine Aufmerksamkeit in besonderem Hasse zuwandte, die relative Häufigkeit dieser Entstehungsursache der endogenen Fettsucht betont und seine Anschauung durch die Mitteilung einiger Krankengeschichten belegt. In unserm Falle lässt sich eine pathologische Vuränderung der Schilddrüse nicht sicher beweisen. Doch spricht die hier unzweideutig vorhandene symmetrische Schwellung der Speicheldrüsen und die fraglich vorhandene doppelseitige Tränendrüsenschwellung in gewissem Grade dafür. Denn gerade die Combination dieser Veränderung mit thyreogener Fettsucht findet sich, wie $M \circ \mathrm{hr}$ in einem Teil der obenerwähnten Fälle als erster gezeigt hat - auch der weiter unten behandelte Fall KI. (S. 460/461) gehört hierher - relativ häufig, wenn ihr die nötige Beachtung geschenkt wird; sei es, dass die Parotisveränderung als luetische Parotitis, sei es, dass sie als compensatorische oder Reizungshypertrophie infolge gleichzeitig bestehender Veränderung der Genitaldrüsen (in unserem Falle wohl möglich) zu erklären ist.

Auch der Ausfall der Abderhaldenschen Blutiermentreaction spricht für die endogene Natur der Fettsucht (siche $\mathbf{M o h r}$, Congress für innere Medicin, 1914). Im vorliegenden Falle wurde Schilddrüse und Hoden abgebaut. Die beweisende Diagnosis ex therapia (Thyreoidin) haben wir in späterer Zeit nach dem Abschluss dieser Untersuchungen zur weiteren Aulklärung der vorliegenden Verhältnisse herangezogen. Es wurden bei dem Kranken 4 Perioden mit Thyreoidindarreichung von je 14 'agen in Abständen von 3 Wochen durchgeführt. Die tägliche Dosis betrug $3 \mathrm{~b} \% w$. 4 mal $0,3 \mathrm{~g}$ Thyreoid. Merck. Einer jedesmaligen Thyreodinperiode ging eine achttägige Periode mit 2,0 g Digipurat-Tabletten voraus. Die Gewichtsabnahme während der Thyreodindarreichung betrug $4,3,31 / 2$ und $2,8 \mathrm{~kg}$. Wir dürfen wohl nach fremden und eigenen Erfahrungen diesen Erfolg als eine weitere Stütze für unsere Auffassung, dass ein endogener Factor in dem Gesamtbilde eine nicht geringe Rolle spielt, betrachten.

\section{B. Versuchsanordnung.}

$\mathrm{Da}$ in den drei anderen Fällen, in denen das von $\mathrm{Kauffmann}$ angegebene Palladiumhydroxydul ohne gleichzeitige Diätbeschränkung angewendet - dies sei hier vorweggenommen - einen Einfluss auf die Intensität des Gaswechsels bzw. Körpergewichts nicht nachweisbar ausgeübt hatte (zwci Fälle von exogener Fettsucht, ein Fall von dysgenitaler Fettsucht), so sollte nun möglichst einwandfrei in diesem weiteren Falle ein Urteil darüber gewonnen werden, wie weit die Gewiehtsverluste, die Kauffmann bei streng durchgeführter, „wesentlicher Einschränkung der Nahrungszufuhr", dosierter Muskelarbeit und gleichzeitiger Anwendung seines Mittels erzielt, direct auf das Conto des Leptynols zu setzen seien, und welcher Tcil des Gewichtsverlustes durch Diätbeschränkung allein crklärt werden könnte. Patient Or. schien besonders geeignet; denn Kauffmann betont, bei hochgradiger Fettsucht die besten Erfolge gehabt zu haben. Auch sei erwähnt, dass Kauffmann hervor- 
hebt, bei Patienten mit Störung der inneren Secretion Erfolge erzielt zu haben.

Folgende Versuchsanordnungen einer intermittierenden Entziehungskur - 1. Periode ohne, 2. mit Leptynot - wurde gewählt (vgl. Tabelle I.). Patient wurde, nachdem zweimal sein normaler Grundumsatz bestimmt worden war, vier Tage lang auf reine Milchnahrung gesetzt. Die tägliche Vilchmenge wurde in Anlehnung an die Moritzsche Specialvorschrift (8) der sogenannten Carrelschen Cur auf $2000 \mathrm{ccm}=1300$ Calorien festgesetzt. Gleichzeitig hält Patient mit Aussehluss eines täglichen $1 / 2$ stündigen Spazierganges Bettruhe. Nierenfunction und Herztätigkeit, auf die in diesem Falle besonders zu achten war, wurden durch das Verfahren sehr günstig becinflusst. lis konnte von vornherein von der vorher geplanten medicamentösen Unterstützung der Herztätigkeit Abstand genommen werden - gleichzeitig ein Vorteil für die Reinheit des Versuches. Schon nach den ersten 24 Stunden gab Patient wesentliche subjective Erleichterung an, der objectiv gesteigerte Diurese, gute Herztätigkeit und erhöhte körperliche Leistungsfähigkeit entsprach. Während dieser Periode wurden der durch Kohle abgegrenzte Kot und der Irin gesammelt und ihre Stickstoffmenge nach Kjeldahl bestimmt (3). Nun folgte eine mehrtägige Zwischenpause, in welcher Patient unter Bettruhe und reichlicher Erhaltungskost annähernd sein früheres Gewicht wieder erreichen sollte; in Wirklichkeit wurde nur gewartet, bis etwa $2 / 3$ des Gewichtsverlustes wieder eingeholt waren.

Nun kam die Wiederholung der Entziehungskur, welche wiederum vier Tage daverte, gleichzeitig mit alleiniger Nahrung von 2 l Mileh, mit dem einzigen lnterschied, dass diesmal ausserdem $10,0 \mathrm{~g}$ Leptynol injiciert wurden. Während dieser Periode wurde nur die Úrinstickstoffmenge nach $\mathrm{Kjeldahl}$ bestimmt; die Kotstickstoffmenge schätzungsweise dem während der ersien gefundenen Werte gleichgesetzt. Im Einklang mit der Kauffmannschen Angabe, welche die besten Resultate verspricht, wenn der Organismus in 2 bis 5 Tagen mit $\mathrm{Pd}(\mathrm{OH})_{2}$ förmlich überschwemmt wird, wurde am ersten 'lage die Menge von 6,0 g Leptynol $=150 \mathrm{mg}$ Palladiumhydroxydul injiciert (24.9.). (Es wurde nicht wie in den übrigen Fällen die Paraffinlösung, sondern die als Verbesserung bezeichnete Sesamöllösung benutzt. - Kauffmann selbst ist bis zu $140 \mathrm{mg}$ in einmaliger Einspritzung ohne schädliche Nebenwirkung gegangen.) Gemäss unserer Frfahrung in den andern Fällen gingen wir, um die Resorptionsmöglichkeit recht günstig zu gestalten, so vor, dass in das Fettgewebe der Bauchdecken hinein im ganzen sechs Einzeldepots von je $1,0 \mathrm{~g}$ an verschiedenen Stellen, 3 mal rechts, 3 mal links in einer 'Tiefe von etwa $3,5 \mathrm{~cm}$ angelegt wurden. Im übrigen verfuhren wir genau nach der Kauffmannschen Vorschrift $(1,2)$.

Am Nachmittag wurden dann ausser dem üblichen $1 / 2$ stündigen Spaziergang (etwa $2500 \mathrm{kgm}$ ) noch weitere $5000 \mathrm{kgm}$ durch Treppensteigen an Arbeit geleistet.

24. 9. abends keine Temperaturerhöhung, Mattigkeit und Schwere in den Beinen. 
25. 9. Injection von $1,5 \mathrm{~g}$ Leptynol $=37 \mathrm{mg} \mathbf{P d}\left(\mathrm{OH}_{2}\right)$; nachmittags wegen Mattigkeit die Muskelarbeit unterlassen. Patient ist auffallend schläfrig, Puls langsam, regelmässig, weniger gespannt.

Urin: Esbach $1 / 3$ pM. gegen $3 / 4 \mathrm{pM}$, vorher.

26. 9. Allgemeinbefinden besser. Injektion von $2,5 \mathrm{~g}$ Leptynol. Mittag werden, aus dem Rahmen der Kur fallend, zu anderen Zwecken (siche weiter unten) ausser den täglichen 2 l Milch oine Mittagsmahlzeit voll 900 Kalorien verabreicht. Abends: gute Diurese. Nachmittags wie am 24. dosierte Muskelarbeit.

27. 9. Keine Störung im Allgemeinbefinden.

\section{c. Leptynolwirkung.}

'Treten wir nun in die Betrachtung der in Tabelle I (S. 423) und Tabelle III (S. 428/429) zusammengestellten Versuchsresultate ein.

Um Wiederholungen zu vermeiden, sei hier den weiteren lirörterungen über die Fragen des medicamentös nicht beeinflussten Gaswechsels die Besprechung der Jeptynolwirkung aul denselben vorangestellt. ${ }^{1}$ )

Anmerkung: Hier sei eine Bemerkung über die Scbnelligkeit der Resorption des Leptynols eingeschaltet: Wenn die Injektion nicht allzu tief erfolgte, wies rogelmässig auch monatelang nachher die Haut über der Injektionsstelle in ca. 2 Markstück-Ausdehnung eine bläulich-schwarze, aus den subcutanen Partien her durchschimmernde Verfärbung auf, die bei ihrer gleichmässig unveränderten Farbe nur von nicht resorbierten Jeptynolresten - und zwar in ziemlich beträchtlicher Mengeherrühren konnte. Diese Verfärbung wurde auch bei einer von Kauffmann selbst mit Ieptynol behandelten Patientin über 6 Monate nach der Injection beobachtet.

Am Kaninchen wurde von uns unter die Bauchhaut eine Menge von je $1,0 \mathrm{~g}$ Leptynol (Paraffinlösung) injiciert und nach $5 \mathrm{bzw}$. 7 Tagen die betreffende Hautstelle excidiert. Es fand sich -- schätzungsweise, nicht quantitativ bestimmt - dio injicierte Menge zum grossen 'Teil wieder. Es fiel allenfalls auf, dass die Lymphstränge otwa bis zu einer Entfernung ron $6 \mathrm{~cm}$ von der Injectionsstelle wit der schwarzbraunen Paraffinlösung injiciert erschienen. Damit stimmen auch die von Pharmakologen gemachten Erfahrungen überein, dass Parafinum liquidum subcutan nur in langen Zeiträumen, fast ausscbliesslich auf leukocytärem Wege resorbiert wird (9). Kauffmann selbst suchto dadurch, dass er das Paraffin durch das etwas leichtflüssigere Sesamöl ersetzte, diesem Mangel abzuhelfen. Nach unserer Beobachtung bedeutet allerdings auch dies noch keinen wesentlichen Fortschritt. Die zweifellos schon aus theorotischen Gesichtspunkten hochinteressanto Wirkung der colloidalen Lösung der Platinmetalle dürfte wohl doch erst praktisch klinisch verwendbar werden, wonn es gelungen ist, diese auch bei Menschen, wio bisher im Tierexperiment ohne Schädigung, sei es intravenös, sei es subcutan, in schneller und resorbierbarer lösung einzuverleiben. Kauffmann selbst gibt dies teilweiso zu. Er konnte beim Hunde $25 \mathrm{mg}$ Palladiumhydroxydul, als Hydrosol injiriert, fast quantitativ im Jarn wieder nachweisen; dagegen konnten von $91 \mathrm{mg}$ als "Paraffinosol " injiciert nur $6 \mathrm{mg}$ im Harn nachgewiesen werden. (Münchener med. Wochenschrift. 1913. S. 525.)

1) Dies geschieht nur aus bosagtem Grunde und weil bei der Diskussion der Leptynolwirkung die kurz vorher behandelte äussere Versuchsanordnung besonders gegenwärtig sein muss. Nach dem Grade des ibnen gebührenden Interesses müsste durchaus die Besprechung der weiter unten behandelten patbologisch-physiologischen - nicht medicamentös beeinflussien - Verhältuisse dieses Falles an der Spitze stehen. 
Auch in diesem Falle konnte schon die erste Forderung eines erhöhten Umsatzes, eine medicamentös bedingte Gewichtsabnahme, wie die Tabelle zeigt, nicht gefunden werden. Vergegenwärtigen wir uns die betreffenden Zahlen:

Gewichtsabnahme während 4 tägiger Entzichungskur: $5,6 \mathrm{~kg}$.

Gewichtsabnahme nach 4 tägiger Entzichungskur + Jeptynol: $3,7 \mathrm{~kg}$ (auf das Anfangsgewicht bezogen).

Das Anfangsgewicht wird im ersten Falle in 4 T'agen bis auf $1,9 \mathrm{~kg}$ wieder erlangt.

Im zweiten Falle ist das Anfangsgewicht bis auf $0,4 \mathrm{~kg}$ in 6 Tagen wieder erreicht. Hiermit ist auch eine verlangsamte bzw. Dauerwirkung des Leptynols in diesem Falle ausgeschlossen. Wird die während der zweiten Periode störende Mehrnahrung von $900 \mathrm{Kal}$. noch in Anschlag gebracht, so wäre hochgerechnet durch sie die Gewichtsabnahme um ein Kilogramm herabgedrückt worden. Es bliebe dann noch ein Mehrgewichtsverlust der ersten Periode von $900 \mathrm{~g}$, welcher wahrscheinlich auf Kosien schlechterer Lintwässerung im zweiten Falle, wie sie sich aus der Urintagesmenge ergibt, zu setzen wäre.

(Wahrscheinlich wirkt das Palladiummetall in dieser Richtung auf die geschädigten Nieren unseres Patienten.)

In beiden Perioden ist der grösste Teil des Gewichtsverlustes auf Entwässerung des Körpers zurückzuführen. Das geht schon aus der Wasserbilanz der Tabelle III hervor. Dass aber in der zweiten Periode eine stärkere Fett- und Eiweisseinschmelzung nur durch geringeren Wasserverlust verschleiert wurde, jst unmöglich, denn die Stickstoffbilanz ist im zweiten Falle günstiger für den Organismus als im ersten Falle, und alleinige Erhöhung der Fettverbrennung müsste sich in einer Verkleinerung des R.-Q. zeigen; dieser jst aber bei Periode I und III nicht verschieden. $\Lambda$ usserdem wäre auch mit dieser Möglichkeit die Wiedererlangung des alten Gewichtes binnen einer Woche nicht zu vereinigen. (Das Niahere ergibt sich aus der weiter unten zu besprechenden Tabelle über die Beteiligung der einzelnen Körper- und Nahrungsbestandteile an der Verbrennung.)

Wie zu erwarten, liefert die Vergleichung des Grundumsatzes das gleiche Resultat. Wir finden hier:

Periode I: Mitielwert (aus Versuch 3 u. 6): 514,9 ecm $\mathrm{O}_{2}$-Zehrung pro Minute.

Periode II: Mittelwert (aus Versuch 11 u. 12): $518,1 \mathrm{cem} \mathrm{O}_{2}$-Zehrung pro Minute.

Es darf demnach ausgesprochen werden, dass in einem zur Prüfung besonders geoigneten Ealle eine reine Entzichungskur eher ein besseres, sicher aber ein gleichwertiges Resultat erzielt hat im Vergleich mit einer hochdosierten Leptynolbehandlung, welche combiniert wurde mit der gleichen Entziehungskur + Muskelarbeit.

Wir werden in der weiteren Betrachtung der Tabellenwerte keinen Fehler begehen, wenn wir den Einfluss des Leptynols auf den Gas- 
wechsel gleich Null setzen und den Umsatz und auch den Stoffwechsel der entsprechenden Versuche $11-17$ als nicht medicamentös beeinflusst bewerten.

\section{Der Grundumsatz.}

Für die Bewertung der Form der Fettsucht hat die Feststellung der Höhe des Grundumsatzes nach den gegenwärtig herrschenden Anschauungen die grösste Bedeutung.

I. Welche Versuchswerte aus Tabelle I sind geeignet, uns ein einwandfreies Bild des Normalgrundumsatzes zu geben?

Versuch 1 und 2 der Tabelle scheiden aus, denn gerade dieser Versuchsperson machte wohl wegen ihrer Kurzatmigkeit die Gewöhnung an die Ventilatmung einige Schwierigkeit, so dass die beiden ersten Versuche noch falsche Werte ergaben. Es stehen uns noch die Werte von Versuch 3-6 und 11 und 12 zur Verfügung - Normalwerte, denn nach allen bisher gemachten Erfahrungen beeinflusst eine Entziehungskur ebenso wenig wie eine Hungerkur die Höhe des Grundumsatzes. (Wie weit das vielleicht zu modificieren ist, werden wir weiter unten sehen.)

In der Zusammenstellung eines Normaldurchschnittwertes sei es nun in diesem Falle erlaubt, einen etwas anderen Weg als sonst einzuschlagen, der den hier im speciellen vorhandenen subjectiven Versuchsschwierigkeiten Rechnung trägt: Gemäss der Versuchsanordnung der Zuntzschen Methode haben die kleinsten gefundenen Werte die grössite Wahrscheinlichkeit für sich, dem wahren Grundumsatz nahe zu kommen. Daher schalten wir hier (abweichend von der in der Tabelle selbst durchgeführten Berechnungsart) die wahrscheinlich zu hohen Werte 4 und 5 aus. Es bleiben dann in guter Uebereinstimmung miteinander für den Minutensauerstoffverbrauch die Zahlen:
Gesamt: $525,7 \mathrm{ccm}$
pro Kilogramm Körpergewicht: $3,56 \mathrm{ccm}$
$504,0 \quad n$
512,0
also Mittelwert: $\frac{524,3 "}{516,5 \mathrm{ocm}}$

$$
\begin{aligned}
& 3,51 " \\
& 3,51 "
\end{aligned}
$$$$
\frac{3,59 ",}{3,54 \mathrm{ccm}}
$$

II. Welche Stellung nimmt der gefundene Grundumsatz unter den bisher lestgestellten Umsatzwerten von Fettsüchtigen ein?

Vergleichen wir die obigen Zahlen mit der von v. Noorden zusammengestellten Tabelle (8) aller bis jetzt auf ihren Grundumsatz untersuchten Fettsüchtigen (siehe Tabelle II Seite 424), so stehen sie denen von Fall E. H. (Jaquet) am nächsten, während ein in Gewicht und Alter auch analoger Fall (Fr. Schn.) (Magnus-Levy) bedeutend geringere Umsatzwerte zeigt; besonders tritt das bei den absoluten Umsatzzahlen hervor:

$$
\begin{array}{lll} 
& 516,5 & \text { (Fall Or.) } \\
\text { zu } & 414,0 \text { (Fall E. H.) } \\
\text { zu } & 282,0 \text { (Fall Fr. Schn.). }
\end{array}
$$

Hierbei ist allerdings zu berücksichtigen, dass letztere Fälle, in der Tabelle die höchsten Gewichte darstellend, immer noch um 23 bzw. 
Ueber den Gaswechsel verschiedener Formen von Fettsucht usw.

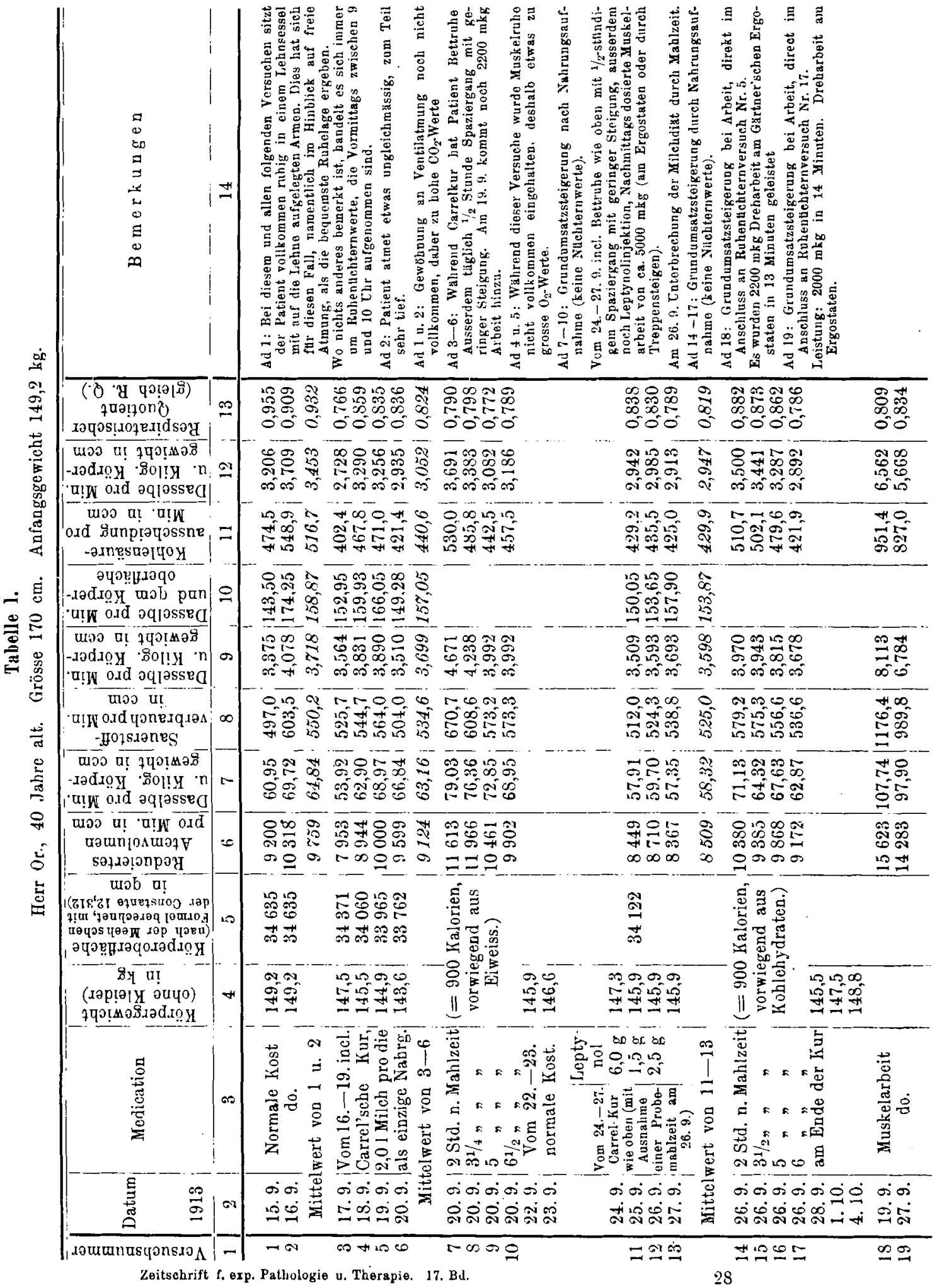


$16 \mathrm{~kg}$ an Gewicht hinter Fall Or. zurückstehen. Aber auch ein grob berechneter und sicher noch zu grosser Abzug von $23 \times 3,54 \mathrm{ccm} \mathrm{O}_{2}$ (= Sauerstoffverbrauch für Patient Or. pro Kilogramm) $=81,4 \mathrm{ccm} \mathrm{O}_{2}$ für $23 \mathrm{~kg}$ Mehrgewicht unseres Falles ergab noch ein Mehr an Umsatz von Fall Or. gegen Fall E. H. von $435,1-414,0=21,1 \mathrm{ccm} \mathrm{O}_{2}$ $=$ rund 5 pCt.

Tabelle II.

v. Noorden's Tabclle aller bisher auf ihren Umsatz untersuchten Fettsüchtigen.

\begin{tabular}{|c|c|c|c|c|c|c|}
\hline $\mathrm{Name}$ & $\begin{array}{l}\text { Alter } \\
\text { Jahre }\end{array}$ & $\begin{array}{c}\text { Ge- } \\
\text { wicht } \\
\text { kg }\end{array}$ & 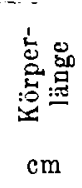 & 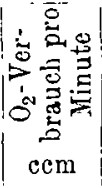 & 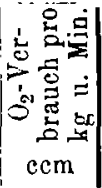 & Autor \\
\hline $\begin{array}{l}\text { Herr D. . . } \\
\text { Frl. . . . } \\
\text { Frau E. . . } \\
\text { Herr P. . . } \\
\text { Kind II. . . } \\
\text { Frl. Mal. . } \\
\text { Frl. Lt. . . } \\
\text { Frl. F. Kr. } \\
\text { Frau Kr. . } \\
\text { Frl. Bn. . } \\
\text { Frl. Ha. . } \\
\text { Frau Schn. } \\
\text { Herr A. S. . } \\
\text { Herr Mar. . } \\
\text { Herr Stab. . } \\
\text { Herr Dr. D. } \\
\text { Herr Ha. . } \\
\text { Herr D. O. . } \\
\text { Herr E. H. . } \\
\text { Herr L. K. . } \\
\text { Herr K. Z. . } \\
\text { Derselbe. . } \\
\text { Frl. J. J. . . } \\
\text { Frl. R. J. . . } \\
\text { Paul G. . . } \\
\text { Mann. . . . } \\
\text { Frau L. . . }\end{array}$ & \begin{tabular}{r|r}
30 \\
35 \\
35 \\
4 \\
64 \\
56 \\
25 \\
57 \\
43 \\
32 \\
41 \\
23 \\
43 \\
71 \\
28 \\
46 \\
48 \\
28 \\
53 \\
46 \\
46 \\
18 \\
16 \\
15 \\
30 \\
25
\end{tabular} & $\begin{array}{r}94,0 \\
70,0 \\
124,5 \\
97,0 \\
48,8 \\
69,5 \\
76,0 \\
77,0 \\
88,0 \\
107,0 \\
111,4 \\
133,3 \\
80,2 \\
80,1 \\
91,5 \\
92,7 \\
96,0 \\
109,0 \\
126,0 \\
112,0 \\
90,0 \\
90,0 \\
98,0 \\
73,0 \\
63,1 \\
91,0 \\
84,0\end{array}$ & $\begin{array}{c}167 \\
\text { klein } \\
-- \\
- \\
129 \\
151 \\
144 \\
156 \\
\vdots \\
160 \\
160 \\
152 \\
174 \\
169 \\
169 \\
167 \\
167 \\
167 \\
163 \\
173 \\
165 \\
165 \\
168 \\
163 \\
139 \\
169 \\
163\end{array}$ & $\begin{array}{l}256,1 \\
233,1 \\
287,2 \\
272,0 \\
153,6 \\
239.8 \\
188,6 \\
226,6 \\
330,2 \\
257,3 \\
320,2 \\
282,0 \\
257,8 \\
278,6 \\
258,0 \\
262,2 \\
231,2 \\
307,2 \\
414,0 \\
357,0 \\
268,0 \\
232,0 \\
249,0 \\
199,0 \\
216,3 \\
254,9 \\
215,0\end{array}$ & $\begin{array}{l}2,71 \\
3,33 \\
2,31 \\
2,80 \\
3,15 \\
3,45 \\
2,48 \\
2,94 \\
3,74 \\
2,40 \\
2,88 \\
2,12 \\
3,22 \\
3,48 \\
2,82 \\
2,83 \\
2,41 \\
2,82 \\
3,29 \\
3,17 \\
2,97 \\
2,58 \\
2,34 \\
2,72 \\
3,49 \\
2,82 \\
2,56\end{array}$ & $\begin{array}{l}\text { v. Noorden } \\
\text { Thiele-Nebring } \\
\text { Stüve } \\
\text { Magnus-Iievy }\end{array}$ \\
\hline
\end{tabular}

Wir stellen also fest, dass die bei Fall Or. gefundenen Umsatzwerte absolut und relativ grösser sind als die bisher gefundenen Werte. Diese hohen Werte würden uns bei Mastfettsucht nicht überraschen, stehen aber bei unserer klinischen Annahme einer endogenen Fettsucht unleugbar mit den bisherigen Anschauungen, welche für endogene Fettsucht einen herabgesetzten Stoffwechsel zwar nur selten nachgewiesen haben, aber für alle Fälle postulieren in einem gewissen Widerspruch, der uns noch weiterhin beschäftigen wird.

Bevor wir näher eingehen auf die Beurteilung der Umsatzhöhe unseres Ealles, sei an dieser Stelle eine allgemeine Bemerkung eingeschaltet. 
III. Warum ist mit der Zuntzschen Methode ein unternormaler Umsatz bei Fettsucht so selten nachgewiesen worden?

Diese Erklärung bezieht sich also nicht auf unseren Fall im speciellen, der auch trotz ihrer keinen unternormalen Umsatzwert ergeben würde. Stähelin fand in einem Falle von Fettsucht nach 17 stündigem Hungern einen niedrigeren L'msatz als nach den üblichen 12 Stunden Nüchternheit. Das gleiche fanden Jaquet und Svenson $(10,11)$. Nun wäre es denkbar - ohne Berïcksichtigung der Frage, ob beim Fettsüchtigen der Gipfel der Steigerungskurve des Umsatzes nach Nahrungsaufnahme niedriger ausfällt als beim Normalen (Jaquets und Svensons Vermutung) - , dass beim Fetten vielleicht im Sinne einer wahren "Verlangsamung des Stoffwechsels" [vgl. von Bergmanns und Bouchards ralentissement (12)] die Umsatzsteigerung nach Nahrungsaufnahme nach den für den Normalen üblichen 7--9 Stunden noch nicht zu ihrem Ende gekommen ist, sondern regelmässig 12 Stunden nach Nahrungsaufnahme in einer beträchtlichen Höhe noch vorhanden wäre. Mit anderen Worten würde das bedeuten: Beim Fettsüchtigen ist es die Regel, dass der in der üblichen Weise nach 12 stündiger Nüchternheit in kurzem Respirationsversuch bestimmte "Grundumsatz" höher ausfällt als der sog. "Erhaltungsumsatz", d. h. der nach einer mindestens 24-48 Stunden langen Hungerperiode bestimmte Grundumsatz.

Beim normalen Menschen existiert zwischen Erhaltungs- und Grundumsatz keine Differenz. Diese Tatsache haben neben zahlreichen anderen Untersuchern vor allem Zuntz und Lehmann in kurz dauernden Respirationsversuchen selbst nach 10 tägigem Hungern an 2 Versuchspersonen bestätigt gefunden $(13,10)$. Dass aber beim Endogen-Eettsüchtigen im Gegensatz zum Normalen hier eine Differenz besteht, legt neben den oben erwähnten Befunden von Stähelin usw. auch Nr. 13 unserer ersten Versuchstabelle nahe. Es handelt sich hier um den nach dem zweiten Nahrungsversuch — also nach Steigerung der an den Tagen vorher verabfolgten Nahrung - festgestellten "Nüchternumsat $z^{*}$ am nächsten Morgen. Die Steigerung von $14,5 \mathrm{ccm} \mathrm{O}_{2}=2,77 \mathrm{pCt}$. gegen die entsprechenden Werte vom Tage vorher (Versuch Nr. 12) liegt allerdings innerhalb der normalen Schwankungsgrenzen dieser Versuchsperson. Andererseits aber gehört der in Betracht kommende Versuch 13 zu den einwandfreiesten, während Versuch 12 wahrscheinlich noch etwas zu hohe Werte ergibt. Die Differenz würde sich unter Zugrundelegung des einen Tag vorher bestimmten Grundumsatzes (Nr. 11) fast verdoppeln. (Wert Nr. 11 deckt sich im übrigen fast mit dem Durchschnitswert.) Leider war es aus äusseren Gründen nicht möglich, an Patient Or. durch reine Hungerversuche diese Vermutung weiter zu erhärten. Auch habe ich Angaben über derartige Versuche in der Literatur nicht finden können.

Zögen wir an unserem Falle die Consequenzen unserer Vermutung, so ergäbe sich für uns gewissermassen ein dreifaches Niveau der Einstellung des Grundumsatzes:

1. Das wahre Niveau während Hungerversuchen - in unserem Falle nicht festgestelit. 
2. Gegen voriges erhöht das Niveau bei beschränkter Nahrungszufuhr - hierher wären sämtliche von uns für den Durchschnittswert verwendete Versuche zu rechnen.

3. Das gegen 2. wiederum erhöhte Niveau des - sogenannten, nicht des wahren - Grundumsatzes bei Erhaltungskost. Für diese Stufe könnte Versuch 13 einen Anhaltswert geben. Sichere Werte haben wir wiederum nicht (Versuch 1 und 2 sind als solche nicht zu rechnen).

Für eine nochmalige Erhöhung des Niveaus, wie wir sie zwischen 2. und 3. angenommen haben, spräche der Satz, dass die L'msatzsteigerung nach Nahrungsaufnahme innerhalb gewisser Grenzen proportional ist der Menge der zugeführten Nahrung (13).

Für die Möglichkeit einer derartigen Verschleierung des wahren Grundumsatzes des Endogenfettsüchtigen bei den üblichen kurzen Respirationsversuchen, wie wir sie eben behauptet haben, liesse sich vielleicht noch ein Punkt ins Feld führen:

Für die Methode der 24 stündigen Umsatzbestimmung ist es gleichgiltig, ob die Kurve der Umsatzsteigerung nach Nahrungszufuhr steiler oder flacher verläuft, wenn nur, geometrisch gesprochen, die Summen ihrer Projectionen den gleichen Flächeninhalt ausmachen, mit anderen Worten, wenn nur die Gesamtarbeitsleistung, welche durch die Nahrung gebunden wird, die gleiche bleibt. (Und daran muss vorläufig festgehalten werden, so lange sich eine Ersparnis bei der Reaction auf Nahrung beim Fettsüchtigen, wie sie Jaquet und Svenson vermutet haben, nicht bestätigt hat.) Nach dieser Nlhode müssten also vergleichende Umsatzbestimmungen (natürlich ist hier von Grundumsat'z die Rede) zwischen Normalen und Endogenfettsüchtigen viel eher eine Differenz zugunsten eines herabgesetzten Stoffwechsels gefunden werden können, als nach der Zuntzschen Methode, wenn das negative Ergebnis, welches letztere Methode an den bisher ca. 30 untersuchten Fällen in bezug auf diese Frage gezeitigt hat, teilweise in der eben ausgesprochenen Vermutung ihre Ursache haben sollte. Und in der Tat hat von Bergmann nach der Pettenkoferschen Wethode schon bei Untersuchung nur dreier, allerdings mit besonderer Sorgfalt ausgewählter Fälle in meinem Falle zum mindesten eine tatsächliche, auch scharfer Kritik standhaltende Umsatzminderung nachweisen können $(12,8)$.

Es sei hier kurz berechnet, wie gross die maximale Abweichung ist, welche der Grundumsatz durch die eben erwälnte „Verschleierung ${ }^{*}$ erleiden könnte. Nach der Angabe von Magnus-Jaevy (11) ergibt sich, dass die Steigerung des Umsatzes bei Zufuhr von Felt etwa $21 / 2 \mathrm{pCt}$. der totalen Verbrennungswärme desselben beträgt; bei der Zufuhr von Stärke etwa 9 pCt., bei der Zufuhr von Liweisskörpern etwa 17 pCt. Hiernach berechnet würde bei einer Nahrung von 2 I Milch die Steigerung im ganzen einer Verbrennung von $20166 \mathrm{~cm} \mathrm{O}_{2}$ entsprechen. Nehmen wir nun den extremen Fall an, der ja in Wirklichkeit nicht zutrifft, dass die Stejgerungskurve während 24 Stunden immer auf der gleichen Höhe bliebe, so würde das über den wahren Grundumsatz (pro Kilogramm und Ninute) ein Mehr von $14,0 \mathrm{ccm} \mathrm{O}_{2}(=$ für unseren Fall 
eine Abweichung von 2,7 pCt.) bedeuten. Für Erhaltungskost würde die maximale Abweichung vom wahren Grundumsatz in unserem Falle ca. 7,5 pCt., in Fällen geringerer $\mathrm{O}_{2}$-Zehrung noch grössere Naximalabweichungen ergeben. (Nach Magnus-Levy ist die Erhöhung des Tagesumsatzes bei zureichender Nahrungsaufnahme auf ungefähr 10 bis 15 pCt. des Grundumsatzes zu schätzen.)

Fahren wir nunmehr in der Betrachtung des Grundumsatzes von Patient Or. fort! Fragen wir uns:

IV. Wie lässt sich der Umsatzwert unseres Falles mit Normalumsatzwert vergleichen und mit welchem Ergebnis?

Auch unter Berücksichtigung eines Fehlers von 2,7 pCt. (siehe oben!) würde der Sauerstoffverbrauch pro Kilogramm und Minute, der sich dann auf $3,44 \mathrm{ccm} \mathrm{O}_{2}$ reducieren würde, mit der Normaltabelle von Magnus-Levy (von Noordens Handbuch, Band I, S. 279) verglichen in die Reihe der Normalwerte für Männer fallen. Der Mittelwert ist hier $3,64 \mathrm{ccm} \mathrm{O}_{2}$.

Nun gibt aber bekanntlich die Beziehung auf Kilogramm Körpergewicht gerade im Vergleich von Normalen und Fettsüchtigen sicher schiefe Vergleichswerte, denn wie von Noorden (8) betont, ist ${ }_{n}$ dic Summe des atmenden Protoplasmas im Körper des Fettleibigen bedeutend geringer .... als im Kilogramm Normalmensch". Mehr Berechtigung hat die freilich gleichfalls mit Fehlern behaftete Vergleichung der $\mathrm{O}_{2}$ Zehrung gleicher Einheiten der Körperoberfläche miteinander. Wenden wir dies in unserem Falle an, und zwar gleich mit Umrechnung auf 24 stündigen Grundumsatz und Kalorienzahl, so finden wir laut Tabelle für Patient Or. einen llittelwert von 1077 Kalorien pro Quadratmeter Körperoberfläche oder mit Abrechnung von 2,7 pCt. 1048 Kalorien pro Quadratmeter gegenüber dem höchsten Normalwert in der Tabelle von Magnus-Levy von 893 Kalorien pro Quadratmeter.

So verglichen wäre also der Lmsatz bei Patient Or. um ein Beträchtliches über den Normalumsatz gesteigert.

Die dritte Möglichkeit der Vergleichung stützt sich auf die absolute verbrauchte Kalorienzahl und Körpergrösse.

Hierbei ist nach dem Vorschlag von Noordens (8) folgendermassen vorzugehen:

Körpergrösse Patient Or. $=170 \mathrm{ccm}$.

Hierfür berechnetes Normalgewicht (obere Grenze) $=170 \times 0,48$ $=81,6 \mathrm{~kg}$. Diesem entspricht ein Grundumsat\% von 2066 Kalorien, mit Erhöhung um 20 Ct. - ein Zuschlag, den von Noorden beim Vergleich zwischen Fettsüchtigen und Normalen als praktisch gefunden hat, $=2480$ Kalorien.

Dagegen der kleinste Wert des für unseren Fall berechneten absoluten Grundumsatzes (vgl. Tabelle II) $=3560$ Kalorien.

Diese ausserordentlich grosse Differenz würde durch eine in unserem Falle wohl berechtigte Vergrösserung des Zuschlags für Circulationsund Atemmehrarbeit etwa auf $40 \mathrm{pCt}$. etwas richtiger gestellt, bleibt aber bestehen. 
Tabelle III.

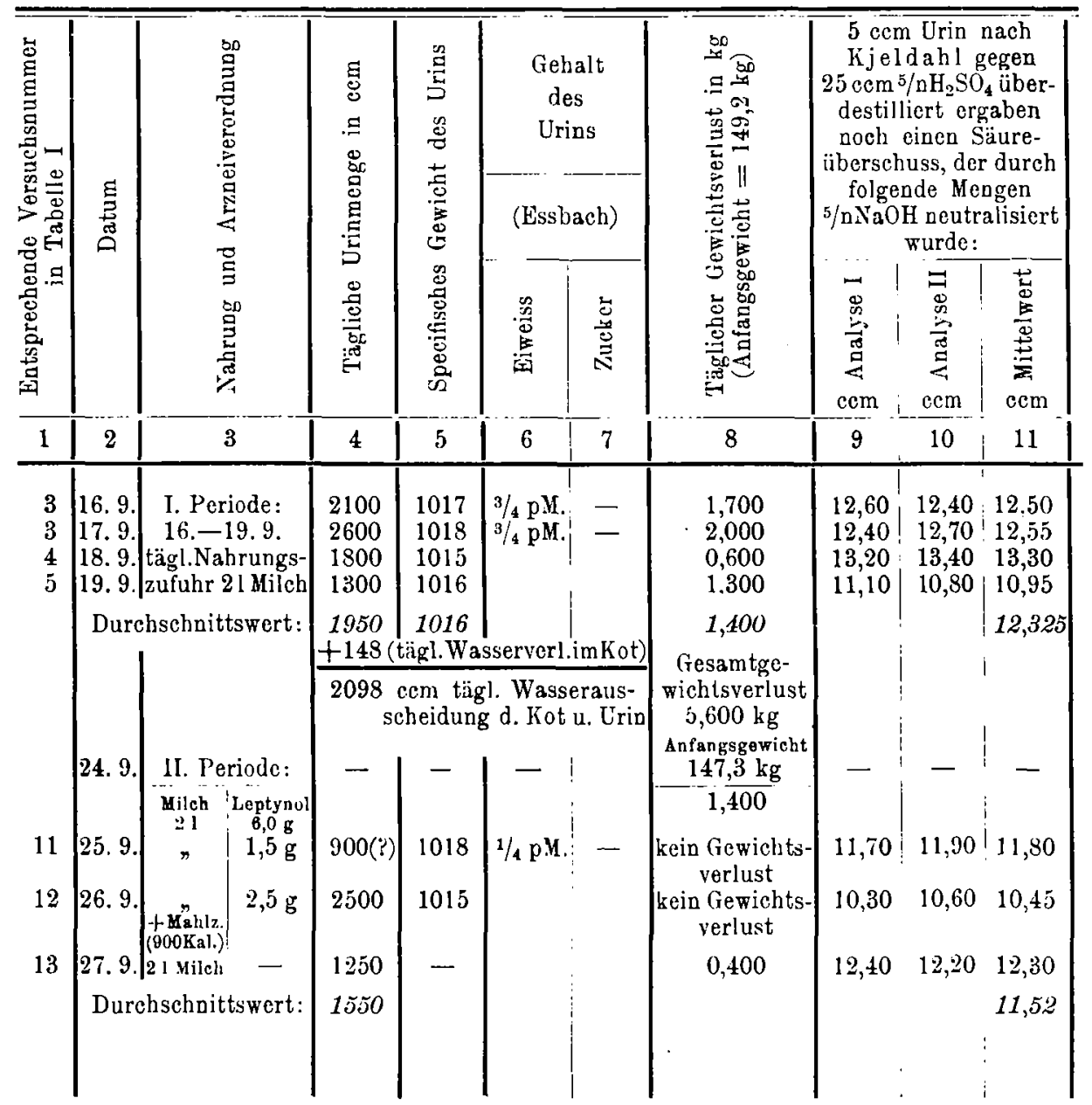

1) Schätzungsweise angenommen auf Grund der Kotanalyse der I. P'eriode. - 2) Der des nicht ausgenutzten Teiles der Nahrung nach Rubners Tabelle berechnet.)

Jede der drei angewandten Vergleichungsarten hat ihren Fehler, und das Fehlen einer absoluten Vergleichseinheit wird gerade in diesem excessiven Falle als Mangel ganz besonders empfunden.

Doch, bevor wir eine bessere Vergleichsmöglichkeit besitzen, sind wir gezwungen, auch so irgendwie Stellung zu nehmen.

Die Beziehung des Umsatzes auf die Einheit der Körperoberfläche kommt einer wahren Vergleichseinheit bis jetzt am nächsten. Sie gibt bei unserer Entscheidung den Ausschlag, dass in diesem Falle ein über den Jouchschnittswert des Normalen beträchtlich gesteigerter Grudumsatz vorhanden ist. (Mindestens 17 pCt. grösser als der höchste Normalwert bei Magnus-Levy. Dieser Procentsatz ist noch zu niedrig, denn die Meehsche Formel (14), die wir benutzt haben, gibt bei ihrer Durchschnittsconstante 12,3 für Fette zu grosse Ober- 
Fall Or.

\begin{tabular}{|c|c|c|c|c|c|c|c|c|c|}
\hline 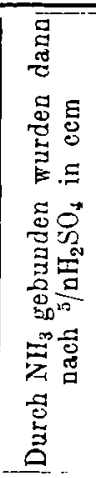 & 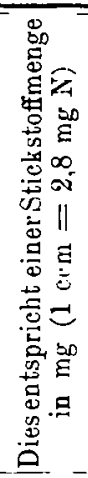 & 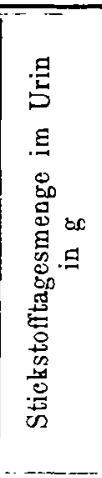 & 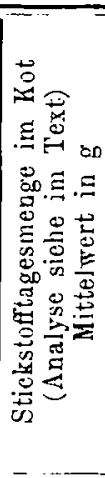 & 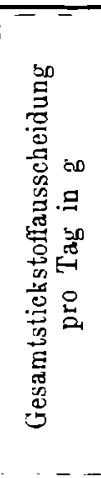 & 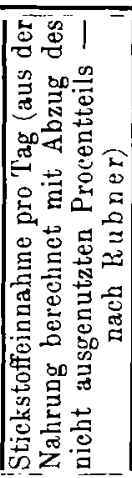 & 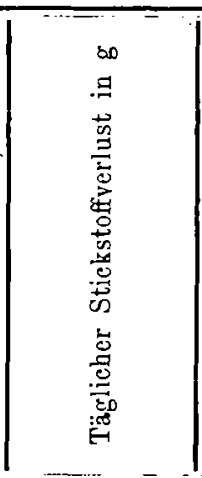 & $\begin{array}{c}\text { Kalo } \\
\text { Grund } \\
\text { Zun }\end{array}$ & 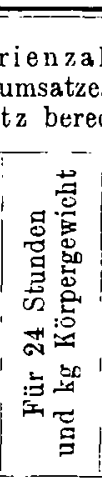 & 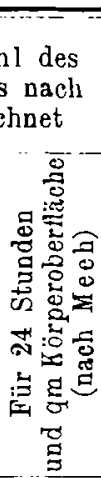 \\
\hline 12 & 13 & 14 & 15 & $1 \overline{6}$ & 17 & 18 & 19 & 20 & 21 \\
\hline $\begin{array}{l}12,50 \\
12,45 \\
11,70 \\
13,05\end{array}$ & $\begin{array}{l}35,00 \\
34,86 \\
32,76 \\
36,54\end{array}$ & $\begin{array}{r}14,700 \\
18,130 \\
11,790 \\
9,500\end{array}$ & $\begin{array}{l}0,85 \\
0,85 \\
0,85 \\
0,85\end{array}$ & $\begin{array}{l}15,550 \\
18,980 \\
12,640 \\
10,340\end{array}$ & $\begin{array}{l}9,290 \\
9,290 \\
9,290 \\
9,290\end{array}$ & $\begin{array}{l}6,260 \\
9,690 \\
3,350 \\
1,060\end{array}$ & $\left.\begin{array}{r}3581,3 \\
3577,8 \\
{[3806,4]} \\
{[3920,3]}\end{array}\right]$ & $\begin{array}{l}24,00 \\
24,26 \\
26,16 \\
27,12\end{array}$ & $\begin{array}{l}1034,0 \\
1041,0 \\
1117,6 \\
1154,2\end{array}$ \\
\hline 12,675 & 34,79 & $13,5.5$ & 0,85 & 14,38 & 9,29 & $\begin{array}{c}5,09 \\
\text { Gesant-X-Verlust } \\
\text { in 4 Tagen: } \\
20,36 \mathrm{~g}=127,25 \mathrm{~g} \\
\text { Kurpereiweiss } \\
\\
-\end{array}$ & . & & \\
\hline 13,20 & 36,96 & 6,56 & $\left.0,85^{1}\right)$ & 7,41 & 9,29 & $-1,88(?)$ & 3564,5 & 24,43 & 1044,6 \\
\hline 14,55 & 40,74 & 20,37 & $(1,201)$ & 21,57 & $\left.17,34^{2}\right)$ & $+4,23$ & 3665,9 & 25,13 & 1074,4 \\
\hline 12,70 & 35.56 & 8,89 & $\left.0,85^{1}\right)$ & 9,74 & 9,29 & $+0,45$ & 3703,3 & 25,38 & 1085,3 \\
\hline 13,45 & 37,75 & 11,94 & 0,97 & 12,91 & 11,97 & $\begin{array}{c}0,93 \\
\text { Gesant-N-Verlust } \\
\text { in } 3 \text { Tagen: } \\
2,80 \mathrm{~g}=17,5 \mathrm{~g} \\
\text { Körporejweiss }\end{array}$ & 3644,6 & 24,96 & 1068,1 \\
\hline
\end{tabular}

Stickstoffgebalt der Probemahlzeit wurde nach $\mathrm{Rubner}$ zu $8,05 \mathrm{~g}$ berechnet. (Unter Abzug

flächenwerte. - Die Bouchardschen Tabellen standen mir leider nicht zur Verfügung.)

Namentlich im Hinblick auf unseren klinischen Befund ist dies Ergebnis überraschend. Nach der bisherigen Umgrenzung der endogenen Fettsucht ist diese, wie wir schon oben erwähnten, mit der Forderung eines verringerten Umsatzes eng verknüpft. von Noorden (8) geht sogar soweit, dass or den Begriff ,endogene oder konstitutionelle Fettsucht" und "Verminderung der Zersetzungsenergie" direct identificiert. Alle Fälle mit normaler und gesteigerter Zersetzungsenergie will er allein durch Yast oder Faulheit erklärt wissen.

Sollen wir in unserem Falle die Beteiligung endogener Factoren, die doch die Fettsucht erst zur Stoffwechselkrankheit machen, fallen lassen? Nach unserem klinischen Befund wäre ein solcher Schritt nicht angängig. 
So bleibt uns denn nur übrig, den Versuch, unseren Fall in das bisherige Einteilungsschema einzugliedern, aufugeben und der Frage näher zu treten:

Unter welchen Umständen ist es denkbar, dass eine durch constitutionelle Faktoren bedingte (= endogene Fettsucht) von einem gesteigerten Umsatz begleitet wird?

Vorweg sei aber noch kurz erörtert:

V. Welche Beziehung kann die Polycythämie unseres Falles zur Umsatzerhöhung haben?

1. Es ist bekannt, dass Polycythämie im Sinne einer einfachen Hypertrophie des Blutes, bei der sogenannten "plethorischen Form" der Fettsucht, gepaart mit "Luxusconsumption", d. h. erhöhtem Lmsatz, vorkommt (8). Umsatzsteigerung und Polycythämie sind hier immer eine gemeinsame Folge einer Uebermästung kräftiger, völlig gesunder Individuen. Dieser plethorische Habitus mag früher bei Patient $0 \mathrm{r}$. in reiner Form bestanden haben (vgl. Vorgeschichte: Früheres Gewicht bei voller Gesundheit und Arbeitskraft $93 \mathrm{~kg}$. Fleischerberuf). Gegenwärtig hat sich ihm sicher eine endogene Componente superponiert, welche die Verhältnisse gänzlich verschieben musste. Der endogen bedingte Gewichtszuwachs musste den vorhandenen Luxusenergieverbrauch - anders ist es nicht denkbar - absorbiert haben. Ist also die Polycythämie ein Residuum der früher vorhandenen wahren Plethora, was zwar unwahrscheinlich ist, aber was wir nicht wissen, so kann sio wohl neben einem gesteigerten Umsatz bestehen; es ist aber nicht ersichtlich, wie sie mit einem solchen noch in irgend einem ursächlichen Zusammenhang stehen sollte.

2. Viel wahrscheinlicher erscheint es, dass es sich bei Or. um eine pathologische, sogenannte "Polycythämie mit gesteigertem Blutdruck" [Geisböck, Münzer (15)] handelt, wie sie als Compensationserscheinung einer central gestörten Circulation oder allgemein jeder Stauung im Kreislauf (etwa durch Compression der grussen Körpervenen durch intrathorakale Fettmassen) oder durch Atherosklerose der kleinsten Gefässe bedingte Störung der Sauerstoffzufuhr zu den Geweben namentlich von Münzer in einer Reihe von Fällen nachgewiesen und eingehend beschrieben worden ist. Bemerkenswert ist, dass der erste von Münzer beschriebene Fall (Herr F. J.) gleichzeitig fettsüchtig ist und mit unserem Patienten Or. weitgehende Uebereinstimmung aufweist: (bei kleiner Figur das beträchtliche Gewicht von $103 \mathrm{~kg}$. Wahrscheinlich endogene Form. - Jymphocytose, starke Thyreoidinreaction. - Auffallende Schlafsucht. - Cyanose vorwiegend des Gesichtes und rorwiegend im Liegen).

Eine Insufficienz der Herztätigkeit (dauernde Cyanose; leicht auslösbare Dyspnoe) ist auch in unserem Falle sicher vorhanden, ebenso lässt sich der erhöhte Blutdruck durch $\Lambda$ therosklerose der Gefässe deuten.

Es ist nun sehr interessant, dass bei derartigen Fällen von compensatorischer Polycythämie ein erhöhter $\mathrm{O}_{2}$-Verbrauch gefunden wurde 
[Senator, Mohr (16)]. Münzer hat seine Fälle nach dieser Richtung nicht untersucht, nimmt bei seinen Fällen einen normalen, nicht gesteigerten Umsatz an und hält die Polycythämie für eine Compensation des durch Stauung geschädigten und in bezug auf seine $\mathrm{O}_{2}$-Bindungsfähigkeit verschlechterten Hämoglobins.

In einem Falle von $\mathrm{Mohr}$ betrug die $\mathrm{O}_{2}$-Zehrung, nach $\mathrm{Zuntz}$ bestimmt, 379,5 ccm $\mathrm{O}_{2}$ pro Minute und Kilogramm Körpergewicht (16).

Wie diese Umsatzerhöhung bei der Polycythämie zustande kommt, ist schwierig zu beweisen; denn die compensierende Wirkung der Polycythämie wird ja durch sie zum Teil wieder aufgehoben. Abzulehnen ist vorläufig, so lange das Pflügersche Gesetz noch allgemein anerkannt wird, dass die einfache Mehranbietung von $\mathrm{O}_{2}$ einen Mehrverbrauch der Gewebe von $\mathrm{O}_{2}$ verursacht (Senator). Za denken wäre an eine allgemeine Reizwirkung auf die Verbrennung der Gewebe durch den vermehrten $\mathrm{CO}_{2}$-Gehalt des Blutes; die Beweise hierfür sind noch nicht erbracht. Die Wolpertschen Versuche (10) allerdings, welche den Einfluss des Kohlensäuregehaltes der Atemluft auf die Intensität des Cinsatzes bestimmen, sprechen eher dagegen als dafür.

Fine weitere Möglichkeit wäre, dass die zwecklose Mehrarbeit des insufficienten Herzens allein . genïgte, um den gesteigerten Umsatz zu erklären. Namentlich bei Fettleibigen, bei denen eventuell die Circulationsarbeit vergrössert ist - also speciell in unserem Fallo - , muss dieser Möglichkeit eine gewisse Bedeutung zuerkannt'werden.

Allerdings konnten die Respirationsversuche an Herzkranken [Kraus (10)] eine Umsatzverminderung zwar ausschliessen, eine der vergrösserten Herzarbeit entsprechende Vergrösserung des Unsatzes aber nicht in dem Masse, als es für unseren Fall nötig wäre, erweisen.

So kaun zwar die Möglichkeit nicht ganz ausgeschlossen werden, dass in unserem Fall eine gleichzeitig mit der Fettsucht vorhandene, aber mit dieser mehr symptomatisch, nicht direct ätiologisch zusammenhängende krankhafte Veränderung neben oder trotz der Fettsucht einen erhöhten Stoffwechsel verursacht. Aber von der Möglichkeit eines Beweises derartiger Verhältnisse sind wir sehr weit entfernt. Und wir sind nach diesem Resultat sehr wohl berechtigt, uns nach einer anderen Deutung der complicierten Verhältnisse unseres Falles umzusehen und weiter zu fragen, ob nicht ein erhöhter Umsatz unter Umständen aus dem Wesen einer auf innerer Ursache beruhenden Fettsucht selbst hergeleitet werden kann. Diese Fragestellung wird uns, wie wir bei der Betrachtung des R.-Q. noch sehen werden, durch die vorurteilsfreie Betrachtung unseres Falles direct aufgenötigt. Es handelt sich nicht um die Erörterung einer blossen Denkmöglichkeit, die mit wirklich Beobachtetem noch keine Eühlung hat.

\section{Wie kann Fettsucht als Stoffwechselstörung eine erhöhte Verbrennung im Körper bewirken?}

1. Fettsucht als Stoffwechselstörung. Bis jetat haben wir das Problem der Fettsucht immer von seiner energetischen Seite aus zu lösen gesucht, wir haben immer den Kraftwechsel der Fettsucht als ihr 
primäres Charakteristicum gesetzt und hofften von da aus ihr stoffliches Kennzeichen, das Vehr an Körpergewicht — ganz allgemein ausgedrückt - einfach causal entwickeln zu können. Wir sind zu dem U'rteil gekommen, dass wir vorläufjg auf diesem Wege nicht zu einer einfachen Lösung kommen.

Nur das Postulat der Einfachheit veranlasst uns daher, den alten Weg, der bei allen naturwissenschaftlichen Problemen zuerst eingeschlagen wurde und uns daher vertrauter ist, einzuschlagen und unser Problem von der stofflichen Seite anzugreifen. Theoretisch müssten beide Wege zum Ziele führen, sind beide Wege gleich richtig (in diesem Sinne bilden die Begriffe Stoff und Kraft eine Antinomie).

Zum Ausgangspunkt einer Betrachtung der Fettsucht als Stoffwechselstörung können wir folgenden Satz von Bergmanns nehmen (17): „Bei der constitutionellen Fettsucht sehen wir..... heute als das Herrschende an: eine in ihrer Ursache ungeklärte Tendenz zur Fettgewebewucherung (sogenannte lipomatöse Tendenz von Bergmanns). Wie dabei die Ersparungen zum Zweckè der Fettgewebevermehrungen erübrigt werden, ist etwas Secundäres. Individuen mit niedrigem Grundumsatz haben es darin leichter, insofern sind sie $n$ disponiert" ; diese Individuen sind aber übrigens ebenso geeignet zur Mastfettsucht."

Diese Definition kommt zwar nicht über die anatomisch-stoffliche Fassung des Fettsuchtproblems heraus, zeigt aber gerade so am besten, wie wenig wir noch wissen. Gibt es doch bisher nur eine tatsächliche Beobachtung, welche geeignet schiene, von der anatomisch-stofflichen, um mich so auszudrücken, zu einer chemisch-stofflichen Definition den Weg zu weisen. Es ist das dic von Waldvogel $(12,18)$ an Fettsüchtigen beobachtete Verlangsamung der Acetonausscheidung nach Infusion von $5 \mathrm{~g} \beta$-oxy-Buttersäure. Um jedoch diese Beobachtung ihrer Bedentung nach auszuwerten, fehlt uns bisher die genaue Kenntnis der physiologischen Auf- und Abbaustoffe des Fettstoffwechsels.

Um so mannigfacher sind dic meist nach Analogie der anderen, besser bekannten Stoffwechselkrankheiten gebildeten Hypothesen, welche die Bergmannsche "Tendenz" durch einen chemischen Prozess erklären wollen. [von Mering, von Noorden, von Bergmann - vgl. v. Bergmann im Handbuch der Biochemie (18]).

lch will auf diese im einzelnen nicht eingehen. Ihrem Kern nach werden sie durch folgendes Citat aus von Bergmanns erster Arbeit über Fettsucht (12) treffend charakterisiert und in ihrer Bedeutung für den Kraftwechsel abgegrenzt. (von Bergmann selbst lehnt sie allerdings - damals noch - nstrictissime ${ }^{\mu}$ ab. Hierin hat er seine Stellung in seinen späteren Arbeiten geändert.)

nIm Hinblick auf die gichtische und diabetische Stoffwechselstïrung ist es ja ein sehr naheliegender Analogieschluss, etwa für die Fettsucht sich vorzustellen, Fett werde ungenügend verbrannt und gelange deshalb zum Ansatz, oder auch dic Umwandlung der Kohlehydrate zu Eett vollziehe sich leichter wie ihre Verbrennung, und das sei der Grund zur Fettaufspeicherung. Für diejenige physiologische Betrachtungsweise, die in den Fetten und Kohlehydraten isodynam 
sich vertretende Energiequellen sieht, die nach Mlassgabe des Bedürfnisses des Organismus herangezogen werden, haben diese Speculationen von Intermediärstörungen, obwohl sie auf dem Gebiete intermediärer Stoffwechselvorgänge zunächst reine Speculationen bleiben, trotzdem die Bedeutung einer bei allen Bilanzaufstellungen beachtenswerten Möglichkeit. Der Organismus müsste an Stelle des für ihn nicht ausnutzbaren Fettes mehr Kohlehydrate und Eiweiss für seinen Energiebedarf heranziehen; dann würde er aber scheinbar einen grösseren Kalorienbedarf haben als der normale Organismus. Er würde z. B. bei einer fettreichen Kost trot\% genügender Kalorienzufuhr Körpereiweiss einschmelzen müssen."

Also eine erschwerte Verbrennung oder erleichterte Bildung aus Kohlehydraten zu Fett sind die beiden Hauptmöglichkeiten einer zur Fettsucht führenden Stoffwechselstörung.

Tabelle IV.

Beteiligung der einzelnen Nahrungs-bzw. Körperbestandteilo an der Verbrennung (nach Zuntz berechnet).

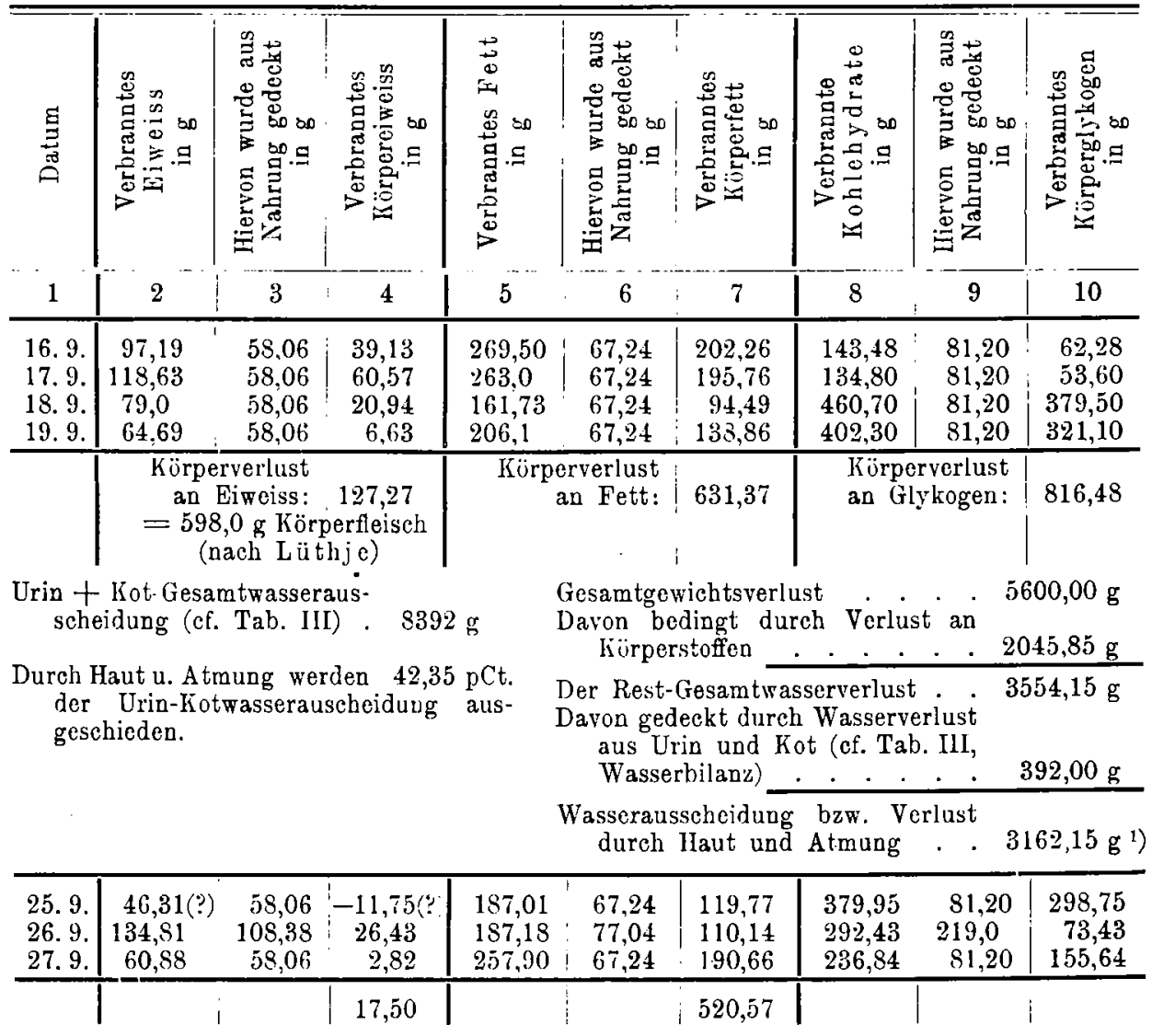

Die einzelnen Gewichtsteile der Nahrung wurden unter Berücksichtigung der Rubnerschen Nahrungsausnutzungstabelle berechnet. Den entsprechenden Werten vom 26. 9. wurden die Ausnutzungszahlen für gemischte Kost von $\Lambda$ twater zu Grunde gelegt.

1) Diese Wassermenge wird, sofern sie nur die Wasserausscheidung, nicht den Verlust angeben soll, noch durch das "Uxydationswasser ${ }^{*}$ [ca. $1-1{ }^{1 / 2} 1$ (hier nicht berücksichtigt)] vergrüssert. 
Wir glauben in unserem Falle (siehe weiter unten) für erstere Möglichkeit sichere Anhaltspunkte gefunden zu haben, und lassen es hierbei offen, ob es sich um eine erschwerte Mobilisation der Fettlager handelt — das wahrscheindichste - oder um eine allgemeine Unfähigkeit aller Körperzellen, das mobilisierte Fett zu verbrennen.

Wir präcisieren danach unsere Frage: Wie kann Fettsucht als Stoffwechselstörung eine erhöhte Verbrennung im Körper bewirken? folgendermassen:

2. Wic kann eine erschwerte Fettverbrennung im Körper, die Fettsucht verursacht, eine erhöhte Verbrennung bewirken? Zunächst sei hier auf die Analogie mit dem Diabetes mellitus hingewiesen. Es ist jetzt sichergestellt, dass es Fälle von menschlichem schweren Diabetes gibt, in denen ebenso wie im experimentellen Pankreasdiabetes der Gesamtumsatz erhöht ist ( $M \circ h r$ u. a.) Die Gründe dafür sind nicht aufgedeckt. Es ist möglich, dass Störungen im Gleichgewicht der inneren Drüsentätigkeit mit Ueberwiegen einer umsatzfördernden Componente (z. B. Schilddrüse) dafür die Ursache sind. Man kann aber auch daran denken, dass die Steigerung des Gesamtumsatzes secundär bedingt ist durch einen infolge des völligen oder teilweisen Ausfalls der Kohlehydrate aus der Zersetzung bedingten vermehrten Umsatz von Eiweiss und Fett. Gerade für unseren Fall von Fettsucht müssen wir an eine solche secundäre Lmsatzsteigerung denken, da, wie bereits erwähnt und weiter unten gezeigt werden wird, eine Einschränkung der Fettzersetzung mit Sicherheit erweislich ist. Es würde so der auffallend hohe Gesamtumsatz unseres Falles verständlich und die paradoxe Tatsache erklärlich, dass entgegen der herrschenden Meinung auch endogene Formen der Fettsucht mit einem erhöhten Stoffumsatz einhergehen können. Uebrigens finden unsere Beobachtungen ein Seitenstück in den Beobachtungen Rubners an einem fettsüchtigen Knaben. Nach Rubners Abbildung würde man heute höchstwahrscheinlich die Diagnose endogene Fettsucht stellen. [Vgl. Rubner, Beiträge zur Ernährung im Knabenalter. 1912. (20).] Dieser Knabe hatte trotz grosser Muskelträgheit einen ebenso grossen Umsatz wie sein gleich grosser magerer Bruder, welcher die gleiche Eruährung hatte. In Bezichung der Wärmebildung auf das im Körper befindliche Liweiss hatte sogar der Fette mehr zersetzt als der Magere. Nun fand Rubner bei diesem Knaben cine beträchtlich geringere Ausnutzung des Nahrungseiweisses vom Darme aus im Vergleich mit dem Hageren. (20,91 pCt. des Nahrungseiweisses gingen beim Fetten verloren, nur 13,15 pCt. beim Mageren.) $\mathrm{Cm}$ den Eiweissbedarf zu decken, so schliesst Rubner, musste die Quantität der Kost erhöht werden, und da die Kost - im Haushalt einer Arbeiterfamilie - ihrer Zusammensetzung nach sich gegenüber dem mageren Bruder höchstwahrscheinlich nicht veränderte, so musste ein Ueberschuss an Fett und Kohlehydraten hieraus resultieren und könnte möglicherweise den unverhältnismässig grossen Fettansatz erklären. Demnach wäre in diesem Fall ${ }_{n}$ die Fettsucht nicht eine Ernährungsanomalie, sondern eine Verdauungsanomalie". 
Eine Erklärung für die relative Umsatzerhöhung seines Falles gibt Rubner nicht; er selbst legt auch obigem Erklärungsversuch für das Zustandekommen des Fettansatzes nur die Bedeutung einer Möglichkeit bei.

Unter wolchen Nahrungsbedingungen und in welchen Perioden mit etwa dazwischen liegenden Pausen sich in unserem Fall die Fettsucht bis zu ihrem jetzigen Grade entwickelt hat, darüber fehlt uns jegliche genaue Angabe und Beobachtung.

Trotzdem sei skizziert, wie sich ihre Entstehung auf Grund der oben dargesteliten Unfähigkeit, Körperfett zu verbrennen, darstellen würde:

$O b$ in unserem Falle jemals eine Periode unternormalen Umsatzes bestanden hat, wissen wir nicht, brauchen es aber nicht anzunehmen. Laut Anamnese nahm Patient 0. R. in 4 Jabren um $57 \mathrm{~kg}$ an Körpergewicht zu; rechnen wir für Vermehrung des Bestandes an Körperwasser nach willkürlicher Schätzung $7 \mathrm{~kg}$ ab (was wahrscheinlich viel zu wenig ist, siehe unten), so kommen wir - ganz grob und schätzungsweise gerechnet - pro Tag auf einen Fettansatz von $34 \mathrm{~g}$. Bei gemischter Kost, die in Norddeutschland bekanntlich meist mehr Fett als die Voitsche Zahl (50 g Fett) enthält, würde also nur ein Bruchteil der resorbierten Kettmenge nicht verbrannt und daher angesetzt werden.

Diese $34 \mathrm{~g}$ Fett werden also dem Umsatz - ganz gleichgiltig, ob dieser normal hoch oder gesteigert angenommen wird - jetzt vorenthalten, können also eigentlich nicht als Nahrung gelten. Wird nun die Nahrungszufuhr nicht secundär verstärkt, so muss zur Bestreitung der unbeeinflussbaren Umsatzgrösse anderes Brennmaterial, also neben dem kosibaren Körpereiweiss vor allen Dingen die Glykogenvorräte herangezogen werden. Sun hat aber $1 \mathrm{~g}$ Glykogen ebensoviel Brennwert wie $1 / 2 \mathrm{~g}$ Fett. Es müsste also trotz Fetlansatzes in dem gesetzten Falle einer secundär nicht gesteigerten Nahrung Gewichtsverlust eintreten. Die einzige Mögliohkeit, diesen auszugleichen, bestände in Wasserretention. Diese spielt meiner Meinung nach in der Tat eine nicht unbedeutende Rolle in dem Stoffwechsel der Fetisüchtigen und dürfte wobl zur Erklärung mancher sich scheinbar. widersprechender Befunde heran. gezogen werden können. Zwar enthält nach neueren Angaben das menschliche Fettgewebe selbst nur einen sehr geringen Procentsalz Wasser, aber die vulgäre Anschauung, dass der hochgradig Fettsüchtige naugeschwemmt" sei, deren Grundlage wobl in der Beobachtung des grossen Flüssigkeitsbedarfes der Fetten zu suchen ist und eben nichts anderes als Wasserretention besagen will, ist leider sebr schwierig exact nachzuprüfen, aber hat sicher ihre Berechtigung. (Dass hochgradige Nahrungsbeschränkung, wiß z. B. unsere Entziehungskur, starke Entwässerung des Körpers herbeiführt, widerspricht dem nichi, sondern bestätigt es.) Leider fehlt uns bisher nocb jede Methode, den Wassergebalt des Körpers in vivo direct zu bestimmen (etwa durch Bestimmung des specifischen Gewichtes oder der elektrischen Leitfähigkeit inneren menschlichen Gewebes, wie z. B. Muskel). Auch an der Leiche ansgeführte Bestimmungen des procentualen Wassergehaltes ron Fetten gegenüber Normalen fehlen. Ebenso sind Wasserbilancen gerade durch die eigenartige Wärmeregulation der Fetten wohl zu errechnen, aber sehr umständlich längere Zeit direct zu messen.

So sind wir hier nur auf Vermutungen angewiesen. Immerhin dürfte dies die einzige Möglichkeit sein, für lürzere Zeitperioden bei gleichbleibender Umsatzgrösse (ebenso gut für gesteigerten Umsatz) ohne Steigerung der Nahrungszufuhr eine Gewichtszunahme zu erklären.

Jedoch wohl nach kaum mehr als wenigen Woohen (siehe weiter unten) müssen die Glykogenvorräte im Körper soweit erschöpft sein, dass nunmehr eine Periode secundär gesteigerter Nahrungsaufnahme folgen muss. Und zwar wird bei selbst ge- 
wählter Kost der Zuschuss an Nahrung zı dem Normalmass zweckmässigerweise zur möglichsten Beschränkung des Fettansatzes möglichst wenig Fett urd möglichst viel Kohlehydrate enthalten. Bekanntlich kann schon im Tierversuch Kohlehydratnahrung, im Ueberschuss gegeben, jede Verbrenuung der Körperfettdepots eliminieren. (Zur Fettbildung aus Kohlehydraten würde es wohl schon wegen des grossen directen Bedarfs an Brennmaterial nur in zu vernachlässigender Menge kommen.)

Es ist nun weiter durchaus denkbar, dass die Verschiebung der Nabrungsbestandteile zugunsten der Kohlehydrate an und für sich wiederum eine Steigerung des Umsatzes zur Folge hat; müssen wir doch berücksichtigen, dass die specifischdynamische Umsatzsteigerung nach Nahrungsaufnabme für Koblehydrate nach Magnus-Levy über $31 / 2$ mal so gross ist wie für Fett (procentuale Lmsatzsteigerung durch Fett $21 / 2$ pCt., durch Kohlehydrate $9 \mathrm{pCt}$.). Freilich wäre in unserem Ealle hierdurch nur ein kleiner Teil der Unsatzsteigerung erklärt.

Nochmals sei der rein theoretische Charakter dieser letzten Erörterung betont, für die wir bei unserem Fall keine äquivalente Beobachtungstatsache haben. Sie hatte nur den $\mathrm{Zweck}$ darzutun, dass die allgemeinen Anschauungen übel Firnährung und Stoffumsatz mit der $A$ uschaung einer mangelhaften Fettrerbrennung als Erklärung für Fălle von endogener Fettsucht - für diese Anschauung glauben wir einige tatsächliche Belege zu haben (siehe weiter unten) - nicht im Widerspruch steht.

\section{E. Der respiratorische Quotient.}

Wenden wir uns nun ins einzelnen zur Besprechung des respiratorischen Quotienten und des Stickstoffwechsels während der beiden Perioden der Entziehungskur.

Zur Erläuterung der Tabelle II muss zuvor noch Folgendes vorausgeschickt werden:

1. Die in Tabelle III verwendeten Kotstickstoffzahlen wurden folgendermassen durch Analyse gewonnen:

Der Kot vom 16. bis 19. 9. wurde durch gepulverte Kohle abgegrenzt und gesammelt. Das Feuchtgewicht betrug:

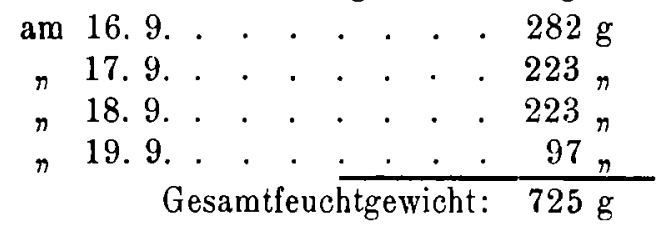

Der Kot der 4 Tage wurde zusammen getrocknet (im Wärmeschrank bei $100^{\circ} \mathrm{C}$ ) und gepulvert.

Als Trockengewicht ergab sich daraus . . $131 \mathrm{~g}$

Gesamte Kotwassermenge . . . . . $594 \mathrm{ccm}$

Durchschnittliche Tageswassermenge im Kot 148 n

Es wurde $1,0 \mathrm{~g}$ getrockneter Kot nach Kjeldahl gegen $50 \mathrm{~g}$ $5 / \mathrm{nH}_{2} \mathrm{SO}_{4}$ überdestilliert. Zur Neutralisation waren

nach Analyse I . . . . . . . . . $32,9 \mathrm{ccm}$

$$
" n \text { II . . . } \frac{. \quad . \quad .33,1 n}{\text { im } \frac{.}{\text { Mittel } . ~} \cdot 33,5 \mathrm{ccm} 5 / \mathrm{nNaOH}}
$$

nötig. Durch $\mathrm{NH}_{3}$ wurde demnach gebunden:

$$
17 \mathrm{ccm} 5 / \mathrm{nH}_{2} \mathrm{SO}_{4} \text {. }
$$

Dies entspricht $47,6 \mathrm{mg}$ Stickstoff. 
Die ganze im Kot ausgeschiedene Stickstoffmenge ist also:

$$
6,235 \mathrm{~g} \text {, }
$$

Stickstofftagesmenge: $1,559 \mathrm{~g}$.

Davon ist abzuzichen als Verlust durch mangelhafte Nahrungsausnutzung (nach Rubner für Milch 7,1 pCt., also bei $21=10$ g Stickstoff: $0,71 \mathrm{~g} \mathrm{~N}$ ). Die durchschnittliche tägliche Stickstoffausscheidung durch den Darm beträgt also $1,559-0,71 \mathrm{~g}=0,85 \mathrm{~g} \mathrm{~N}$.

2. Die Kaloriengrösse des Tagesumsatzes in Tabelle III wurde folgendermassen nach 7 unt $z$ berechnet (Boispiel 6. 9.):

Gesamttagesstickstoffausscheidung: $15,550 \mathrm{~g}$. (Es wird hier nach dem Vorgang von P'lüger auch ein Teil des Kotstickstoffs in Rechnung gezogen.)

Stickstoffausscheidung pro Ninute: $10,80 \mathrm{mg} \mathrm{N}=67,44 \mathrm{mg}$ Eiweiss. Nach Zuntz braucht $1 \mathrm{~g}$ lïweiss zur Oxydation im Körper $966,1 \mathrm{ccm} \mathrm{O}_{2}$ und bildet $781,7 \mathrm{ccm} \mathrm{CO}_{2}$ und 4,423 Kalorien.

Gesamtumsatz laut Tabelle I (in diesem Falle, als dem einzigen, wurde nicht der am Anfang der 24stündigen Sammelzeit des Harns gelegene Umsatz Tabelle I Nr. 2, sondern der am Ende dieser Zeit liegende Umsatz Tabelle I Nr. 3 gewählt, welcher mit demselben Recht hierzu zu verwenden und, wie oben bemerkt, richtiger ist):

\begin{tabular}{|c|c|c|c|c|}
\hline & $\mathrm{ccm} \mathrm{O}_{2}$ & $\mathrm{cem} \quad \mathrm{O}_{2}$ & Kalorien & R.- - (l. \\
\hline $\begin{array}{l}\text { Gesamt-Minutenumsatz . . } \\
\text { Auf } 67,44 \mathrm{mg} \text { Eiweiss fallen }\end{array}$ & $\begin{array}{r}525,7 \\
65,2 \\
\end{array}$ & $\begin{array}{r}402,4 \\
52,7\end{array}$ & $\overline{299}, 6$ & $\stackrel{0,766}{-}$ \\
\hline Für Fett und Kohlehydrate bleibt: & 460,5 & 349,7 & - & 0,759 \\
\hline
\end{tabular}

Bei dem R.-Q. 0,759 beträgt nach der Zuntzschen Berechnungsweise (vgl. die Arbeitsversuche) für $1 \mathrm{ccm} \mathrm{O}_{2}$ der kalorische Wert:

4,750 Kalorien, also auf $460,5 \mathrm{ccm} \mathrm{O}_{2}$

kommen . . . . . . . . 2187,4 Kalorien

299,6 Kalorien (aus Eiweiss)

pro Minute werden gebildet: 2487,0 Kalorien.

Energie-Grundumsatz pro Tag 3581,3 Kalorien, pro Kilogramm 24,0 Kalorien, pro Quadratmeter Oberfläche 1034,0 Kalorien.

Der respiratorische Quotient während der Entziehungskur: Ist man überhaupt berechtigt aus ihm Schlüsse zu zichen, oder soll man die gegenüber unserer Erwartung um einige Zehntel zu hohen Werte von vornherein allein durch forcierte Atmung und dadurch bedingte zu starke $\mathrm{CO}_{2}$-Abdunstung erklären? Die Jünge der Versuchsdauer spricht dagegen, ebenso die Constanz der Werte.

Es kommen hier in Betracht:

$$
\begin{aligned}
& 0,859 \\
& 0,835 \\
& 0,836 \\
& 0,838 \\
& 0,830
\end{aligned}
$$

(Versuch 3 und 17 gehören nicht hierher, was weiter unten erklärt wird.) 
Auch die charakteristischen Ausschiäge des R.-Q. bei den später zu discutierenden Versuchen nach Nahrungsaufnahme sprechen für seine Zuverlässigkeit. Für eine ausgiebige Beteiligung des Körperfettes an der Verbrennung ist der R.-Q. bedeutend zu gross. Das wird anschaulich, wenn wir nach $Z$ untz aus dem R.-Q. und dem Stickstoffumsatz die Beteiligung der einzelnen Körperbestandteile bzw. Nabrungsbestandteile an der Verbrennung berechnen (13). Vergleiche auch Tabelle IV. Versuch 4 z. B. würde ergeben:

\begin{tabular}{c|c|c}
\hline \hline Verbrannte Nahrung & $\begin{array}{c}\text { Hiervon aus Nahrung } \\
\text { gedeckt }\end{array}$ & $\begin{array}{c}\text { Durch Körperbestandteile } \\
\text { zu deckender Rest }\end{array}$ \\
\hline 79,0 g Eiweiss & 60 g Fiweiss & 19 g Eiweiss \\
$161,73 \%$ Fett & 71 Fett & $90,73 \%$ Fett \\
460,7 , Stärke & $90,2 \%$ Stärke & $370,5 \%$ Glykogen
\end{tabular}

Zur Rechtfertigung dieses Befundes bestehen zwei Möglichkeiten:

1. Entweder war es ein Fehler, dass wir den am Morgen zwischen 9 und $10 \mathrm{Uhr}$ gewonnenen R.-Q. auf den 24 Stundenumsatz bezogen. Dann könnte sich sein hoher Wert (etwa im Sinne der von uns wahrscheinlich gemachten abnorm verlangsamten Reaction auf Nahrungszufuhr) durch eine auffallend späte Verbrennung der wenn auch spärlichen durch die Nahrung eingeführten Kohlehydrate erklären lassen. Schon der R.-Q. des Versuchs $17 \mathrm{im}$ Contrast zu denen der Versuche 12, 14-16 (Näheres siehe weiter unten) sprechen direct dagegen, denn sie beweisen eindeutig, dass die Kohlehydrate in unserem Falle sehr schnell verbrannt werden.

2. Es bleibt consequenterweise als Erklärung nur übrig, eine ganz aussergewöhnliche Beteiligung des Glykogenvorrates in dieser Periode des Hungerstoffwechsels, wenn man sie im. Extrem so charakterisieren wollte, anzunehmen. Dies müsste eine Folge sein der schon weiter oben einmal erwogenen Unfähigkeit, Körperfett in grösserem Massstabe zu verbrennen. Gemischte Kost, auch mit reichlicher Kohlehydratbeteiligung, müsste dann den R.-Q. des Grundumsatzes gegenüber dem R.-Q. des Hungergrundumsatzes erniedrigen; denn wic wir eben sahen, werden die Nahrungskohlehydrate grösstenteils gleich zu Anfang verbrannt, und im Normalnüchternwert hat auch dann infolgedessen die Nahrungsfettverbrennung das Uebergewicht (= niedriger R.-Q.) im Vergleich zum Hungernüchternwert, während die im Normalnüchternzustand noch etwa zur Verbrennung kommenden Kohlehydrate der notgedrungen ungeheuren Glykogenverbrennung beim Hungernüchternwert in keinem Fall die Wage halten können.

Unsere Versuche bewahrheiten diese Folgerungen gänzlich. Vergleiche hierzu die R.-Q. von Versuch 13 und 3 im Gegensatz zu denen von Versuch 4-6 und 11 u. 12; auch Versuch 3 gehört hierher (Grundumsatz nach dem ersten Hungertag); denn er beweist eclatant die über 24 Stunden lang andauernde Wirkung der vorher genossenen selbst ge- 
wählten Kost und zeigt, dass der Iunger-R.-Q. sich erst am zweiten Versuchstage (Versuch 4) einstellt, um als solcher auffallend constant zu bleiben.

So unglaubhaft auch auf den ersten Blick ein täglicher Glykogenverlust von $370 \mathrm{~g}$ erscheint, so wissen wir doch, dass die Glykogendepots des Körpers ffür den Normalmenschen wird der Glykogengehalt gleich 2 pCt. des Gesamtorganismus angenommen; in unserem Falle (Gewicht ca. $150 \mathrm{~kg}$ ) würde man danach wohl schätzungsweise $1500 \mathrm{~g}$ Glykogenbestand ( $2 \mathrm{pCt}$. von dem Gewicht eines ebenso grossen gesunden Mannes, $75,0 \mathrm{~kg}$ ) annehmen, was mit der nach Tabelle IV gefundenen Menge innerhalb 4 Tagen der Entzichungskur verbrannten Glykogens von $816 \mathrm{~g}$ gut übereinstimmen würde] einige Tage lang sehr wohl diesen Bedarf stellen können.

Dass überhaupt die physiologische Möglichkeit besteht, dass die Glykogenlager im Körper ohne weiteres bis auf einen ganz geringen Procentsatz in kürzester Zeit verbraucht werden können, das beweist uns:

I. Der Tierversuch. Beim hungernden, sich frei bewegenden (wohl zu beachten!) Tiere schwindet das Glykogen schon in den ersten Tagen des Hungerns bis auf einen geringen Rest, der dann nur äusserst langsam abnimmt, was durch Körperanalyse festgestellt werden kann.

II. Dass sich in diesem Punkte der Mensch principiell ebenso verhält, beweisen uns die an hungernden Menschen bei gleichzeitiger Arbeit (Raddrehen) von Zunt $z$ und Lehmann (13) ausgeführten Respirationsversuche, welche ein momentan mit der Arbeit einsetzendes Steigen des R.-Q., d. h. eine sofort beginnende Glykogenverbrennung im Körper nachgewiesen haben.

Aber gleichwohl weicht unser Fall O. R. durch seine vorwiegende Glykogenverbrennung im Hungerstoffwechsel principiell vom Verhalten des normalen hungernden Menschen ab ${ }^{1}$ ). Denn Patient 0 . R. befand sich wäbrend der massgebenden IIungerperiode vom 16. bis 19. 9. (vgl. Tabelle I, III, IV) in vollkommener Bettruhe, und zwar dauernd, nicht nur während der Respirationsversuche (einen täglichen cinhalbstündigen Spaziergang und eine einmalige $\Lambda$ rbeitsleistung von $2200 \mathrm{mkg} \mathrm{--vgl.} \mathrm{Tabelle} \mathrm{I} \mathrm{-} \mathrm{glauben} \mathrm{wir} \mathrm{dabei} \mathrm{ver-}$ nachlässigen zu dïrfen) $)^{2}$.

1) Ich bin hier allerdings gezwungen, den „partiellen " Hungerzustand unseres Falles mit dem ntotalen" Hungerzustand normaler Menschen zu vergleichen; an unserem Patienten reine Hungerversuche anzustellen, war leider aus äusseren Gründen nicht möglich. [Reine Hungerversuche bei Lindogenfetten übor mehrere Tage mög. lichst in dauernder Rubelage, nicht nur über 24 Stunden [vgl. von Bergmanns Versuch (12)], scheinen mir übrigens nicht nur zum Nachweis eines verlangsamten Abfallens der Umsatzkurve nach Nahrungsaufnahme (siehe weiter oben), sondern vielmehr noch zur Feststellung oiner Stoffwechselstörung bei Fettsucht von entscheidender Bedeutung.] Andererseits sind mir analoge, partielle ${ }^{\text {i }}$ Hungerversuche am normalen Menschen nicht bekannt.

2) Das ist hier von Bedeutung, da es die Berechtigung erhöht, aus Verbindung eines kurzen Ruhenüchtornwertes mit der Stickstoffausscheidung des ganzen 'Tages die Beteiligung der drei Körperbestandteile an der Verbrennung zu errechnen. 
Und beim ruhenden Normalmenschen im Hunger betrug (Versuch von Zuntz und Lehmann) der R.-Q. weniger als 0,71, was sogar eine Bildung von Glykogen aus Fetien oder Eiweiss beim normalen wahrscheinlich macht, jedenfalls jede Glykogenverbremung ausschliesst.

Dasselbe Ergebnis in noch gewichtigerer Form bringt der 7 tägige Hungerversuch mit 24 stündiger Respirationsmessung von Benedikt am normalen Menschen. Dieser zeigte folgendermassen ein rapides $\Lambda$ bfallen der Glykogenverbrennung (13):

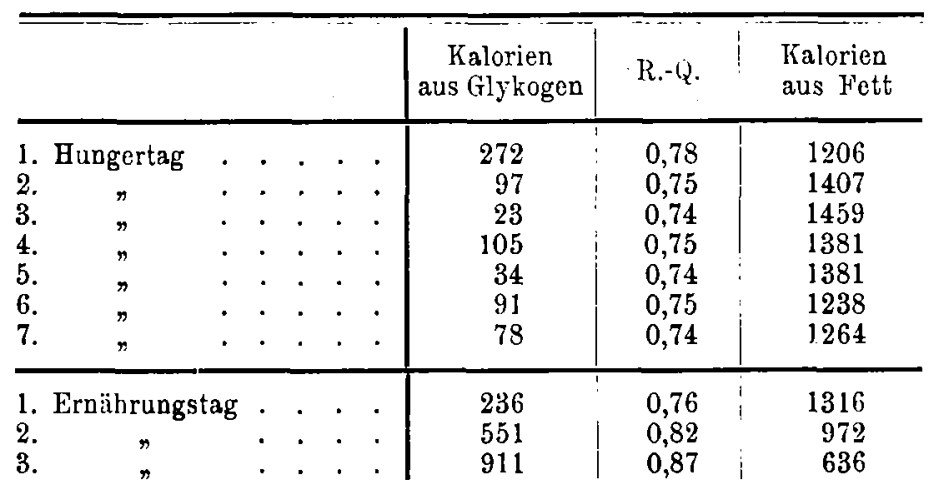

Selbst hier lässt sich an 2 Versuchstagen, dem 2. und 5., eine Bildung von $11 \mathrm{bzw} .21 \mathrm{~g}$ Glykogen aus den obigen Zahlen bercchnen, obwohl natürlich in den 24 stündigen Respirationsversuchen sich diese Bildung viel schwerer nachweisen lässt, weil nin den Perioden stärkerer Muskeltätigkeit das Glykogen wieder verbraucht wird " (citiert nach Zuntz, Stoff- und Kraftwechsel, in seinem Lehrbuch der Physiologie des Menschen).

In unserem Fall ist also die Lage so:

Fett ist im Körper im Ueberschuss vorhanden, Glykogen vermutlich in normalen Mengen. Trotzdem wird enorm viel weniger Fett verbrannt als bei normalen Verhältnissen und enorm viel mehr Glykogen.

Der logische Schluss hieraus, dass der Grund dieses anormalen Verhaltens in der Unfähigkeit des Körpers liegt, die ungeheure Menge Fett in nutabares Brennmaterial umzusetzen, kommt einem 'latsachenbeweis sehr nahe.

\section{F. Der Eiweissstoff wechsel.}

Wie stellt sich nun der Eiweisstoffwechsel nach der Tabelle dar? Durch von Noorden und Dapper ist erwiescn worden (8), dass eine Entziehungskur auch dritten Grades (nach der Einteilung von Noordens) bei geeigneter Anordnung ohne Stickstoffverlust durchgeführt werden kann. Bei einer Carrelkur war dies von vornberein nicht zu erwarten. Die von Moritz und anderen hicr beobachteten siarken Unterbilanzen sind bedingt durch die zu geringe Liweisszufuhr und das ungünstige Verhältnis zwischen der Menge der Kohlehydratkalorien (cf. v. Noorden, Die Fettsucht, S. 211).

Wir fanden (zunächst in Betrachtung der ersten Periode, wolche in dieser Hinsicht die leichter zu analysierende ist und reinere Resultate 
bietet) eine durchschnittliche Tagesunterbilanz von $5,09 \mathrm{~g} \mathrm{~N}$, also in 4 'Tagen einen Verlust von $20,36 \mathrm{~g} \mathrm{~N}=127,25 \mathrm{~g}$ Eiweiss. Win ganz erhebliches Deficit! Bedeutend grösser als der von Moritz gefundene Verlust von $88,9 \mathrm{~g} \mathrm{~N}$ in 48 Tagen. Wir sehen, Patient Or. ist parallel mit der allgemeinen Steigerung seines L'msatzes gegen Liweissbeschränkung auffallend intolerant im Gegensatz zu der bei Fettsüchtigen mit gemindertem Umsatz vorhandenen Toleranz auch gegen Beschränkung der Stickstoffzufuhr.

Der Mittelwert der täglich verbrannten Eiweissmengen aus den beiden ersten Tagen beträgt (cf. Tab. IV):

\section{$17,26 \mathrm{~g}$ Stickstoff', $108 \mathrm{~g}$ Fiweiss.}

Berechnen wir annähernd den Sormaleiweissbedarf: Körperlänge $170 \mathrm{~cm}$. Obere Grenze des Normalgewichtes $81,6 \mathrm{~kg}$, in der Ruho genügende Eiweisszufuhr, pro Kilogramm $==1,0 \mathrm{~g}$ Eiweiss; ausreichender Eiweissbedarf demnach: $81,6 \mathrm{~g}$ gegenüber einem Verbrauch von $108 \mathrm{~g}$ bei Unterbilanz.

Hiernach wäre eine gewisse Steigerung des Eiwoissstoffwechsels wahrscheinlich, vor allem wenn man noch beachtet, dass Patient schon 2 Tage vorher sich in Bettruhe und bei normaler Krankenhauskost (also sicher kein $\mathrm{N}$-Ueberschuss) sich befand.

Zichen wir nun den 3. und 4. Tag hinzu, so ändert sich allerdings das Bild etwas: wir finden, dass parallelgehend mit den Grössen für die tägliche Harnmenge, nach einem Maximum am 2. Tage auch das Stickstoffdeficit allmählich heruntergeht, analog etwa cinem beliebigen Hunger versuch, und sich, freilich erst spät, der Beschränkung bis zu gewissem Grade anpasst, ohne dass es zum Stickstoffgleichgewicht kommt.

Nicht eindeutig lässt sich die zweite Periode analysieren. Die Zahl der ursächlichen Teilcoëfficienten ist zu gross: Der Durchschnitt der N.Verluste ist kleiner als bei Periode I. Doch ist nicht $\mathrm{zu}$ entscheiden, ob an eine eiweisssparende W'irkung des Leptynols zu denken ist oder eine durch die vorhergehende 1. Periode bewirkte schnellere Anpassung an die Stickstoffeinschränkung vorliegt (unwahrscheinlich!).

Woran es liegt, dass eine eiweisssparende Wirkung der Kohlehydratezulage in der Reihe vom 26.9. nicht hervortritt und welche der in Frage kommenden Versuchsfactoren nicht beachtet werden, wurde nicht aufgeklärt.

\section{G. Umsatzsteigerang nach Nahrungsanfnahme.}

Mit Patient Or. wurden zwei Versuchsreihen zur Feststellung der Umsatzsteigerung nach Nahrungsaufnahme gemacht (vgl. Tabelle I, 6-10 und 12-17). Die bei den Versuchen zu berücksichtigenden Einflüsse waren: 1. relative Lnterernährung, die dem ersten Versuch 4 Tage, dem zweiten Versuch 2 Tage lang vorhergehen; 2. 10,0 g Leptynolinjection, welche dem zweiten Versuch innerhalb zweier Tage vorherging. - Die beiden Versuche begannen mit der Feststellung des Ruhenüchternumsatzes, dann folgte die Einnahme der Mahlzeit (mittags). Diese 
bestand (nach der Tabelle von Schwenkenbecher berechnet) bei Versuch I aus:

\begin{tabular}{|c|c|c|c|c|}
\hline & & Kalorien & $\begin{array}{c}\text { Stärke } \\
\mathrm{g}\end{array}$ & $\begin{array}{c}\text { Eiweiss } \\
\mathrm{g}\end{array}$ \\
\hline \multirow[t]{2}{*}{$\begin{array}{l}\text { Reissuppe } \\
\text { Kalbsbraten } \\
\text { Kartoffeln } \\
1 / 2 \text { Semmel } \\
\text { Mehlpudding }\end{array}$} & 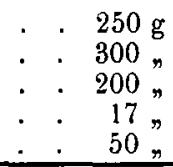 & $\begin{array}{r}56 \\
558 \\
192 \\
44 \\
\text { ca. } 50 \\
\end{array}$ & $\begin{array}{r}8,0 \\
\overline{2} \\
42,0 \\
9,4 \\
2,0\end{array}$ & $\begin{array}{r}1,5 \\
91,2 \\
4,2 \\
1,2 \\
2,0\end{array}$ \\
\hline & & $\begin{array}{c}900 \\
\text { Es blieb }\end{array}$ & $\begin{aligned} & 61,4 \\
&= 252 \mathrm{Ka} \\
& \text { Hir Fett: }\end{aligned}$ & $\begin{aligned} & 100,1 \\
&= 410 \mathrm{~K} \\
& \text { Kalorien }\end{aligned}$ \\
\hline
\end{tabular}

Bei Versuch II bestand die Mahlzeit aus:

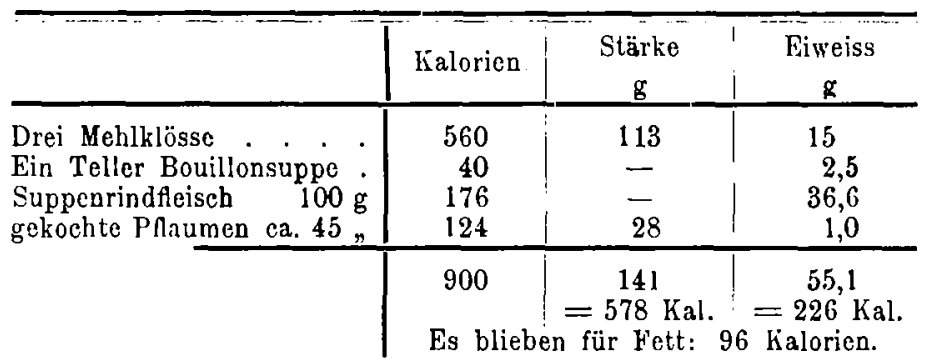

Darauf wurden bei jedem Versuch im Abstand von 1-2 Stunden je 4 mal der Ruheumsatz bestimmt. Nach Versuch II ein fünftes Mal 20 Stunden nach der Nahrungsaufnahme. In den Zwischenzeiten hielt Patient - zeitwcise sogar schlafend - Bettruhe. So wurde jede nicht durch die Nahrung bedingte Steigerung des Umsatzes ausgeschlossen.

Nebenstehende graphische Darstellung veranschaulicht das Ergebnis der beiden Nahrungsversuche, wie wir sie der Kürze halber bezeichnen wollen. Zu ihrer möglichst einwandfreien Beurteilung sei erst die Vorfrage erörtert: Wie weit ist es denkbar, dass die vorhergehende Nahrungsbeschränkung die Steigerungskurve abänderte von einem Verlauf, den sie voraussichtlich unter normalen vorhergchenden Nahrungsverhältnissen gehabt hätte? Es ist nicht wahrscheinlich, dass die Drüsenarbeit, Darmarbeit und Circulations- und Nieren-Mehrarbeit in ihrer Summe verändert wird. Wohl abcr wäre es denkbar, dass schon durch die reflectorische Wirkung des physischen Hungergefühls alle diese Vorgänge in ihrem Ablauf beschleunigt würden und vielleicht auch eine schnellere Resorption einträte. Ersterer Umstand würde bewirken, dass das Maximum der Steigerungskurve zeitlich früher erreicht würde; letzterer würde namentlich die Wirkung derjenigen Stoffe, welche nach ihrer Resorption „specifisch-dynamisch" umsatzsteigernd hervortreten - der Eiweisskörper -, beeinflussen and es wäre nicht unwahrscheinlich, dass durch vorwiegend eiweisshaltige und kohlehydratarme Nahrung die Steigerungskurve nicht nur schneller als gewöhnlich, sondern im Hinblick auf eine durch rasche Resorption ermöglichte plötzliche Ueberschwemnung des Körpers mit "Circulationseiweiss" auch höher als gewöhnlich ansteigt. Und andererseits würde bei vorwiegender Kohlehydratnahrung - Kohle- 
hydrate setzen bekanntlich den Eiweissumsatz merklich herab - diese übernormale Steigerung nicht zu erwarten sein.

Vergleichen wir nur unsere Versuchsergebnisse mit den von MagnusLevy gefundenen Werten lür den Normalmenschen (11).

Dieser stellte zwei Versuchskategorien auf:

1. Versuche mit möglichst rein nur aus einer der drei Nahrungsbestandteile bestehenden Kost von ungefähr 700-800 Kalorien.

2. Versuche mit gemischter Kost, eine Mittagsmahlzeit von etwa 1100-1500 Kalorien, der allerdings ein Frühstück vorausgeht.

Unsere Versuche stehen an Kalorienzahl und auch was die Nahrungszusammensetzung anbetrifft, ungelähr in der Mitte zwischen beiden Gruppen

Lmsatzsteigerung nach Nahrungsaufnahme (Fall Or.).
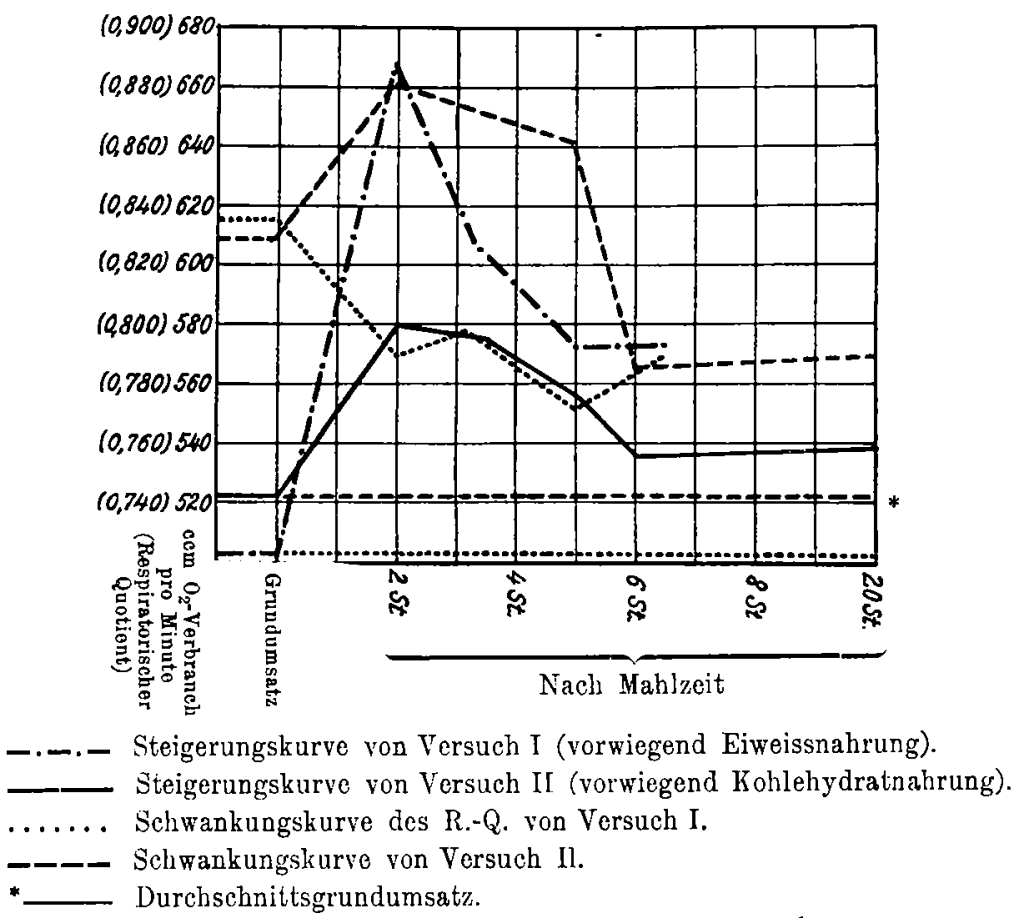

und können deshalb eigentlich nur mit Heranziehung beider mit dem Normalen verglichen werden.

I. Der Anstieg der Kurve erreicht in unseren beiden Versuchen etwa um die zwcite Stunde sein Vaximum; natürlich ist es nicht ausgeschlossen, dass sie dies etwas früher erreicht (besonders bei Nahrungsversuch. II ist das wahrscheinlich) und dann vielleicht etwas höher ausgefallen wäre. Bei Nagnus-Levy ist nach der gemischten Mittagskost der grösste Anstieg schon eine Stunde nach der Mahlzeit erreicht, bei einseitiger Kost im Mittel in der vierten und fünften Stunde, nach Kohlehydraten (abgesehen ron einem sofort mit Anfang beginnenden sehr erheblichen Kurvengipfel, der wohl durch die bei dieser Nabrung besonders erhebliche Kaumuskelaction, also hier nicht in Betracht kommende 
willkürliche Bewegung und Beteiligung der Speicheldrüsen bewirkt wird) ein Maximum in der siebenten Stunde.

Die Stellung unserer Versuche zu diesen beiden Extremen näher zu präcisieren, geht nicht an, ist auch nicht von grossem Belang. Stellen wir nur die Tatsache fest, dass ihr Maximum zwischen den von MagnusLevy aufgestellten Extremfällen liegt und dass der Kurvenanstieg (vielleicht allerdings nur auf Grund der weiter oben erwähnten Frwägung) nicht abnorm langsam verläuft.

Wichtiger ist die Frage nach der absoluten Höhe der Maximalsteigerung. Hier fällt zunäehst die gewaltige Differenz zwischen I und II auf. Wie durch die später folgende Betrachtung des R.-Q. noch ergänzt wird, drückt dem Versuch I die vorwiegende Eiweisskost, dem Versuch II die vorwiegende Kohlehydratkost ganz ihr charakteristisches Gepräge auf. Nach Magnus-Levy verhalten sich die Anstiegshöhe bzw. die totale Verbrennungssteigerung durch Eiweiss zu denselben Grössen bei Kohlehydraten wie $20^{1} / 2$ zu $11 \frac{1}{2}$ bzw. wie $17 \mathrm{zu} 9$. Dass sich in unserem Falle das Verhältuis noch etwas zugunsten der Eiweisssteigerung verändert hat, bestätigt die zu Anfang dieses Abschnittes ausgesprochene Vermutung.

Versuch II, mit den Normalzahlen verglichen (für diesen Versuch haben die Zahlen für gemischte Kost mehr Berechtigung wie für Versuch I), ergibt einen llaximalwert von ca. $60 \mathrm{ccm} \mathrm{O}_{2}$ gegenüber einem solchen von $82 \mathrm{ccm} \mathrm{O} \mathrm{O}_{2}$ Tormaltabelle. Bedenken wir, dass in unserem Falle ca. 200-250 Kalorien weniger verabreicht wurden, so ist die Differen\% nicht gross genug, um daraus eine Ersparnis bei der motorischen und secretorischen Tueistung in unserem Falle zu construieren. Versuch I dagegen zeigt uns, dass auch der specifisch-dynamische Reiz der Nahrung, der durch Eiweisszufuhr bei gleichzeitigem Kohlehydratmangel besonders deutlich zur Geltung kommt, in unserem Falle nicht etwa im Sinne von Jaquet und Svenson weniger stark wirkt als beim Normalen (11).

Wir kommen nun zum Abfall der Kurve. In beiden Versuchen hat sich dieser nach $6^{1} / 2$ bzw. 6 Stunden bis zu einem gewissen Grade vollzogen. Versuch 1 bricht dann ab. Versuch II zeigt das oben besprochene $\Lambda$ nhalten der Steigerung auf einem geringen Leberniveau. $1 \mathrm{~m}$ übrigen fällt in Versuch II die Kurve analog der von Magnus-Levy nach Nittagsbrot gefundenen Normalkurve ab. Jedenfalls ist ein vorzeitiges Abfallen aus Versuch II und auch aus Versuch I nicht \%u entrehmen.

Durch das Verhalten des R.- $\}$. wird das allgemeine Bild der Beteiligung der einzelnen Nahrungsstoffe noch schärfer umrissen. Beide Male setzen die R.-Q. in der für die Entziehungskur eigenartigen Höhe ein, während sie mit einem bedeutenden Wert (in guter lebereinstimmung miteinander) auslaufen.

Weiter oben wurde schon berührt, dass dieses Herabsinken auf eine Höhe, die sich der eines Normalnüchternwertes (d. b. also hier eines Individuums, das seinen Kalorienbedarf aus der Nahrung bestreiten kann, nicht Körperbestandteile —- Fett, Glykogen — hinzuziehen muss) 
nähert, als Stütze für die Behauptung verwertet wurde, dass der hohe R.-Q. während der Entziehungskur den wahren Verhältnissen entspräche und in der Tat durch eine vorwiegende Verbrennung des reichlichen Glykogendepots verursacht würde.

Zwischen dem Anfang und Endpunkt, dic beiden R.-Q. gemeinsam sind, gehen diese nun während der Versuche weit auseinander: In Versuch I sinkt der R.-Q. annähernd bis auf die Höhe reiner Eiweissverbrennung und beweist dadurch, dass die gleichzeitige Steigerung des Umsatzes in der Tat durch exquisit vorwiegende Eiweissverbrennung hervorgerufen wurde, während eine zweite, noch etwas tiefere Senkung in der fünften Stunde wahrscheinlich auf die nachfolgende Fettverbrennung zu beziehen ist.

In Versuch II steigt die Kurre des K.-Q. last parallel mit der Umsatzkurve auf einen Wert, dessen Höhe nur durch ganz vorwiegende Kohlehydratverbrennung $z u$ erklären ist, um dann wieder parallel der Umsatzkurve abzufallen. Die Verbrennung des Eiweissbestandes der Nahrung kann sich unmöglich hier im Verhältnis ihrer Grösse, auch wenn man berücksichtigt, dass sie in diesem Falle nur klein ist, beteiligt haben, wird vielmehr durch die Verbrennung des neiweisssparenden" Kohlehydrats, wie das auch im Tierexperiment beobachtet wird, hintangehalten und kommt erst zur Geltung, nachdem die Kohlebydratmengen der Nahrung im wesentlichen verbrannt sind. Meines Erachtens darf man hieraus auf die zeitlichen Verhältnisse der Verbrennung der einzelnen Nahrungsbestandteile bei anderer, bzw. normaler Kostzusammensetzung beim Fettsüchtigen keine folgenschweren Schlüsse ziehen; ob ein Teil der Fettsüchtigen auch bei normaler, gemischter Kost eine andere Folge der Verbrennung cinhält als der Normale, wissen wir vorläufig noch nicht. Auch die R.-Q. nach Nahrungsaufnahme der Versuchspersouen Jaquets und Svensons geben hierüber keinen einheitlichen Aufschluss.

Berechnen wir aus den Kurven der L'msatzsteigerung nach Nahrungsaufnahme die $\mathrm{O}_{2}$-Menge, welche in den Nahrungsversuchen während der Beobachtungsstunden ( $61 / 2$ Stunden) mehr verbrannt wurde als in Durchschnitts-Ruhenüchternumsatz, so finden wir, dass die $\mathrm{O}_{2}$-Mehrverbrennung infolge Nahrung beträgt:

Versuch I: gefundene Mehrverbrennung $=29700 \mathrm{ccm} \mathrm{O}_{2}$

Stellen "wir diesen "Zahlen dic $\mathrm{O}_{2}$-Menge gegenüber, welche - bei der in beiden Versuchen bekannten Zusammensetzung der Mahlzeit über den Grundumsatz hinaus verbrannt werden müsste, wenn in unserem Falle die von Magnus-Levy für den Normalen gefundenen procentualen Steigerungswerte der Verbrennungswärme durch die einzelnen Nahrungsqualitäten zu recht beständen. (Nach Magnus-Levy beträgt die Steigerung bei Zufuhr von Fett $2^{1 / 2}$ pCt., bei Zufuhr von Stärke 9 pCt., bei Zufuhr von Eiwciss 17 Ct. der totalen Verbrennungswärme der zugeführten Nahrungsmengen. Wir nehmen bei unserer Berechnung für $1000 \mathrm{cem} \mathrm{O}_{2}$ aus Eiweiss eine Wärmeerzeugung von 4,5 Kalorien, aus Fett von 4,6 Kalorien, aus Stärke yon 5,9 Kalorien an.) 
Hiernach würden wir finden:

Versuch I: normale Mehrverbrennung $=21300 \mathrm{ccm} \mathrm{O}_{2}$ $n$ II: $n \quad=19450, n$

Die aus unserer Kurve gefundenen Werte sind beide um schätzungsweise einige Liter $\mathrm{O}_{2}$ zu klein, da wir beide Versuche nicht bis zum vollständigen Absinken der Steigerungskurve auf die Grundumsatzhöhe fortgesetzt haben, bzw. dass nach dem zweiten Versuch (vgl. Tabelle l) zwischen dem Respirationsversuch nach 6 Stunden und dem nach 20 Stunden die für den Versuchstag angesetzten 21 Milch noch ausserdem genossen wurden und ein gänzliches Absinken der Kurve auf die bisherige Höhe verhinderten, was wir oben schon einmal besprachen.

Berücksichtigt man dies, so stimmt bei Versuch II (vorwiegende Kohlehydratnahrung) die gefundene Mehrverbrennung - ca. $16 \mathrm{lO}_{2}$ und die normale (gerechnete) Mehrverbrennung - ca. $19 \mathrm{lO}_{2}$ - vorzüglich überein und zeigen, dass bei gemischter, kohlehydratreicher Kost weder unökonomischer noch ökonomischer verbrannt wird als beim Normalen.

Die Spannung dagegen zwischen gefundener Mehrverbrennung ca. $29^{1} / 2 \mathrm{I} \mathrm{O}_{2}$ - und normaler Mehrverbrennung - ca. $211 \mathrm{O}_{2}-$ in Versuch I wird durch obige Erwägung noch beträchtlich vergrössert, schätzungsweise auf $50 \mathrm{pCt}$, und zeigt uns, dass überwiegend eiweisshaltige Kost in unserem Falle erheblich unökonomischer verbrannt wird als beim Normalen.

Es sei dahingestellt, ob dies eine Folge der oben erörterten besonderen Hungerverhältnisse unseres Falles ist oder ob es als allgemeines Kennzeichen der in unserem Falle vorhandenen schweren Stoffwechselstörungen aufgefasst werden muss. Als solches wäre es in Beziehung zu setzen 1. mit dem in unserem Falle gefundenen erhöhten Grundumsatz, 2. mit dem bei der Entziehungskur festgestellter abnorm hohen Stickstoffverlust.

Bisher haben wir einen mögliehen Einfluss des Leptynols auf Nahrungsversuch II ganz vernachlässigt. Mit welchem Recht geschah das?

Die Prüfung, ob durch das Jeptynol gemäss der ihm zugeschriebenen umsatzsteigernden Wirkung bei sonst unbeeinflusstem Umsatze vielleicht die Steigerung nach Nahrungsaufnahme erhöht würde, war der Anlass der Nahrungsversuche. Der nun in Versuch I als Wirkung der Eiweisszufuhr zu erklärende äusserst hohe Anstieg der Steigerungskurve veranlasste uns im zweiten Versuch, als bei Prüfung der Jeptynolwirkung, von dem Postulat absolut gleichbleibender sonstiger Versuchsbedingungen abzugehen dadureh, dass wir an Stelle einer vorwiegend eiweisshaltigen Mahlzeit eine vorwiegend kohlehydrathaltige Mahlzeit gaben, denn, so war unsere Ceberlegung, wenn durch das Palladiumhydroxydul eine Steigerung hervorgerufen wurde - sehr wahrscheinlich schien es ja von vornherein nicht -- so konnte sie durch eine dynamische Eiweisswirkung verdeckt werden; dagegen eine kohlehydratbaltige Mahlzeit musste cine specifisch-dynamische Reizwirkung des Leptynols, wenn eine solche vorhanden war, viel sicherer zur Darstellung bringen. Wie schon aus 
unserer Besprechung hervorging, beweist Versuch II mit Sicherheit, dass eine dynamische Reizwirkung des Leptynols in diesem Falle nicht bestanden hat.

\section{H. Arbeitsversuche.}

Zur Vervollständigung des Bildes vom Umsatz dieses in seinem Verhalten nicht ganz gewöhnlichen Falles wurde noch die Reaction des Gaswechsels auf körperliche Arbeit bestimmt. Wir reden der Kürze halber von Arbeitsversuchen.

Arbeitsversuch I (Versuchsprotokoll rom 19. 9. 13): Nach einigen Vorversuchen, die dem Patienten die nötige Uebung in der Ausführung der Dreharbeit verschaffen sollten - die Hauptvorbedingung für gleichmässige Resultate -, wurde unmittelbar im $A$ nschluss an einen Ruhenüchternrespirationsversuch in demselben gut temperierten Raum am Gärtnerschen Drehergostaten in 13 Minuten $2200 \mathrm{kgm}$ Arbeit (abgelesen an der Ergostatenskala) durch Drehung der Kurve mit beiden Händen gegen mittleren Widerstand geleistet. Während dieser 'Zeit war Patient genau wie bei den Roheversuchen mit dauernder Ventilatmung an die Gasubr bzw. die auch sonst gebrauchte Bürette angeschlossen. Dieses wurde trotz der Bewegungsexcursionen des Patienton bei der Arbeit dadurch ermöglicht, dass das Atmungsmundstück mit einem kleinen Zügel am Kopfe des Patienten befestigt wurde und die Darmventile selbst in ihren Glaskapseln gekreuzt auf dem Nacken des Patienten lagen, nit dem Mundstück durch verlängerte Gummischläuche verbunden, die obne eine Knickung zu machen recbts und links über die Schultern des Patienten geführt wurden.

Pro Minute wurden ca. 12 Kurbelumdrehungen in gleichmässig langsamem Tempo ausgefübrt. Aus Rücksicht auf den Patienten mussten kleine Ruhepausen von höcbstens 30 Socunden eingeschoben werden.

Die Vorperiode (zur Einstellung der regelmässigen Atmung) dauerte 9 Minuten, während deren $1500 \mathrm{lgm}$ Arbeit geleistet wurde. Die Hauptrersuchsperiode, während deren die Fxspirationsluft in dio Bürette abgesogen wurde, musste nach 4 Minuten bzw. $700 \mathrm{kgm}$ weiterer Arbeit aus Schonung für den Patienten, und um dio beginnende Arbeitsdyspnoe als Fehleruuelle nicht berücksichtigen zu müssen, abgebrochen werden. Nach dem Vorsuch ergab die mit Rücksicht auf die geschädigte Herzfunction ausgefübrte Untersuchung einen regelmässigen, kräftigen, in seiner Frequenz nur wenig gesteigerten Puls. In Aubetracht dessen, dass die Exspirationsluft des Versucbsboginnes nicht zur Analyse verwendet wurde, konnte auch die Periode der sogenannten Nachwirkung der Arbeit auf den Gaswecbsel ${ }^{k}$ vernachlässigt werden. Aus den Zahlenergebnissen des Versuches (siehe Versuch 5 und 18, Tabelle I) wurde der Nutzeffect der „Muskelmaschine“, der sogenannte ökonomische Quotient, wie folgt berechnet:

Grundumsatzsauerstoffverbrauch pro Minute . . $\quad 564,0 \mathrm{ccm} \mathrm{O}_{2}$

Arbeitssauerstoffverbrauch pro Minute . . . . . . $1176,4 \quad \% \quad n$
Differenz ( $=$ Sauerstoffmehrverbrauch pro Minute): $612,4 \mathrm{ccm} O_{2}$

Demnaoh ist der Sauerstoffmehrrerbrauch für die ganze Arbeit (13 Minuten) $=13 \times 612,4=7961 \mathrm{ccm} 0_{2}$.

Nun entspricht nach $/ \mathrm{Luntz}$ (11) $1000 \mathrm{~cm} \mathrm{O}_{2}$ :

$\begin{array}{llllll}\text { bei Stätkeverbrennung } & . & . & . & 5,047 & \text { Kalorion } \\ \text { "Fettrorbrennung } & . & . & . & 4,686 & \\ \text { "Eiweisszersetzung } & . & . & 4,476 & \end{array}$

Andererseits ontspricht (nach $Z$ untz) reiner Stärkeverbrennung der R.-Q. 1,000, reiner Fettverbrennung der R.-Q. $0,70 \pi$, reiner Fiweisszersetzung der R.-Q. 0,809 . 
Aus diesen Zahlen lassen sich für jeden R.-Q. zwei Grenzwerte des jeweiligen $1 \mathrm{l} \mathrm{O}_{2}$ entsprechenden Kalorienwertes berechnen. $\mathrm{Um}$ den Maximalwert zu finden wird angenommen, dass dic beiden grössten Kalorienspender, nämlich Koblehydrate und Fett, an der Verbrennung beteiligt sind. Demnach liegt die entsprechende Kalorienzahl zwischen 5,047 und 4,686. Im ersteren Falle ist der $R .-Q .=1,000$, im zweiten $=0,707$. Es nimmt also bei einem Zuwachs des R.-Q. um 0,293 der Kalorienwert um 0,361 zu, d. h. es kommen (mit ungefährer Genauigkeit) auf einen Zuwachs des R.-Q. um 0,001 ein Kalorienzuwachs von 0,00123. Unser R.-Q. beträgt (cf. Tabelle I, Nr. 18) 0,803, d. h. 0,096 mehr als der R.-Q. für Fett. Die Kaloriengrösse beträgt also $0,00123 \times 96 \mathrm{mehr}$ als 4,686. Demnach $1 \mathrm{l} \mathrm{O}_{2}=4,809$ Kalorien - maximal; ebenso werden als Minimalwert unter Annahme reiner Fett- und Eiweissverbrennung 4,502 Kalorien gefunden.

\section{7,691 l $\mathrm{O}_{2}$ entspricht maximal: 38,28 Kalorien minimal: 35,84}

Demnach kommt auf $1 \mathrm{mkg}$ Dreharbeit (Gesamtarbeit $=2200 \mathrm{mkg}$ ):

$$
\begin{aligned}
& 0,0174 \text { Kalorien maximal, } \\
& 0,0163 \quad n \text { minimal. }
\end{aligned}
$$

Mithin, da das mechanische Wärmeäquivalent für $1 \mathrm{mkg}=0,00235$ beträgt, ist der Nutzeffekt (in Procenten):

$$
\begin{aligned}
& 0,235: 0,0174=13,50 \mathrm{pCt} \text {. Maximalwert, } \\
& 0,235: 0,0163=14,42 \text { n Minimal wert. }
\end{aligned}
$$

Arbeitsversuch II: Der Arbeitsversuch wird in derselben Weise wie der erste am Ergostaten ausgefübrt, direct im Anschluss an einen Rubenüchternversuch, und $z$ war am letzten Tage der mit Leptynolinjection verbundenen Carrelkur.

Versuchsdauer: 14 Minuten geleistete Dreharbeit: $2000 \mathrm{mkg}$. Sauerstoftüberschuss ïber den Grundumsatz (laut Tabelle I, Versuch 19) pro Minute 451,0 ccm $0_{2}$, pro 14 Minuten $6314,0 \mathrm{ccm} \mathrm{O}_{2}$. Bei dem R.-Q. 0,834 entspricht $11 \mathrm{O}_{2}$ : maximal (nur Fett- und Kohlehydratverbrennung angenommen): 4,842 Kalorien, minimal (nur Eiweiss- und Koblehydratverbrennung angenommen): 4,551 Kalorien.

(Ein anderer Minimalwert, für reine Eiweiss- und Fettverbrennung gerechnot, ist bier ausgeschlossen, da der R.-(2. 0,834 ja gar nicht mehr zwischen dem R.-Q. des Fettes und Eiweisses liegt, daher nicht als aus diesen Partialquotienten gebildet angenommen werden kann.)

$6314,0 \mathrm{ccm} \mathrm{O}_{2}$ entspricht demnach:

$$
\begin{aligned}
\text { maximal: } & 30,571 \text { Kalorien } \\
\text { minimal: } & 28,735
\end{aligned}
$$

Demnach lrommt auf $1 \mathrm{mkg}$ Dreharbeit:

$$
\begin{aligned}
& \text { maximal: 0,01529 Kalorien } \\
& \text { minimal: } 0,01437 \quad r
\end{aligned}
$$

Der Nutzeffect: maximal: $1 \mathbf{0}, 36 \mathrm{pCt}$.

$$
\text { minimal: } 16,38 \text {, }
$$

Vergleichen wir den aus den beiden Versuchen gewonnenen Durchschnittswert von 13,5-16,5 pCt. mit den von anderen Autoren gewonnenen Resultaten am Normalmenschen. Heinemann fand bei Dreharbeit am Ergostaten bei cinem Arbeiter im günstigsten Falle nach 
langer Einübung einen Nutzeffect von $22-25$ pCt. Katzenstein fand bei einem Individuum, das nicht der Arbeiterklasse angehörte, einen Nutzeffect von $14-18$ pCt. (21).

Die Versuchsbedingungen des letzteren (Fehlen von langer Uebung und nicht Arbeiter) sind unseren Versuchsbedingungen am ähnlichsten. Die Werte stimmen auch nahezu überein. Dass diese in unserem Falle noch etwas niedriger sind, wird durch die Erwägung verständlich, dass beim Fettsüchtigen jede nicht in Ergostatenarbeit umgewandelte Luxusbewegung entsprechend der grösseren Körpermasse auch mehr verlorene Arbeit erfordert und ausserdem wahrscheinlich in unserem speciellen Fall das insufficiente Herz bei Muskelbetätigung unökonomisch arbeitet.

Von Interesse ist es, die Tatsache festzustellen, dass in diesem Falle ebenso wenig wie ein horabgeminderter Ruhestoffwechsel als ursächliches Woment oder als Begleiterscheinung der Fettsucht ein verringerter Arbeitsstoffwechsel festgestellt werden konnto (was dasselbe besagt als ein vergrösserter Nutzeffect und was theoretisch $z$ u postulieren ja nahe läge). Analoge Versuche an Fettsüchtigen von Reach und Jaquet und Svenson kommen zu dem gleichen Ergebnis (10).

Betrachten wir nunmehr die Werte von Versuch I und II gegeneinander.

Was uns zur Anstellung derartiger Versuche bewog, war die Vermutung Kauffmanns, dass "die mit der Muskelarbeit verbundene Wärmeentwicklung dic katalytische Wirkung des Palladiumhydroxyduls" (gemeint ist dic Steigerung der Oxydationsprocesse im Körper) nerhöhen könnte."

Ilierdurch kamen wir zu der Fragestellung:

Wird die steigernde Wirkung des $\mathrm{P}_{0}(\mathrm{OH})_{2}$ auf die Intensität des Stoffwechsels, wenn sie beim Ruheumsatz auch noch latent ist, wie in unserem Falle, vielleicht erst beim Arbeitsstoffwechsel manifest in einer Verschlechterung des Nutzaffectes gegen dessen Normalwerte?

Die Mittelwerte der Versuche: $14 \mathrm{pCt}$. (Normal) und 15,9 pCt. (Leptynol), daraufhin verglichen, ergeben ein verneinendes Resultat. Die Differenz von 1,9 pCt. in entgegengesetztem Sinne liegt nach den oben erwähnten Resultaten von Versuchen am normalen Menschen innerhalb der Schwankungsbreite, wie sie, sei es durch subjective, momentane Disposition, sei es durch äussere Einflüsse (etwa Temperatur, Luftfeuchtigkeit) bedingt, sich nicht vermeiden lässt.

2. Fall. (Knabe W. R.)

(Vgl. Tabelle V.)

Wesentlich einfachere klinische Verhältnisse bieten die nun zu besprechenden beiden Fälle von endogener Fettsucht im Kindesalter.

A. Krankengeschichte. (22.9.13.)

Patient: W. R., Schüler, 13 Jahre alt.

Diagnose: Dysgenitale Fettsucht (Degeneratio adiposo-genitalis).

Anamnese: Ftwa mit 9 Jahren trat, angeblich ziemlich schnell, und zwar gloich in hohom Grade, allgemeiner Fettansatz auf. Ob im Anschluss an eine In- 
foctionskrankheit, ist nicht zu eruieren. Seit etwa 3 Jahren soll die Corpulenz nicht mehr zugenommen haben.

Nahrungsaufnabme angeblich nicht enorm gross. Sexual indifferent, Erectionen und Pollutionen fehlen fast vollständig.

Frïhere Krankbeiten: mit 7 Jahren Scharlach, Masern, im Anschluss an ersteren Gelenkrheumatismus. Mehrmals Diphtherie, darunter im Alter von 5 Jabren ein bosonders schwerer Fall.

Heredität: Patient ist viertes Kind. Ein Bruder, 16 Jabre alt, auch fettsüchtig. Ausserdem zwei normale Geschwister. Mutter wog vor cinem Jahre über 250 Pfund, nahm auf Thyreoidinkur bis 21180 Pfund ab. Vater ebenfalls sohr corpulent. Gewicht über 200 Pfund. Beide Eltern sind angeblich in ihrer Jugend normal gewesen.

Status praesens: Körpergrösse $155 \mathrm{~cm}$, Körpergewicht (ohne Kleider) $65,9 \mathrm{~kg}$, Halsumfang $33 \mathrm{~cm}$, Brustumfang $89 \mathrm{~cm}$, Bauchumfang in Nabelhöhe $95 \mathrm{~cm}$, 'laille $85^{1} / 2 \mathrm{~cm}$, Scbädel: Circumferentia submento-occipitalis $61 \mathrm{~cm}$, Circumferentia fronto-oocipitalis $55 \mathrm{~cm}$, Oberarmumfang $29 \mathrm{~cm}$, Oberschenkelumfang $53 \mathrm{~cm}$, Unterarm (maximal) $26 \mathrm{~cm}$, Unterschenkel $39 \mathrm{~cm}$.

Für sein Alter gut entwickelter, kräftiger Knabe, auffallend fett. Weiblicber Fettverteilungstypus. Mammae zeigen starke Fettansammlung, vorgewölbt. Ausserdem besonders in der Gluläalgegend beiderseits, sodann in den Partien seitlich über den Hüften und in der Unterbauchgegend sehr starke Fettpolster. Sehr ausgesprochene Querfalte in der Regio pubica. Bläuliche Verfärbung des prallen Fettpolsters am Oberarm. Penis klein, Hoden kirschgross. Ohrspeicheldrüse nicht vergrössert, desgleichen Sublingualdrüse nicht vergrössert. Geringe Prognathie des Oberkiefers. Gebiss und Rachen normal. Thyreoidea eher vergrössert als verkleinert. Thymus percussorisch nicht als vergrössert nachweisbar.

Thorax: Lungen- und Herzbefund normal.

Puls: regelmässig 65 in der Minute.

Abdomen: Milz und Leber nicht fühlbar.

Urin: kein Zuoker, kein Eiweiss.

Nervensystem: ohne Störungen. Patellar: und Pupillenreflexe normal. Augenbewegungen frei. Refraction: ganz geringe Myopie.

Sebschärfe nicht herabgesetzt.

Stimme noch nicht mutiert, hat wenig Klang, jedoch nicht gerade raub.

Temperament ist auffallend ruhig und gleichmässig. Schulerfolg mässig.

Röntgenaufnalıme des Schädels zeigt normale Verhältnisse der Schädelbasis.

Die Röntgendurchleuchtung des Brustkorbes zoigt normale Verbältnisse, insbesondere keine 'l'bymusvergrösserung.

An den Stellen der Leptynolinjectionen (Oberbauchgegend) nocb deutlich schwarze Verfärbungen und geringe Infiltrationen. eyten 5000 .

Blutbild: Hämoglobingehalt (Sahli) 83 pCt., Erythrocyten 5300000 , Leuko-

Blutausstrich: neutrophile Leukocyten $70 \mathrm{pCt}$., Lymphocyten $14 \mathrm{pCt.,}$ grosse Lymphocyten 4 pCt., grosse Mononucleäre 4 pCt., Fosinophile. 6 pCt., Basophile 1 pCt.

Der Befund ergibt klinisch eindeutig das Bild der dysgenitalen Fettsucht, wie sie durch den abnormen Fettverteilungstypus und gleichzeitige Hodenhypoplasie charakterisiert ist. Während eine Beteiligung der Hypophyse und des Thymus klinisch unwahrscheinlich ist, ist eine eventuelle IIypofunction der Schilddrüse nicht ausgeschlossen. Interessant sind die hereditären Verhältnisse, insbesondere dic thyreogene Fettsucht der Vutter. 
Der Verlauf der Versuche ergibt sich aus der Tabelle. Es sei hier nur erwähnt, dass Patient während der sich fast über 4 Monate erstreckenden Versuchszeit dauernd nur ambulant beobachtet wurde, dass ihm bis auf die Anordnung, nüchtern vormittags zum Respirationsversuch zu kommen, keine weiteren diätetischen Vorschriften gegeben wurden, und dass wohl einige Schwankungen, namentlich des respiratorischen Quotienten (vgl. Tabelle) durch die der heissen Jahreszeit mehr oder weniger angepasste verschiedene Kostzusammensetzung, sowie den Unterschied während der Schulzeit und während der Ferien, in denen die Versuche gleichfalls fortgesetzt wurden, zu erklären sind und keine weiteren Schlüsse gestatten.

Es sind ferner noch, um falsche Schlüsse bei der Beurteilung der in unserem Falle vorhandenen Schwankungen des Körpergewichts späterhin zu vermeiden, einige diese Verhältnisse betreffenden äusseren Einflüsse abzugrenzen.

1. Bei unserer spontan ziemlich bewegungsträgen Versuchsperson ist die Schulzeit mit ihrer Anregung zur Leistung von mehr Muskelarbeit als gewichtsherabsetzender Factor in Anschlag zu bringen; umgekehrt die Ferienzeit als gewichtssteigernder Factor ( $F a u l h e i t s-$ fettsucht $\left.{ }^{4}\right)$. Dies drückt sich eklatant in unseren Gewichtszahlen aus: am 18. 4., kurz nach Ende der Ferien, ist das Körpergewicht noch auf sein "Faulheitsniveau" von $67,4 \mathrm{~kg}$ eingestellt, sinkt dann während der Schulzeit continuierlich, wenn auch langsam, bis auf sein Arbeitsniveau von etwa $66,000 \mathrm{~kg}$, um in den im Juli liegenden Fcrien wiederum langsam auf das Faulheitsniveau zu steigen.

2. ist zum Teil der Einfluss der Temperatur zu beobachten: Zwischen dem 25. 5. und 3. 6. 1913 macht sich die damals gerade über Mitteldeutschland ziehende abnorm hohe Hitzwelle deutlich bemerkbar [wohl infolge eines Missverhältnisses zwischen Nahrungsverminderung (um Darmarbeit zu sparen) und doch gleichzeitig geforderte Schularbeitsleistung]. Diese Gewichtssenkung wird durch den weiteren auffallend kühlen Verlauf des Monats Juli wieder kompensiert.

\section{B. Der Umsatz.}

Beginnen wir mit der Betrachtung des Umsatzes. Trotz einzelner vorliegender Untersuchungen des Umsatzes bei Degeneratio adiposogenitalis ist mit bisherigen Methoden eine ausserhalb der Grenzen des Normalen liegende Herabsetzung noch nicht festgestellt worden.

von Noorden (8) sicht dafür den Grund in dem Umstand, dass bei Degeneratio adiposo-genitalis die Fetlanreicherung nur sehr langsam erfolgt, daher erst von einer prïciseren Methodik festgestellt werden könne.

Noch schwieriger als bei Erwachsenen ist es bei Kindern, einen sachlichen Vergleich des Umsatzes mit dem Normalen anzustellen, denn, während bei Erwachsenen das Lebeusalter [in der Normaltabelle zwischen 22 und 43 Jahren (11)] den Umsatz in keiner Weise ändert, sind wir bei den Kindern neben den sonstigen Vorbedingungen eines Vergleichens auch noch an die Berücksichtigung des Alters gcbunden. 
Von vornherein unzweckmässig wäre es selbstverständlich, einen fetten Knaben mit einem normalen Erwachsenen zu vergleichen. In diesem Falle hat nur eine Vergleichung mit einem gicichfalls im Pubertätsalter befindlichen Knaben von möglichst derselben Grösse Sinn. In der von $1 /$ agnus-Levy zusammengestellten Normaltabelle für Kinder findet sich nur 1 Kind (Mädchen) im Alter von 13 Jahren. Seine Grösse beträgt $1,38 \mathrm{~m}$. Das ergäbe gegen unseren fall eine Spannung von $18 \mathrm{~cm}$, welche einen Vergleich nicht mehr erlaubt. Es zeigt aber ein Blick auf die Normaltabelle, welcho nach steigendem Körpergewicht geordnet ist, dass, während bei dieser Anordnung die Umsatzgrösse mit nur vereinzelten Ausnahmen stetig und gleichsinnig zunimmt, die $\Lambda$ lterszahlen durchaus diese ordnungsmässige Aufeinanderfolge vermissen lassen. So steht z. B., dem Gewicht nach, annähernd auch dem Umsatz nach, ein 12 jähriges Kind an 9., dagegen ein 11 jähriges an 22. Stelle, dem an 21. Stelle ein 17jähriges vorhergeht. Fast ganz gleichsinnig dagegen mit den Gewichtszunahmen steigen die Zahlen für die Körpergrösse, also ganz unabhängig vom Alter und auch auffallend unabhängig vom Geschlecht. Daraus folgt für uns, dass in erster Linie ein Uebereinstimmen der Körpergrösse einen zwockmässigen Vergleich des Umsatzes zweier Kinder garantiert, dass erst in zweiter Linie die Altersstufe berücksichtigt werden-darf.

Wählen wir nach diesem Gesichtspunkte passende Vergleichsfälle aus, so kommen die Knaben $\mathrm{Nr} .12,13,14,15$ in Betracht mit einer Körpergrösse von $154,149,154,160 \mathrm{~cm}$, dem Alter 17, 14, 17, 16 Jahren und dem Minutenumsatz von 198,0, 204,4, 212,7, 235,6 ccm O 2 .

Der Umsatz unseres Ealles W. R. (267 cem $\mathrm{O}_{2}$ pro Minute) scheint, wenn wir für ein Mehr an Circulationsarbeit und Atemarbeit (s. oben) analog dem von von Noorden bei Erwachsenen eingeschlagenen Verfahren 20 pCt. abziehen, mit diesen Werten (also in der reducierten Form von $214 \mathrm{ccm} \mathrm{O}_{2}$ ) gut übereinzustimmen, auch wenn wir den etwas kleineren Durchschnittswert aus der 3. Versuchsserie (Tabelle V) von (reduciert) $205 \mathrm{ccm}$ zu Grunde legen, so wird die untere Grenze der normalen Schwankungsbreite doch nicht erreicht. Aus dieser Vergleichung lässt sich also keine Herabsetzung des L'msatzes bei Patient W. R. nachweisen. Diese Tatsache wird nicht ohne weiteres dadurch beeinträchtigt, dass die auf $1 \mathrm{~kg}$ Körpergewicht reducierte Sauerstoffzehrung pro Minute von $4,0 \mathrm{ccm} \mathrm{O}_{2}$ in unserem Falle bedeutend unter den Normalwerten der Tabelle: 4,95, 5,13, 4,80, 4,10 steht, denn diese Vergleichung darf bei Fetten nicht den Ausschlag geben (siehe oben.)

Wie gestaltet sich das Verhältnis zum normalen Umsatz, wenn wir als Vergleichseinheit die $\mathrm{O}_{2}$-Verbrennung pro Quadratmeter Körperoberfläche zu Grunde legen? Is sei die Kalorienzahl des Tagesgrundumsatzes verglichen mit der hierfür für den Erwachsenen aufgestellten Normaltabelle. Die Werte unseres Falles müssen zu dem Zweck noch durch die Relationszahlen, welche in der Normaltabelle für Kinder ausgerechnet sind, dividiert werden. 
Die betreffenden Relationszahlen sind:

$$
\text { Kind zu Erwachsenem } \left.=\begin{array}{r}
123 \\
130 \\
123 \\
140
\end{array}\right\}: 100
$$

Unsere Werte ändern sich von:

\section{1,4 Kalorien auf}

maximal: $808,3 \quad n$ pro Quadratmeter Körperoberfläche

minimal: $708,3 \quad n \quad "$ in

und für den kleineren Durehschnittswert der 3. Versuchssorie von:

881,0 Kalorien auf

maximal: $773,2 \quad n$ pro Quadratmeter Körperoberfläche

minimal: $678,0 \quad " n \pi n$

Der letzte Minimalwert ist der einzige, welcher in $\mathrm{zu}$ beachtender Weise ausserhalb der. Normalgrenzen von 710-893 Kalorien pro Quadratmeter fällt, und zwar hat der durch die hohe Relationszahl erhaltene, also der Minimalwert, in unserem Falle mehr Wahrscheinlichkeit, dem Richtigen nahe zu kommen, für sich.

Endlich sei auch die $\mathrm{O}_{\mathrm{s}}$-Zehrung pro Kilogramm Körpergewicht mit dem Normalwert der Erwachsenen verglichen. Ls hat dies mehr Sinn, als der an zweiter Stelle durchgeführte und abgelehnte directe Vergleich dieser Beziehungen mit den entsprechenden Kindernormalzahlen, denn bei Erwachsenen ist bei der grösseren Zahl vorliegender Normaluntersuchungen auch die normale Scbwankungsbreite grösser, also auch richtiger als diejenige, die wir aus den 4 Kinderfällen erhalten. Die entsprechenden Relationszahlen sind $1,50-1,20$, aus ihnen ergeben sich fïr unseren Durchschnittswert:

$$
\begin{array}{ccc}
\text { maximal } & 3,35 \mathrm{ccm} \mathrm{O}_{2} \\
\text { minimal } & 2,68 \quad n \quad n
\end{array}
$$

Für den kleineren Durchschnittswert:

$$
\begin{array}{ll}
\text { maximal } & 3,22 \mathrm{ccm} \mathrm{O}_{2} \\
\text { minimal: } & 2,58 \mathrm{n} "
\end{array}
$$

Die Normalwerte liegen zwischen 4,53 und $2,76 \mathrm{ccm} \mathrm{O}_{2}$. Hier also fallen beide Minimalwerte, der erste nur unerheblich, der zweite beträchtlich unter den Normalwert.

Fassen wir unser Urteil über den Umsatz von Fall W. R. zusammen:

Wonn wir in der Tabelle $V$ die maximalen Abweichungen der Einzel- von den Durchschnittswerten betrachten, so fällt uns auf, dass diese bedeutend grösser sind als bei der Versuchsperson A. M., obwohl die Untersuchung beider Fälle mit denselben Apparaten und zur selben Zeit vorgenommen wurden. Dio grösseren Schwankungen können also nicht allein durch Fehler der Technik und \%ufällige Einflüsse erklärt werden. Andererseits aber brachte es der Patient W. R. in der Technik der vorsätzlichen Muskelruhe und ruhigen Atmung zu ziemlicher Vollkommenheit. Wir wagen es daher doch, den Schluss zu ziehen, dass in unserem Fall der Grundumsatz sich noch nicht so constant eingestellt 
hat, wic wir es bcim Erwachsenen unter allen Umständen zu finden gewohnt sind, sondern mit gewisser Labilität um ejnen Mittelwert schwankt, der als solcher allerdings wiederum auffallend constant sein kann (vgl. Durchschnitswert der 1. und 2. Versuchsserie). Diese T'atsache ist vielleicht analog den beim Kinde bis zum Pubertätsalter noch unregelmässigen und grösseren Schwankungen der Körpertemperatur gewissermassen auf noch unvollkommene Uebung des betreffenden Regulationsmechanismus bzw. - chemismus zurückzưühren.

Diese kleinen Schwankungen sind also wohl physiologisch und für uns weiter nicht von besonderem Interesse. Interessant aber ist, dass in unserem Falle ausserdem noch in längeren Perioden sich der Darchschnittsgrundumsatz zu verändern scheint (vgl. den Durchschnittswort. der 3. Versuchsserie mit den beiden ersten). Zwischen Versuchsserie 2 und 3 liegt eine Pause von fast 6 Wochen. Freilich ist die gefundene Differenz von $11,12 \mathrm{ccm} \mathrm{O}_{2}$ pro Hinute an und für sich unerheblich und liegt innerhalb der Eehlergrenze des Einzelversuchs. 'Wir sind aber berechtigt, anzunehmen, dass sich die nicht vermeidbaren Versuchsfehler in den Durchschnittswerten einer Anzahl von Versuchen immer nach derselben Richtung ausgleichen, und also auf diese Weise die Durchschnittswerte nach einer engeren Fehlergrenze beurteilt werden müssen und viel feinere Ausschläge zur Darstellung bringen können. Anschaulich zeigt dies die Uebereinstimmung des 1. und 2. Durchschnittswertes bei grosser Schwankung der Linzelwerte.

So gewinnt die Differenz des Durchschnittsumsatzes in unserem Falle doch eine gewisse Bedeutung, zumal auch dadurch, dass, wenn wir uns aus allen verschiedenen Vergleichsarten zusammenfassend ein Urteil bilden - von ausschlaggebender Bedeutung ist hier dio Beziehung auf die Körperoborfläche -, der grössere Umsatzwert noch im Bereich des Normalen, der kleinere dagegen unter dem Grenzwert des Normalen liegt. Doch wir brauchen uns gar nicht an die Voraussetzung zu binden, dass es für den Menschen eine allgemein giltige Norm des Umsatzes gäbe: auch wenn wir unseren Fall isoliert betrachten, so genügt die relative Differenz des kleineren Umsatzwertes, nur auf den grösseren als in diesem Falle normalen bezogen, um in grösseren Zeitabschnitten eine bedentende Gewichtszunahme bei gleichbleibender Nahrungszufuhr zu bewirken. In den 60 Tagen, um die es sich hier handelt, entspräche ein Weniger von $11,12 \mathrm{~cm} \mathrm{O}_{2}-V$ erbrennung etwa einem Fettansatz von $475 \mathrm{~g}$.

Auffallend ist es, dass das Körpergewicht nach den Angaben der Tabelle kleine Schwankungen zeigt, die genaumit den Schwankungen der Umsatzintensität parallel gehen. Wie oben näher ausgeführt, ist ein Teil dieser Schwankungen durch äussere Einflüsse zu erklären; aber, wenn wir diese genau abwägen, so bleibt doch noch ein anders zu erklärender Rest übrig: wir sahen oben, dass am 31. 7. und am 18. 4. (Anfangsdatum) die äusseren Bedingungen, die zu einer mässigen ${ }^{2}$ Faulheits"gewichtszunahme über das während der Arbeitszeit gehaltene Gewicht von $66 \mathrm{~kg}$ geführt hatten, sich ungefähr dio Wage hielten. Sollte es nun hier nur Zufall sein, dass am 
31. 7. das Gewicht um $400 \mathrm{~g}$ höher ist als am 18. 4.? Also gerade etwa um die Gewichtsgrösse, welche wir als Consequenz der Umsalzverminderung berechnct hatten.

\section{¿. Thyreoidinwirkung.} klären?

Wie ist nun die periodische Schwankung des Umsatzes zu er-

Zunächst ist sie nur als die Wirkung einer oder einiger bei der dysgenitalen Fettsucht beteiligten Drüsen mit innerer Secretion zu denken.

Nach den bisherigen Erfahrungen ist bekanntlich die Unterfunction der Hodensubstanz bzw. der Hodenzwischensubstanz wahrscheinlich auch in den Fällen, in denen eine Hypophysenveränderung nicht nachweisbar ist, erst die Folgo eines primären Hypopituitarismus. Und - wenn wir hierin der Anschauung von Noordens folgen wollen - haben weder Hypophysensubstanz noch Hodenzwischensubstanz einen unmittelbaren Einfluss auf den Energiewechsel. Dieser wird vielmehr erst manifest, wenn, wahrscheinlich auf dem Utmwege HypophyseHodenzwischensubstanz tertiär die Tätigkeit der Schilddrüse in der Richtung einer Hypofunction geschädigt wird. Es läge daher nahe, die Schwankung des Umsatzes in unserem Falle durch eine periodische Schwankung der Schilddrüsentätigkeit zu erklären. Kwar ist es mit den bisherigen Vlethoden nicht möglich gewesen, das Vorkommen derartiger Schwankungen einer Drüsenfunction direct nachzuweisen; wir können aber - und hier kommt die theorctische Bedeutung des Medicamentes zur Geltung - indireet den jeweiligen Functionszustand der Schilddrüse dadurch prüfen, dass wir den Grad feststellen, in welchem der Organismus jeweilig auf Schilddrüsensubstanz reagiert.

Nach den spärlichen experimentellen Daten, die vorliegen, scheint es, dass bei Iyperfunction der Schilddrüse (Morbus Basedowii) die Verabreichung von Schilddrüsensubstanz die Umsatzhöhe wahrscheinlich gar nicht beeinflusst, (die beiden Basedow-Kranken, deren Gaswechsel von Magnus-Jewy (11) nach Thyreoidinverabreichung untersucht wurden, ergaben dies Resultat), dass bei normaler Function der Schilddrüse (hier kommen auch nicht thyreogene Fettsüchtige in Betracht) entweder gar keine oder meistens eine Wirkung mässigen Grades - ca. 15 pCt. Umsatzsteigerung - eintritt, dass dagegen bei Hypo-, Dys- und Afunction der Schilddrüse eine bedeutend höhere Umsatzstejgerung, die sich wieder graduell abstuft und bis $72 \mathrm{pCt}$. Steigerung beobachtet worden ist, bei gleicher Dosierung eintritt.

Finden wir daher in unserer Tabelle, dass einmal nach Thyreoidinverabreichung keine Reaction erfolgt, acht Wochen später aber zur Zeit eines verminderten Umsatzes eino deutliche Steigerung $(18,22 \mathrm{pCt}$.) eintritt, so liegt es nahe, von dieser Coincidenz von normal hohem Lmsatz und Thyreoidinunwirksamkeit einen Causalzusammenhang zu folgern in dem Sinne, dass in unserem Falle die Umsatzschwankungen zwischen normal und unternormal cine reine Function (in mathematischem Sinne) einer Schwankung der Schilddrüsentätigkeit zwischen normal und unternormal darstellt. 
Tabelle V. Knabe W. R., 12 Jabre 9 Monate alt (am 18.4. 1913).

\begin{tabular}{|c|c|c|c|c|c|c|c|c|c|}
\hline 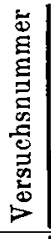 & \begin{tabular}{|} 
Datum \\
1913 \\
\end{tabular} & Medikation & 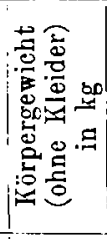 & 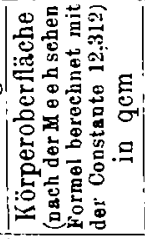 & 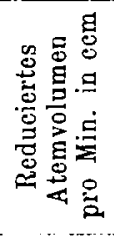 & 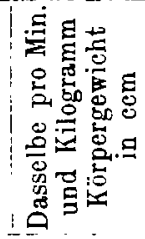 & 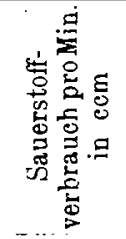 & 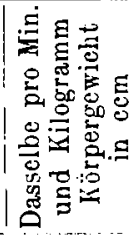 & 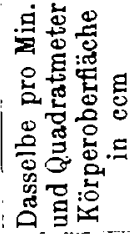 \\
\hline 1 & 2 & 3 & 4 & 5 & 6 & 7 & 8 & 9 & 10 \\
\hline $\begin{array}{l}20 \\
21 \\
22\end{array}$ & $\begin{array}{l}18.4 . \\
23.4 . \\
25.4 .\end{array}$ & & 67,4 & & $\begin{array}{l}7295 \\
5537 \\
6368\end{array}$ & $\begin{array}{r}108,23 \\
82,25 \\
\cdot 94,48\end{array}$ & $\begin{array}{l}321,79 \\
261,74 \\
283,72\end{array}$ & $\begin{array}{l}4,77 \\
3,90 \\
4,19\end{array}$ & \\
\hline $\begin{array}{l}25 \\
26\end{array}$ & $\begin{array}{r}27.4 . \\
4.5 . \\
10.5 . \\
13.5 . \\
14.5 . \\
15.5 . \\
16.4 .\end{array}$ & & 66,5 & 20209 & $\begin{array}{l}5267 \\
4787 \\
4870 \\
5408 \\
5080 \\
5530 \\
5766\end{array}$ & $\begin{array}{l}79,20 \\
71,99 \\
73,26 \\
81,25 \\
76,38 \\
88,06 \\
85,51\end{array}$ & $\begin{array}{l}282,10 \\
238,39 \\
259,57 \\
233,92 \\
245,36 \\
274,85 \\
284,26\end{array}$ & $\begin{array}{l}3,69 \\
4,16 \\
4,22\end{array}$ & $\begin{array}{l}139,59 \\
117,97 \\
128,46 \\
140,48 \\
121,43 \\
135,98 \\
141,03\end{array}$ \\
\hline \multirow{4}{*}{$\begin{array}{l}30 \\
31 \\
32 \\
33 \\
34\end{array}$} & \multicolumn{2}{|c|}{ Mittelwert von Vers. 23-29 } & & 20148 & 5244 & 79,66 & 266,92 & 4,02 & 132,11 \\
\hline & $\begin{array}{r}16.5 . \\
18.5 . \\
20.5 . \\
\geq 3.5 . \\
25.5 . \\
27.5 . \\
3.6 .\end{array}$ & 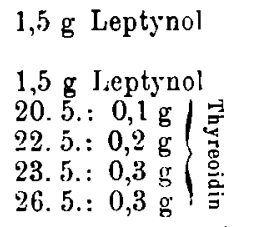 & $\begin{array}{l}66,35 \\
66,65 \\
66.30 \\
66,0\end{array}$ & & $\begin{array}{l}5404 \\
5336 \\
5960 \\
5137 \\
4840\end{array}$ & $\begin{array}{l}82,00 \\
80,97 \\
89,83 \\
77,07 \\
73,00\end{array}$ & $\begin{array}{l}272,90 \\
265,74 \\
276,55 \\
254,89 \\
260,38\end{array}$ & $\begin{array}{l}4,14 \\
4,03 \\
4,17 \\
3,84 \\
3,93\end{array}$ & \\
\hline & \multicolumn{2}{|c|}{ Mittelwert von Vers. 30-34 } & & 20148 & 5337 & 80,57 & 266,07 & 4.02 & 132,05 \\
\hline & & $\begin{array}{l}1,0 \mathrm{~g} \text { Leptyn } \\
1,0 \mathrm{~g}\end{array}$ & & & & & & & \\
\hline 35 & 9.7. & 1, & 66,2 & & 53 & & 24 & 3,7 & \\
\hline $\begin{array}{l}36 \\
37\end{array}$ & $\begin{array}{l}\text { 12.7. } \\
15.7 .\end{array}$ & $1,0 \mathrm{~g} \ldots$ & & & & $\begin{array}{l}88,25 \\
79,97\end{array}$ & $\begin{array}{l}276,60 \\
256.50\end{array}$ & $\begin{array}{l}4,16 \\
3,90\end{array}$ & \\
\hline 38 & $\begin{array}{l}\text { 17. } 7 . \\
23.7 .\end{array}$ & \multirow{2}{*}{$\begin{array}{l}1,0 \mathrm{~g} \text { leptynol } \\
1,0 \mathrm{~g}\end{array}$} & 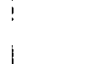 & & 5626 & 84,73 & 261,00 & 3,97 & \\
\hline \multirow[t]{3}{*}{39} & $\begin{array}{l}24.7 . \\
31.7 .\end{array}$ & & & & 5404 & 81,39 & 237,80 & 3,58 & \\
\hline & Mittelw & rt von Vers. $35-39$ & & 20189 & 5.516 & 83,08 & 25.50 & 3,47 & 126,70 \\
\hline & $\begin{array}{l}31.7 . \\
1.8 . \\
2.8 . \\
3.8 .\end{array}$ & 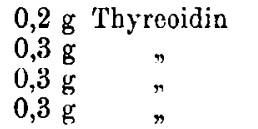 & 67,80 & & & & & & \\
\hline 10 & 4. 8. & & 66,40 & 20188 & 5324 & 80,18 & 302,40 & 4,55 & 149,78 \\
\hline
\end{tabular}

Um die Beobachtung, die dieser Folgerung zu Grunde liegt, - nicht die Folgerung selbst - zu sichern, muss noch auf einige Punkte hingewiesen werden:

1. von Bergmann und Magnus-Jevy haben in ihren Lntersuchungen gefunden, dass die umsatzsteigernde Wirkung des Thyreoidins erst am 7. bis 10 . Tag nachzuweisen wäre. Dass diese Beobachtung nicht ohne weiteres verallgemeinert werden darf, geht eclatant aus dem später zu besprechenden Fall (Kind KI.) hervor, bei welchem 24 Stunden nach Verabreichung von 0,2 'Thyreoidin eine Steigerung des Umsatzes um 33 pCt. gefunden wurde. Ls entkräftigt dies den Einwand, das Fehlen jeder Reaction des Lmsatzes auf die erste Thyreoidingabe bei 
Grösse: $156 \mathrm{~cm}$ (am 18.4. und 31. 7. gemessen).

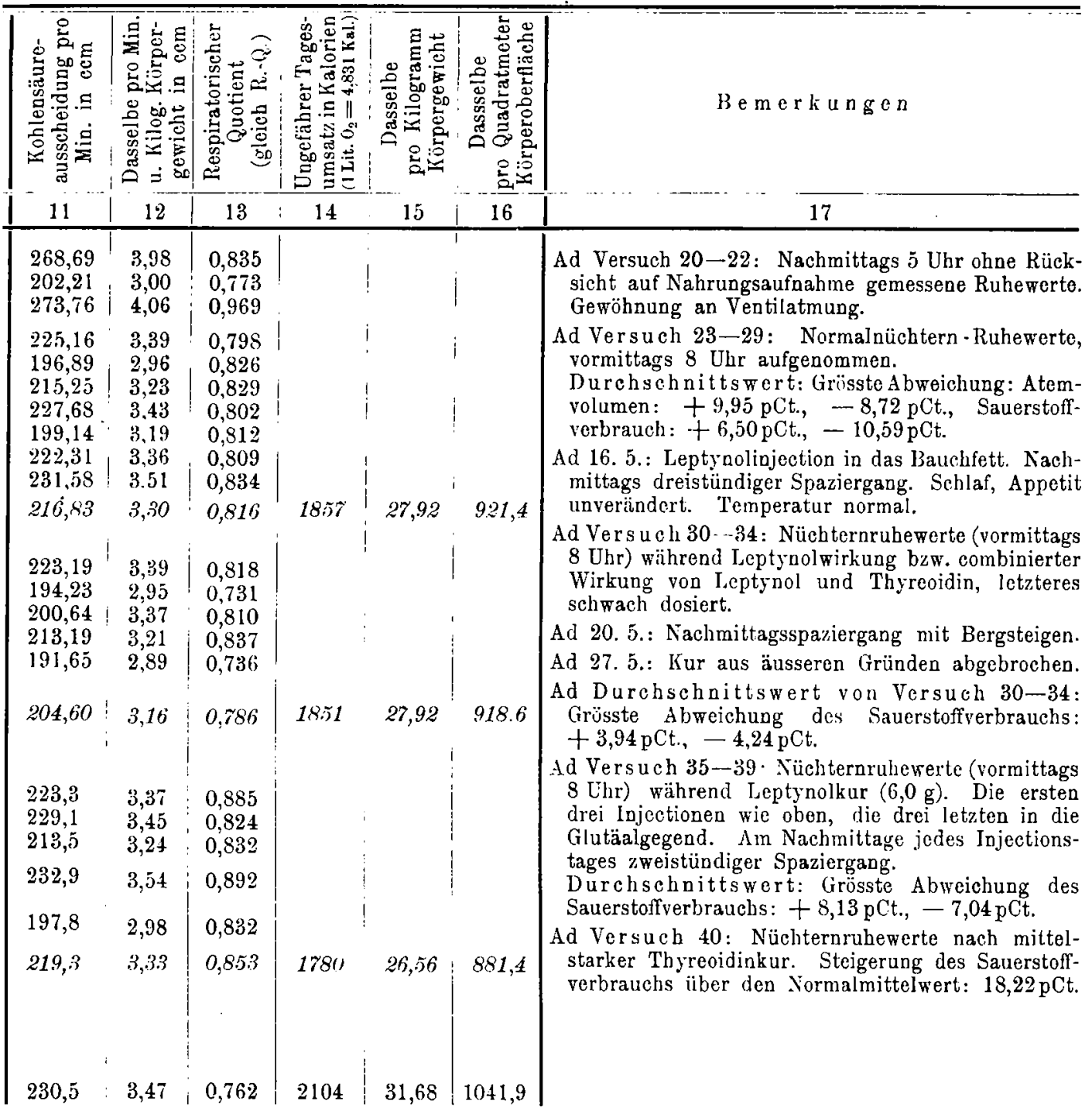

unserer Versuchsperson (W. R.) rühro nur daher, dass der Zeitpunkt des Manifestwerdens nicht abgewartet worden wäre. Immerhin wurde der Uimsatz bis zum 7. Tage nach der ersten Verabreichung gemessen, während beim 2. Versuch mit Thyreoidin schon am 4. Tage die erste Umsatzmessung die oben erwähnte von $28,22 \mathrm{pCt}$. Steigerung ergab.

2. Zwischen der 1. und der 2. Thyreoidinverabreichung bestehen Unterschiede in der Dosierung. Einer Menge von $0,9 \mathrm{~g}$ Thyreoidin in Versuch I steht in Versuch II bis zur ersten gemessenen Reaction eine Menge von 1,2 $\mathrm{g}$ Thyreoidin gegenüber. Weiterbiu wurde das erste Mal eine steigende Dosis nur alle 2 Tage verabfolgt, das zweite Mal dagegen von vornherein die volle Dosis. Objectiv diese Differenz abzuwägen, ist 
nicht möglich, aber die Beobachtung, dass extrem hohe Dosen wohl toxisch stärker wirken, aber den Umsatz nicht stärker beeinflussen können, als normal hohe Dosen, lässt uns doch dahin entscheiden, dass auch eine spärliche Dosierung während des 2. Versuches eine positive Reaction ergeben hätte.

3. Es sei nochmals betont, dass wir die Gewichtsabnahme vom 25. 5. bis 3. 6. auf äussere Ursachen zurückführen müssen und dass es nicht angängig erscheint, ohne nachweisbare Umsatzsteigerung diese Gewichtsabnahme der Thyreoidinwirkung zuzuschreiben.

\section{Leptynol wirkung.}

Es bleibt noch übrig, die Leptynolwirkung zu besprechen: Mit welchem Recht haben wir diese in der bisherigen Besprechung ganz vernachlässigt?

Würden wir die Tabelle betrachten, ohne die übrigen Daten zu kennen, so müssten wir bei der ersten $\Lambda$ nwendung des Mittels $(3,0 \mathrm{~g}$ $=75 \mathrm{mg} \mathrm{Pd}(\mathrm{OH})_{2}$ während 4 Tagen) unter Berücksichtigung der folgenden 5 Tage eine Gewichtssteigerung von $750 \mathrm{~g}$ bei gleichbleibendem Umsatz als Wirkung des Palladiums bezeichnen.

In dem zweiten Falle (Injection von $6 \mathrm{~g}=150 \mathrm{mg} \mathrm{Pd}(\mathrm{OH})_{2}$ innerhalb von 18 Tagen) und unter Berücksichtigung von weiteren 8 Tagen nach der letzten Injection würde dann eine Gewichtszunahme von $800 \mathrm{~g}$ und gleichzeitig eine Herabsetzung des Umsatzes constatiert werden müssen.

Selbstverständlich liegt es uns fern, eine derartige Wirkung vertreten $z u$ wollen. Aber es dürfte einleuchten, dass wir in unserem Falle berechtigt waren, die Wirkung des Leptynols combiniert mit Muskelarbeit, aber ohne Diätbeschränkung gleich Null zu setzen.

\section{Fall. (Kind KJ.)}

A. Krankengeschichte. (30.12.13.)

Patient: Kl., Schülerin, 13 Jahre alt.

Diagnose: 'l'byreogene Fettsucht, symmetrische Speicheldrüsenschwellung, geringe Vergrösserung der 'Tränendrüsen.

Anamnese: Als kleines Kind Diphtherie und Masern, vor 2 Jahren Scharlach. Patientin, die bis dahin mager war, wurde seit der Zeit zusehends dicker. Schmerzen sind nicht aufgetroten. Im 11. Jahre zweimal menstruiert, seitdem nicht wieder.

Heredität: Patientin ist sechstes Kind. Eltern, besonders Mutter, sollen sehr dick sein. 4 Geschwister; 2 gestorben, 2 gleichfalls dick. Auch Grosseltern mütterlicherseits sollen dick sein.

Status praesens: Körpergrösse $151 \mathrm{~cm}$, Gewicht $69 \mathrm{~kg}$, Halsumfang $35 \mathrm{~cm}$, Brustumfang $95 \mathrm{~cm}$, Abdomen (Umfang in Nabelhöhe) $101 \mathrm{~cm}$, Taille $81 \mathrm{~cm}$, Schädel: Circumferentia submento-0ccipitalis $53 \mathrm{~cm}$, Biceps: rechts $36 \mathrm{~cm}$, links $36 \mathrm{~cm}$, Unterarm: maximal: rechts $25^{1} / 2 \mathrm{~cm}$, links $25 \mathrm{~cm}$, Oberschenkel, Mitte (zur Patella und Spina iliaca) rechts $58 \mathrm{~cm}$, links $57^{1} / 2 \mathrm{~cm}$, Unterschenlel: maximal: rechts $34^{1} / 2 \mathrm{~cm}$, links $341 / 2 \mathrm{~cm}$.

Für sein Alter gut entwickeltes, ziemlich muskulöses, auffallend fettes Kind (Mädchen). An Wangen, Brüsten, Oberarmen, Oberschenkeln, Bauch und namentlich in der Glutäalregion ausgedehnte Fottablagerungen, bläuliche Färbung der Haut in der Glutäal- und Oberschenkelgegend. Unterarm und Unterschenkel weniger befallen. Nirgends erhebliche Drüsenschwellung. 'Thyreoidea füblbar, nicht abnorm gross. 
Gebiss gut ausgebildet. Lungen-Lebergrenze: 6. Rippe; verschiebbar. Keine Dämpfung, überall Vesikuläratmen. Herz nicht verbreitert. Töne rein.

Puls: 88, regelmässig.

Abdomen: sehr fettreich, unterer Leberrand schlägt bei Inspiration an, Milz nicht fühlbar, nirgends Druckempfindlichkeit.

Nervensystem: keine aufallende Störung. Augen frei. Patellar- und Pupillarreflexe normal.

Die Röntgenuntersuchung des Schädels ergibt normale Verhältnisse an der Basis. Thymusvergrösserung röntgenologisch nicht nachweisbar.

Blutbild:

Vor der Behandiung:

Nach 10 tägiger 'T'byreoidinbehandlung $(0,2 \mathrm{~g}$ pro die):

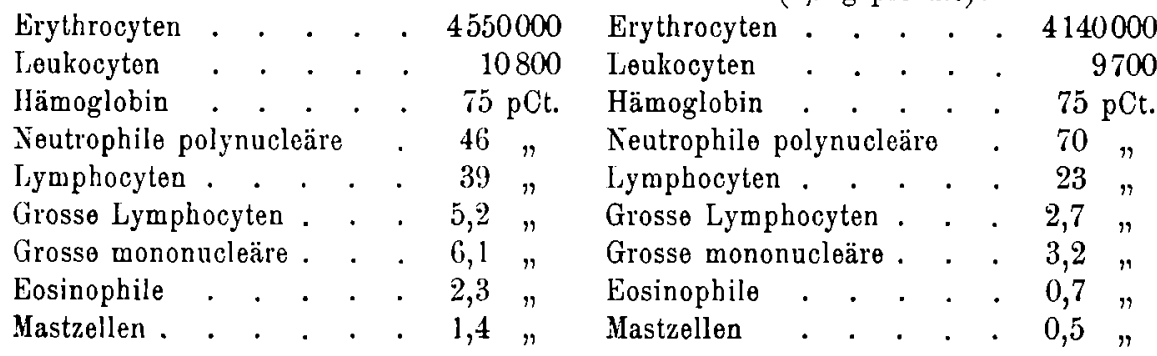

Nebenbei interessant ist in diesem Falle, wie das Blutbild die Lymphocytose ist als Teilerscheinung eines Status lymphaticus aufzufassen - unter dem Einfluss der Schilddrüsensubstanz normal wird. Bemerkenswert sind auch hier, wie im vorigen Falle, die hereditären Verhältnisse. Der Fettverteilungstypus weist auf eine endogene Form der Fettsucht hin. Die klinische Diagnose näher zu präcisieren ist nicht möglich. Zwar lässt sich die symmetrische Speicheldrüsenschwellung nach der Beobachtung von Mohr (6) als compensierende Hypertrophie bei primärer functioneller Schädigung der Keimdrüsen deuten; doch wird diese Vermutung beim Fehlen eines pathologischen Genitalbefundes klinisch nicht weiter gestützt. Auch bei Hypophyse, Thymus und Schilddrüse ist klinisch ein abnormer Befund nicht vorhanden. In höherem Grade also wie bei den vorigen Fällen ist hier der Einfluss des Medicamentes von diagnostischer Bedeutung.

Die Prüfung der Reaction auf Thyreoidin gab denn auch eine sichere Aufklärung und bewies (dies sei hier vorweggenommen) die exquisit thyreogene Natur dieses Falles. Zu erwähnen ist noch, dass auch in diesem Falle während der Thyreoidinbehandlung keinerlei Aenderung der Diät vorgenommen wurde.

\section{B. Der Grundumsatz.}

Die Betrachtung der T'abelle VI ergibt Folgendes: Analog zum vorigen Fall wird wiederum der respiratorische Quotient durch Thyreoidinbehandlung nicht beeinflusst. Er ist - wohl nur cine individuelle Eigentümlichkeit - um einige Hundertstel niedriger als im vorigen Fall. Zur Beurteilung des Umsatzes in seiner Stellung zur Norm wird hier in derselben Weise vorgegangen wie beim vorigen Fall. Wie aus der Normaltabelle für Kinder hervorgeht, sind die Differenzen des Umsatzes beider Geschlechter voneinander in diesem Alter nicht grösser als Normal- 
Tabelle VI. Mädchen Kl.,

\begin{tabular}{|c|c|c|c|c|c|c|c|c|c|}
\hline 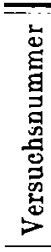 & Datum & Medikation & 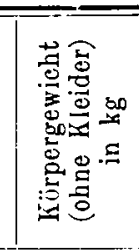 & 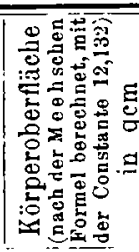 & 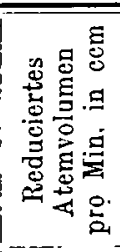 & 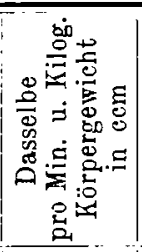 & 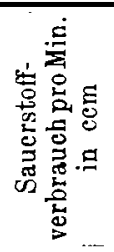 & 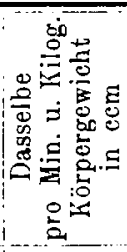 & 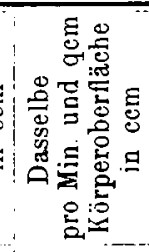 \\
\hline 1 & 9 & 3 & 4 & 5 & 6 & 7 & 8 & 0 & 10 \\
\hline $\begin{array}{l}58 \\
59 \\
60\end{array}$ & $\begin{array}{rr}30 . & 10 . \\
31 . & 10 . \\
1 . & 11 . \\
9 . & 11 .\end{array}$ & & 69,000 & 20697 & & & & 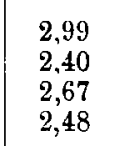 & $\begin{array}{l}99,82 \\
83,20 \\
89,00 \\
82,48\end{array}$ \\
\hline & $\begin{array}{c}\text { Mittelwer } \\
\text { 9. } 11 .\end{array}$ & Vars & & & 3582 & 52,00 & 175,7 & 2,55 & 84,89 \\
\hline 6 & $\begin{array}{l}10 \\
11\end{array}$ & $\begin{array}{l}0,2 \mathrm{~g} \\
0,2 \mathrm{~g}\end{array}$ & & & 912 & 35 & ,3 & 3,35 & 11,76 \\
\hline 6 & $\begin{array}{l}\text { 12. } 11 . \\
13.11\end{array}$ & $\begin{array}{l}0,2 \mathrm{~g} \\
0,2 \mathrm{~g} \\
0,2 \mathrm{~g}\end{array}$ & 67,000 & 10 & 4193 & & & 9 & $\begin{array}{l}29,00 \\
01,97\end{array}$ \\
\hline & Mittelwer & on Vers. $62-$ & & & 4867 & 71,73 & 231,8 & 3,40 & 113,02 \\
\hline
\end{tabular}

differenzen innerhalb desselben Geschlechtes. Nach übereinstimmender Körpergrösse wählen wir zum Vergleich: Mädchen Nr. 8 und 9 und Knaben Nr. 11, 12, 13, 14 der Tabelle. In der Vergleichung halten wir uns an die im Fall W. R. eingeschlagene Reihenfolge:

1. Vergleich des ganzen Minutenumsatzes mit Abzug von 20 pCt.:

Kind Kl.:

$140,6 \mathrm{ecm} \mathrm{O}_{2}$ normal:

$194,4 \mathrm{ccm} \mathrm{O}_{2}$ (minimal)

$220,4 \pi$, (maximal)

Abweichung vom Normalminimum $=27,7 \mathrm{p}(\mathrm{t}$.

2. Vergleich des Minutenumsatzes pro Kilogramm Körpergewicht:

Kind Kl.:

$2,55 \mathrm{ccm} \mathrm{O}_{2}$ normal:

$$
\begin{aligned}
& 4,91 \mathrm{ccm} \mathrm{O}_{2} \text { (minimal) } \\
& 5,13 \quad n \quad \text { (maximal) }
\end{aligned}
$$

3. Vergleich der nach Relation reducierten 'lageskalorienzahl pro Quadratmeter Körperoberfläche mit den Normalwerten für Erwachsene (die Relationszahl schwankt zwischen 113 und 130):

Kind Kl.:

normal:

minimal: 493,9 Kalorien (reduciert) minimal: 710 Kalorien maximal: 52 maximal: 893

$\Lambda$ bweichung des Maximalwertes vom Normalminimum $=26,5 \mathrm{pCt}$.

4. Vergleich des nach Relation reducierten Minutenumsatzes pro Kilogramm Körpergewicht nit dem Normalwert für Erwachsene (die Relationszahl schwankt zwischen 130 und 150):

Kind $\mathrm{Kl}$ : :

minimal: $1,79 \mathrm{ccm} \mathrm{O}_{2}$ maximal: $1,96 n n$ normal:

minimal: $2,76 \mathrm{ccm} \mathrm{O}_{2}$ maximal: $4,53 \% \pi$

Abweichung des Maximalwertes vom normalen Minimalwert $=29,0$ pCt. 
13 Jahre alt. Grösse $151 \mathrm{~cm}$.

\begin{tabular}{|c|c|c|c|}
\hline 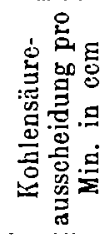 & 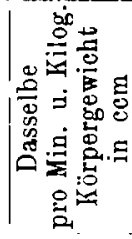 & 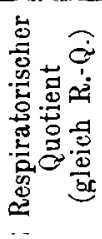 & B e merkungen \\
\hline 11 & 12 & 13 & 14 \\
\hline 158,4 & 230 & 0.766 & \multirow{10}{*}{$\begin{array}{l}\text { Ad Versuch 58: Gewöhnung an die Ventilatmung. Daher naturgemäss } \\
\text { alle Werte zu hoch. Alle Versuche sind Normalnüchternruhewerte, } \\
\text { während der 7eit vormittags } 10-11 \text { Uhr aufgenommen. } \\
\text { Ad Durchschnittswert von } 59-61 \text { : Grösste Abweichung des } \mathrm{O}_{2} \text {-Ver- } \\
\text { brauchs: }+2,85 \mathrm{pCt},-4,84 \mathrm{pCt} \text {. Berechneter durchschnittlicher Tages- } \\
\text { grundumsatz ( } 1 \text { Liter } \mathrm{O}_{2}=4.831 \text { Kalorien): } 1222 \text { Kalorien. Dassolbe } \\
\text { pro Kilogramm Körpergewicht: } 17,71 \text { Kalorien, dasselbe pro Quadrat- } \\
\text { meter Oberfläche: } 590 \text { Kalorien. } \\
\text { Ad Versuch } 62: \text { lateressant ist, dass die Wirkung der Arznei schon } \\
\text { am zweiten Tage manifest wird. Steigerung des durchschnittlichen } \\
\text { Grundumsatzes: 33,2 pCt., berechneter durchschnittlicher Tages- } \\
\text { umsatz: 1613 Kalorien, dasselbe pro Kilogramm Körpergewicht: } \\
24,07 \text { Kalorien, dasselbe pro Quadratmeter Oberfläche: 794. Kalorien. }\end{array}$} \\
\hline 131,6 & 1,91 & 0.764 & \\
\hline 142.4 & 2,06 & 0,773 & \\
\hline 138,0 & 2,00 & 0,808 & \\
\hline 137,3 & 1,99 & 0,782 & \\
\hline 177,3 & 2,57 & 0,767 & \\
\hline 196,5 & 2,89 & 0,876 & \\
\hline 206,6 & 3,08 & 0,780 & \\
\hline & 2,36 & 0,765 & \\
\hline 181,7 & 2,73 & 0,797 & \\
\hline
\end{tabular}

Der Normalvergleichswert unter 3. und 4. ist entsprechend der Normaltabelle nur von männlichen Individuen genommen; da aber der auf Quadratmeter Oberfläche bzw. Kilogramm Körpergewicht bezogene Umsatz der weiblichen Erwachsenen im Durchschnitt um etwa 10 pCt. höher ist als der der männlichen, so ist die procentuale Spannung in Wirklichkeit noch etwas grösser.

Dieses Ergebnis bedarf keiner weiteren Erklärung. Es beweist eine Herabsetzung des Umsatzes, die sich auch von der schärfsten Kritik nicht abstreiten lässt. Eingeordnet in die von Noördensche Tabelle des Umsatzes Fettsüchtiger würde sie den tiefsten bisher mit dieser Methodik beobachteten Wert darstellen (vgl. Tabelle II).

\section{Thyreoidinwirkung.}

Die Reactiọn auf Schilddrüsensubstanz äussert sich in einer Steigerung des Grundumsatzes von 33,2 pCt. Diese Steigerung würde in 6 T'agen die Verbrennung von knapp $250 \mathrm{~g}$ Körperfett bei gleichbleibender Nahrung bewirken können. Es wurde dagegen ein Gewichtsverlust von $2,0 \mathrm{~kg}$ beobachtet.

Es liegt kein Grund vor, diesen durch negative Wasserbilanz allein erklären zu wollen. Es zeigt sich vielmehr nach unserer Meinung hier eine lü̈cke der bisherigen Beobachtungen der Schilddrüsenwirkungen: Es ist von vornherein durchaus nicht von der Hand zu weisen, dass, analog der Steigerung des Grundumsatzes, auch die Steigerung des Umsatzes nach Nahrungszufuhr (insbesondere die specifisch-dynamische Componente) erhöht oder der Nutzeffect bei Muskelarbeit erniedrigt würde. Exacte Untersuchungen über beide Möglichkeiten liegen bisher nicht vor (mit Ausnahme der Beobachtung von Jaquet und Svenson, welche bei zwei Fettleibigen nach Thyreoidingabe keine Steigerung des Grund- 
umsatzes, dagegen eine solche des Umsatzes nach Mahlzeit nachweisen konnten). Beim Yorbus Basedowii konnte Magnus-Levy (11) in zu diesem Zweck angestellten Untersuchungen des Gaswechsels nach Nahrungsaufnahme kein vom Normalen abweichendes Resultat beobachten.

Eine Verschlechterung des Nutzeffectes bei Muskelarbeit dürfte von vornherein nicht gänzlich durch eine nervös bedingte motorische Unruhe zu erklären sein, analog dem Morbus Basedowii.

Bemerkenswert ist die schon oben berührte Tatsache des momentanen Anstieges zugleich auf eine Höhe, die der dann eingehaltenen Durchsehnittssteigerung schon sehr nahe kommt.

Während der Schilddrüsenbehandlung beobachten wir ohne äusseren Grund (bei vorsätzlicher Muskelruhe) beträchtliche Schwankungen des gesteigerten Umsatzes. Diese bilden vielleicht ein Analogon zu der Beobachtung Steyrers (18), der bei Morbus Basedowii grosse tägliche Schwankungen des Grundumsatzes parallelgehend mit Schwankungen der nervösen Erscheinungen fand. (Ebenfalls bei vorsätzlicher Muskelruhe.) $\mathrm{Ob}$ der Grund zu diesem Verhalten in einer Tonusänderung auch des entspannten Muskels liegt, ist nicht erwiesen. Gegen eine solche Beeinflussung des Grundumsatzes durch Muskeltonus sprechen die mit der Zuntzschen Methode an Nervenkranken angestellten Untersuchungen.

Zum Schluss sei dieser Fall noch kurz dem vorhergehenden gegenübergestellt.

Beide Fälle stimmen in allen zu einem directen Vergleich erforderlichen Dimensionen (Gewicht, Grösse, Körperoberfläche, Alter) so gut zusammen, dass sie fast mit demselben Rechte wie zwei verschiedene Zustände eines Individuums miteinander verglichen werden können.

Trotzdem besteht ein Unterschied in der Umsatzintensität, der sich in dem Verhältnis

$$
\text { ca. } 1,58 \text { (W. R.) : 1,00 Kalorien }
$$

ausdrückt. Dieses Verhältnis scheint auf eine gewisse gesetzmässige Beziehung zwischen Lmsatzhöhe und Thyreoidinempfindlichkeit (bzw. Schilddrüsentätigkeit) hinzuweisen. Nicht nur, wie wir sie weiter oben folgerten, für verschiedene Zustände eines Individuums, sondern auch allgemeingiltig unter Einbeziehung verschiedener Individuen. Es trifft schematisch zusammen:

\begin{tabular}{|c|c|c|c|}
\hline & Umsatz: & $\begin{array}{l}\text { und Thyreoidin- } \\
\text { reaction: }\end{array}$ & $\begin{array}{l}\text { daraus zu folgernder } \\
\text { Grad der Schild- } \\
\text { drüsentätigkeit: }\end{array}$ \\
\hline $\begin{array}{l}\text { W. R. Serie } 1 \text { u. Il } \\
\text { W. R. Serie III . } \\
\text { KI. } \quad . \quad \cdot \quad \cdot \quad \cdot \quad .\end{array}$ & $\begin{array}{l}\text { 1. } \quad \text { noch normal } \\
\text { 2. wenig unternormal } \\
\text { 3. bedeutend unternormal }\end{array}$ & $\begin{array}{c}\text { fehit } \\
\text { mässige Reaction } \\
\text { starke Reaction }\end{array}$ & $\begin{array}{l}\text { nicht herabgesetzt } \\
\text { mässig herabgesetzt } \\
\text { stark herabgesetzt }\end{array}$ \\
\hline
\end{tabular}

Allgemein liesse sich hieraus formulieren:

Die absolute Höhe des Grundumsatzes ist eine directe Function der Intensität der Schilddrüsentätigkeit und bestimmt im voraus die Grösse der Thyreoidinempfindlichkeit. 
4. Fall. ( $\Lambda$. M.)

Hauptsächlich um die lirfahrung über die Wirkung des Jeptynols noch weiter auszudehnen, wurde folgender Fall von exogener Fettsucht zunächst auf seine Reaction auf Leptynol, sodann zum Vergleich auf seine Reaction auf Thyreoidin untersucht.

A. Krankengeschichte. (15. 9. 15).

Patient: A. M., Medicinalpraktikant, 32 Jahre alt.

Diagnose: Exogene Fottsucht geringen Grades.

Anamnese: Neigt seit Beginn seines Studiums zur Korpulenz. Nicht übermässiger Essser. Frühøre Krankheiten: Masern, Scharlach mit Nephritis, vor 2 Jahren Pleuritis exsudativa sinistra. Potus und Nikotinabusus negiert, ebenso sexuelle Infektion.

Heredität: Nichts Besonderos.

Status praesens: Körpergrösse $167 \mathrm{~cm}$, Körpergewicht (ohne Kleider) $79,65 \mathrm{~kg}$, Halsumfang $40 \mathrm{~cm}$, mittlerer Brustumfang $99 \mathrm{~cm}$, Abdomen (Umfang in Nabelhöhe) $108 \mathrm{~cm}$, Taille $94 \mathrm{~cm}$, Oberarm: Mitte rechts $31 \mathrm{~cm}$, links $30 \mathrm{~cm}$, Unterarm: grösster Umfang rechts 28, links $27 \mathrm{~cm}$, Oberschenkel (Mitte) $52 \mathrm{~cm}$, Unterschenkel (grösster Umfang) $39 \mathrm{~cm}$.

Untersetzter, kräftiger Patient mit gutentwickelter Muskulatur, überall gute Fettpolster, insbesondere an Nacken, Schultern, sowie den Bauchdecken.

Rachenring: Leicht gerötet, Pharyngitis granularis; keine Halslymphdrüsenschwellung, Schilddrüse eben zu fühlen; Lungen o. B., Horz 0. B., Puls nicht gespannt, regelmässig, langsam.

U rin: Kein Eiweiss, kein Zucker.

Nervensystem: Ohne grobe Störung.

Es ist dies ein leichter Fall von exogener, wahrscheinlich Mastfettsucht ohne Complicationen. Fs wurde keine Diätvorschrift gegeben. Das Körpergewicht zeigt während der Untersuchung, weit mehr als bei den anderen Fällen, individuell bedingte Schwankungen von Tag zu Tag bis zu $1000 \mathrm{~g}$, welche das wahre Bild der Gewichtsschwankungen etwas verschleiern, aber grössere Ausschläge doch annähernd bestimmen lassen.

\section{B. Leptynolwirknng.}

Das Gewicht bleibt während der Beschickung des Körpers mit Leptynol auf seiner Höhe. Ein Einfluss auf die $\mathrm{O}_{2}$-Zehrung ist weder im Einzelnen nach jeder Injection noch im allgemeinen nach dem Durchschnittswert zu erkennen. In diesem Falle einer Versuchsperson mit geschärfter Selbstbeobachtung sei noch auf die sonstige Wirkung des Leptynols eingegangen: Euphorie und Verminderung der Appetenz wurde niemals beobachtet. Nach der 2. Injection trat am $\Lambda$ bend vorübergehend geringe Temperaturerhöhung auf, bei der aber eine andere Ursache als das Leptynol nicht mit Sicherheit ausgeschlossen werden konnte. Sie wiederholte sich nicht.

\section{c. Der Grundumsatz.}

Wir können auch hier die Werte der Leptynolversuchsserie als Normalwerte ansehen und legen zweckmässig, ähnlich wie in den anderen Fällen, nicht die naturgemäss noch etwas zu hohen Durchschnittswerte der Versuche 41-43 (Tabelle VII), sondern den der Versuche 44-49 der Betrachtung des Grundumsatzes zugrunde. 
Tabelle VII. Herr A. M.,

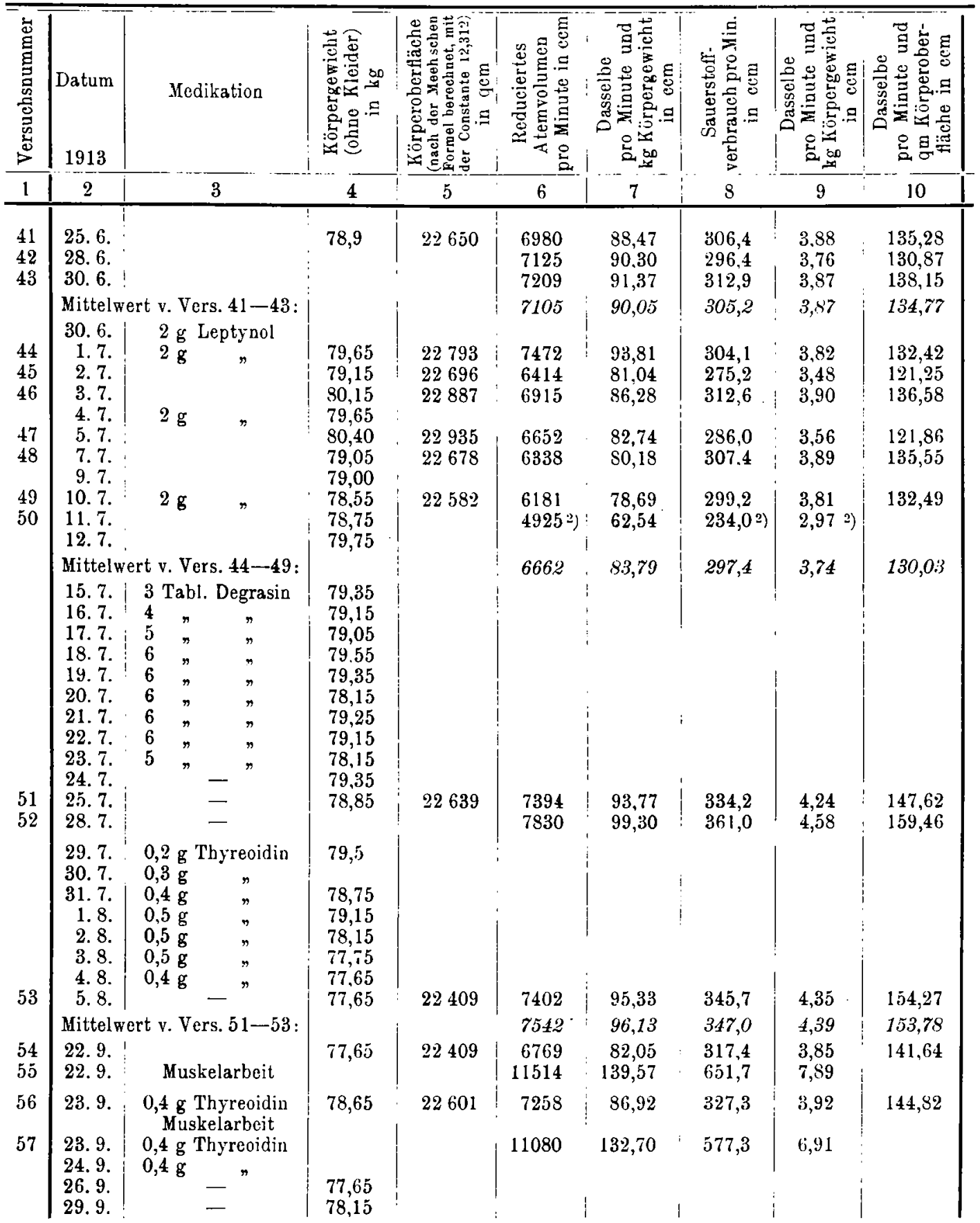

Nr. 10 und 11 der Magnus - Levy schen Normaltabelle haben dieselbe Grösse $(167 \mathrm{~cm}$, Gewicht $67,5 \mathrm{~kg})$, gestatten also einen directen Vergleich. Der Minutenumsatz unseres Falles $\left(297,4 \mathrm{~cm} \mathrm{O}_{2}\right)$ mit Abzug von $20 \mathrm{pCt}$. $=237,9 \mathrm{ccm} O_{2}$ ist etwas höher als der Normalwert $231,3 \mathrm{ccm} O_{2}$. 
32 Jahre alt. Grösse $167 \mathrm{~cm}$.

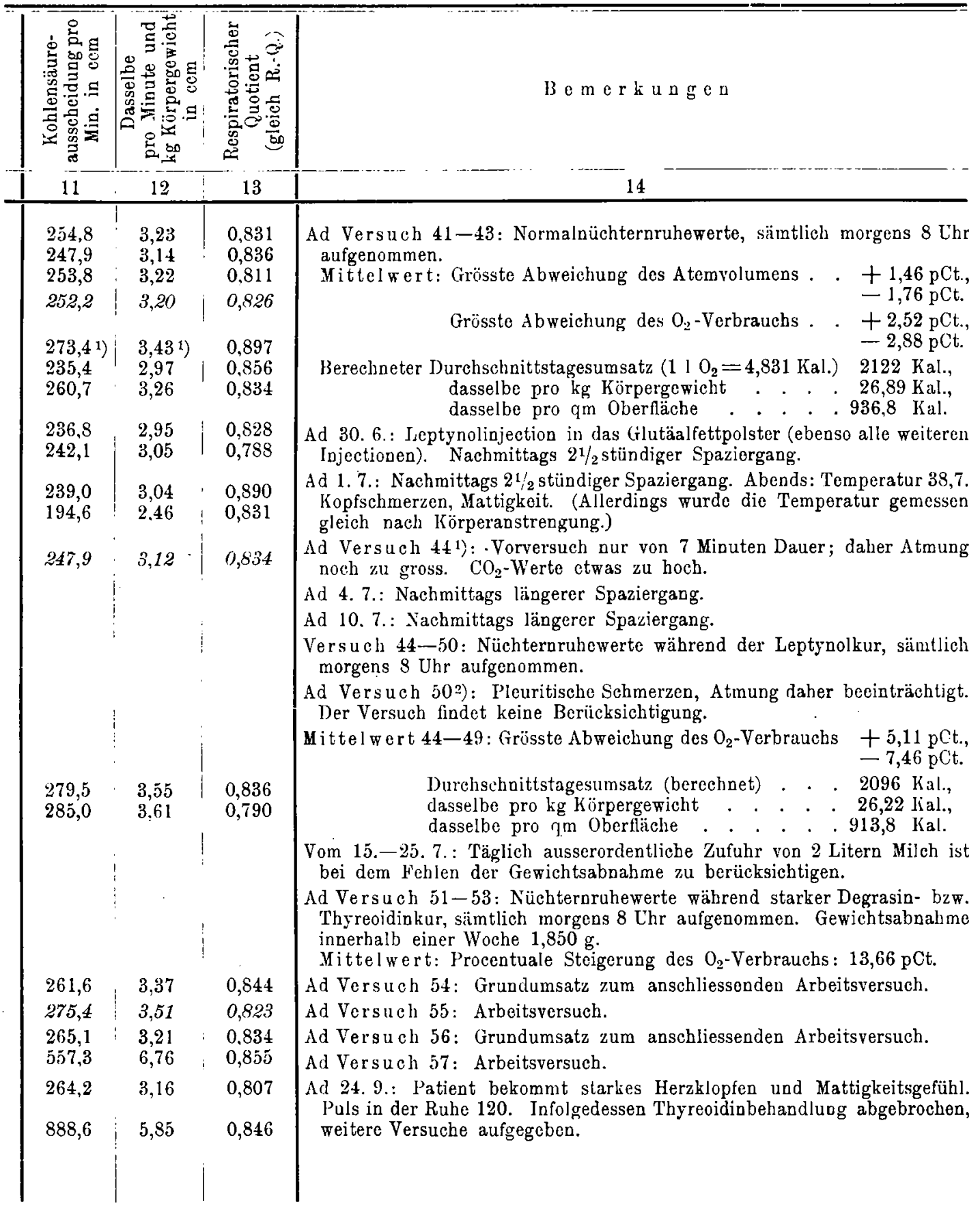

Ebenso ergibt sich bei Vergleichung der Tageskalorienzahl pro Quadratmeter Körperoberfläche, dass der entsprechende Wert unseres Falles 913,8 Kalorien - unbedeutend grösser ist, als der grösste Wert der Normaltabelle (893 Kalorien). Alle Beziehungen auf Kilogramm Körper- 
gewicht, wie das in der Natur der Sache liegt, geben günstigere Werte. Wir haben es also hier mit einem Grundumsatz zu tun, der an der oberen Grenze des Normalen liegt.

\section{I). Thyreoidinwirkung.}

Lässt sich dic oben abstrahierte Beziehung zwischen L'msatzhöhe und Thyreoidinreaction auch auf das Normalgebiet verallgemeinern, so hätten wir hier eine geringe Reaction des Umsatzes auf Thyreoidin zu erwarten.

Was den Gewichtsverlust anbelangt, so finden wir diese Voraussage bestätigt: Trotz Maximalhöhe der Dosen in den ersten beiden Wochen kein Gewichtsverlust, in der dritten Woche ein Gewichtsverlust von ungefähr $1 \mathrm{~kg}$.

Weniger gut bestätigt - unsere Erwartung der Grundumsatz, welcher - nach 10 Tagen zum ersten Mal gemessen - eine Steigerung von 13,66 pCt. zeigt. Immerhin ist diese Reaction einer über 3 Wochen ausgedehnten so hohen Dosierung als Unterdurchschnittswirkung beim Normalmenschen zu beurteilen, und würde sich als solche doch ungezwungen dem obigen Schema eingliedern.

Im übrigen sind wieder die charakteristischen Schwankungen zwischen den einzelnen Steigerungswerten zu beobachten. Beachtenswert ist endlich, dass nach 17 thyreoidinfreien Tagen noch eine über der Fehlergrenze liegende Steigerung des Umsatzes vorhanden ist. Auffallend und wohl mit den in den übrigen Fällen gemachten Beobachtungen im Einklang stehend ist die Tatsache (auf die weiter unten noch näher eingegangen wird), dass gerade in diesem Falle - der hohe an der Grenze des Normalen stehende Umsatz liess eine Prädisposition nach der BasedowRichtung vermuten -- trotz (nach unserer Auffassung müsste es heissen: wegen) einer ziemlich geringen Reaction des Umsatzes auffallend früh Symptome des Thyreoidismus (also durch die toxischwirkende Componente, nicht durch die umsatzsteigernde bedingt) auftraten.

\section{E. Arbeitsversuche.}

Zwei Arbeitsversuche wurden bei Fall A. M. in etwas anderer Weise als bei Fall Or. folgendermassen ausgeführt: Patient lag in derselben Weise wie beim vorhergehenden Ruheversuch in horizontaler Lage. Lr hob dann in gleichmässig, ruhiger Bewegung mit beiden Händen ein Eisengewichtsstück aus dem Niveau seiner lage bis zur verticalen Streckstellung seiner beiden Arme. Im Moment der erreichten höchsten Hubhöhe, möglichst ohne dass eine Pause dazwischen lag, in der das Gewicht mit gestreckten Armen ruhig gehalten werden musste, wurde ihm dieses von einer beistehenden Person abgenommen. Sodann liess er die Arme ganz schlaff, möglichst ohne jede Muskelanspannung, in die Anfangslage zurückfallen, um das Gewicht zum zweiten Hube von der beistehenden Person wieder anzunehmen. Diese Methode hat vor der Ergostatenmethode den Vorteil 1. der directen absolut sicheren Dosierung der geleisteten Arbeit, 2. der besseren Entspannung aller nicht arbeitenden Muskeln, 3. der besseren Ausschaltung jeder nicht in Arbeit sich um- 
setzenden Nebenbewegung; 4. das Fortfallen der Notwendigkeit einer langen Vorübung wegen der Einfachheit dieser Bewegungen; 5. das Beibehalten derselben Lage während des vorhergehenden Ruheversuches und des nachfolgenden Arbeitsversuches.

Das gehobene Gewicht betrug $10 \mathrm{~kg}$. Die Hubhöhe wurde zu $46 \mathrm{~cm}$ gemessen. Zu der hierdurch gemessenen Arbeit muss noch diejenige Arbeit hinzuaddiert werden, die erforderlich ist, um die Arme ohne Gewicht zu heben. Als Armgewicht wird auf Grund der Messungen von Harlass, Braune und Fischer für den normalen Erwachsenen 6,2 pCt. des Körpergewichts angegeben [Gegenbauer-Fürbringer, Lehrbuch der Anatomie (22)]. Diese Zahl braucht in unserem Fall, in dem das geringe Mehrfett ziemlich gleichmässig auf alle Körperteile verteilt, nicht geändert zu werden. Lm die Hubhöhe zu finden, denken wir uns das Armgewicht in den Schwerpunkt des Armes verlegt. Es dürfte wohl die Annahme, dass sich das Gewicht ziemlich gleichmässig auf die einzelnen Partieen des Ober- und Unterarmes verteilt, also der Schwerpunkt des ganzen Armes etwa im Niveau der halben Hubhöhe liegt, keinen zu grossen Fehler enthalten, zumal wenn wir in Erwägung ziehen, dass das Gewichtsstück auf den Handballen aufruht, also die Hände die Hubhöhe nicht mehr becinflussen, das Gewicht der Hände sich aber zu den distalen an sich etwas leichteren Hälften der Arme hinzuaddiert.

Körpergewicht (bekleidet): $83,0 \mathrm{~kg}$. Demnach Gewicht beider Arme $12,4 \mathrm{pCt} .=10,3 \mathrm{~kg}$. Halbe Hubhöhe $=23 \mathrm{~cm}$.

Arbeit eines IIubes durch Armgewicht verursacht . . $2,37 \mathrm{mkg}$

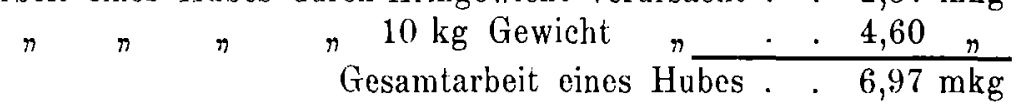

Arbeitsversuch I: Versuchsdauer 13 Minuten, und zwar wurden während der ersten 11 Minuten 221 Hübo in gleichmässigem 'l'ompo ausgeführt, die darauffolgenden 2 Minuten noch als Periode der Nachwirkung der Arbeit mit Körperrube in den Versuch einbezogen. Zwischen vorhergehendem Ruheversuch und Arbeitsversuch wurde die Ventilatmung nicht abgosetzt, daher erübrigt sich die Einschaltung einer neuen Vorperiode zur Atemeinstellung.

$$
\text { Geleistete Arbeit: } 6,97 \times 221=1540,37 \mathrm{mkg} \text {. }
$$

Sauerstoffmehrverbrauch (cf. Tab. VII, Versuch 54 u. 55) pro Minute $334,3 \mathrm{ccm} \mathrm{O}_{2}$, Gesamtsauerstoffmehrverbrauch: $4346 \mathrm{ccm} \mathrm{O}_{2}, \mathrm{R} \cdot-\mathrm{Q} .=0,855$; demnach entspricht:

$$
\begin{array}{rrr}
1 \text { Liter } \mathrm{O}_{2} \text { maximal: } & 4,868 \text { Kalorien } \\
\text { minimal: } & 4,623 \quad " \\
4346 \mathrm{ccm} \mathrm{O}_{2} \text { maximal: } & 21,156 \text { Kalorien } \\
\text { minimal: } & 20,091 " ~
\end{array}
$$

$1 \mathrm{mkg}$ Arbeit verbraucht also: 0,01374 Kalorien maximal

$$
\begin{aligned}
& 1 " n ", \quad 0,01304 \text { " minimal. } \\
& \left.\begin{array}{ccc}
\text { Nutzeffeot: } & 17,13 \text { pCt. maximal } \\
" & 18,04 \ldots \text { minimal }
\end{array}\right\} \text { Mittel : } 17,6 \text { pCt. }
\end{aligned}
$$

Arbeitsversuoh Il wurde in derselben Weiso ausgeführt. Versuchsdauer: 16 Minuten, davon 4 Minuten Nachperiodo. Arbeitsleistung: 220 Ilübe. Am Tage rorher war $0,4 \mathrm{~g}$ Thyreoidin genommen worden. 
Geleistete Arbeit: $15,334 \mathrm{mlg}$.

Sauerstoffmehrverbrauch (cf. Tab. VII, Vers. 56 u. 57) pro Minute: $250,0 \mathrm{ocm} \mathrm{O}_{2}$, Gesamtsauerstoffmehrverbrauch: $4000 \mathrm{ccm} 0_{2}, R .-Q .=0,846$; demnach entspricht:

$$
\begin{aligned}
& 1 \text { Liter } \mathrm{O}_{2} \text { maximal: 4,857 Kalorien } \\
& \text { minimal: } 4,587 \quad \text {, } \\
& 4000 \mathrm{ccm} \mathrm{O}_{2} \text { maximal: } 19,428 \text { Kalorien } \\
& \text { minimal: } 18,348 \text { " } \\
& 1 \mathrm{mkg} \text { Arbeit verbraucht also: } 0,01267 \text { Kalorien maximal } \\
& 1 " n, " 0,01198 \text { n minimal. } \\
& \left.\begin{array}{cc}
\text { Nutzeffect: } & 18,57 \mathrm{pCt} \text { maximal } \\
n & 19,66, \text { minimal }
\end{array}\right\} \text { Mittel: } 19,1 \mathrm{pCt} \text {. }
\end{aligned}
$$

Wir finden also mit dieser Versuchsmethode Werte, die zwar etwas grösser als die oben erwähnten Katzensteinschen Zahlen sind, allerdings die optimalen Werte für die obere Extremität von $23-25 \mathrm{pCt}$. (Heinemann). Mag das nun seine Ursache darin haben, dass doch auch bei dieser Versuchsanordnung Extramuskelleistungen (Fixation des Thorax) und des Schultergürtels, vor allen Dingen Spannung der Bauchpresse, nicht ganz zu umgehen sind, andererseits die Antagonistenspannung bei geringer Uebung doch auch hier mehr, als wir zu Beginn annahmen, ins Gewicht fällt, so ist diese Differenz für unsere Fragen nicht von ausschlaggebendem Interesse. Ls sei nur constatiert, dass auch bei dieser Versuchsperson eine Vergrösserung des Nutzeffectes gegenüber dem Normalen nicht zu beobachten war.

Vergleichen wir beide Versuche gegeneinander! Hier müssen wir vorausschicken, dass der zu Versuch 2 gehörige Grundumsatzsauerstoffverbrauch (wohl schon als Wirkung der 0,4 g Thyreoidin) gegen den von Versuch 1 um $10 \mathrm{ccm}$ pro Minute erhöht ist (vgl. T'ab. Vll, Vers. 54 und 56).

Wie es die Regel ist, finden wir in beiden Arbeitsversuchen den R.-Q. gegen den Ruhewert erhöht ( $\mathrm{CO}_{2}$-Ueberschwemmung des Blutes). Die Werte der beiden Versuche selbst (Mittelwert von Versuch 2 um 1,5 pCt. grösser als der von Versuch 1) stimmen gut überein und lassen keine Steigerung des Arbeitsstoffwechsels in Versuch 2 erkennen. Dies ist allerdings einen 'Tag nach Beginn der 'T'hyreoidinkur von keiner ausschlaggebenden Bedeutung.

Vielmehr war folgende weitere Versuchsfolge geplant worden: Die Versuchsperson, die in einer früheren Versuchsreihe mässig stark auf Thyreoidintabletten reagiert, und diese bis zu einer T'agesdosis von $0,5 \mathrm{~g}$ ohne jede Nebenerscheinung vertragen hatte, sollte sich nunmehr nach einem Zwischenraum, während dessen allerdings, wie aus Tab. VII, Vers. 54 hervorgeht, der Ruheumsatz noch nicht wieder gänzlich auf seinen Normalwert zurückgegangen war, in möglichst raschsteigender Dosis (bis zu $0,6 \mathrm{~g}$ pro die) einer etwa 7-10 l'age dauernden neuen 'Thyreoidinkur unterziehen. Am Anfang dieser Periode stehen unsere beiden Arbeitsversuche. Am Ende der Periode sollten 'zwei weitere Arbeitsversuche ausgeführt werden, um in analoger Fragestellung, wie bei Arbeitsversuch 1 und 2 (Fall Or.) für das Leptynol, hier zu sehen, inwieweit durch Thyreoidin 
bei sicher gesteigertem Ruhestoffwechsel der Arbeitsstoffwechsel beeinflusst würde.

Leider konnte der Plan nicht ausgeführt werden; denn es stellten sich bei der Versuchsperson am dritten Tage (nach $0,4+0,6+0,4 \mathrm{~g}$ 'Thyreoidinverabreichung) Herzbeschwerden ein, die sich in ziemlich erheblicher Mattigkeit, starkem subjectivem Herzklopfen und einer Pulsbeschleunigung bis 120 pro Minute (in der Ruhe) äusserten, mehrere Tage anhielten und Patient sogar einige Tage arbeitsunfähig machten.

\section{Fall. (Thü.)}

(Vgl. 'Tabelle Vlil, Versuch 66--67.)

A. Krankengeschichte. (30. 5. 1913.)

Patient: 36 Jahre alt, Grösse: $1,68 \mathrm{~m}$.

Gewicht: $88,5 \mathrm{lig}$.

Diagnose: Erworbene endogene Fettsucht, wahrscheinlich auf luetischer Basis.

Anamnese: Patient, früher Kaufmann, ist früher als Offizier sehr schmächtig gewesen, seit ca. 6 Jabren, angeblich ohne besondere Luxusconsumtion, während und nach einem längeren $A$ ufenthalt in Sïdafrika, der mit grossen Strapazen verbunden war, Beginn einer Ciewichtszunabme, die im laaufe der Jabre stärlier geworden ist. Körpergewicht zu Beginn der Behandlung netto $100 \mathrm{~kg}$. Abgesehen von Kinderkrankbeiten nie ernstlich krank gewesen, auch nicht während seines Aufenthaltes in Afrika und Südamerika; dagegen während des Aufenthaltes in Afrika Gonorrhoe und angeblich weicher Schanlier. Keine specifische Behandlung. Vorheiratet, zwei gesunde Kinder. Keine Aborte bei der Frau.

Status: Plethorisch aussehender, fettleibiger Mann. Starke Fettpolster an den Wangen, im Nacken, Abdomen, an den Ï̈̈ften. Beide Ohrspeicheldrüsen sind birnengross, derb. Auch die Submaxillardrüsen vergrössert, Tränendrüsen und Sublinguales anscheinend von normaler Grösse. Beide Lappen der Schilddrüse verdickt. Thymusdämpfung nicht nachweisbar. Genitalorgane von normaler Grösse.

Befund an den inneren Organen: 0 . B. Milz niobt fühlbar.

Wassermannsche Reaction: negativ.

Bisherige Therapie: Trotz des negativen Ausfalls der Wassermannschen Reaction wird mit Rücksicht auf die wahrscheinliche frühere Infection eine Salvarsanbehandlung mit $1,6 \mathrm{~g}$ Neo-Salvarsan im laafe von 24 Tagen eingeleitet. Die Injectionen wurden ohne Reaction vertragen. Die Gewichtsabnahme betrug nach dieser Zeit $8 \mathrm{Pfd}$. In $A$ nschluss daran wurde eine Schilddrüsenbehandlung eingeleitet, täglich $0,3 \mathrm{~g}$ Trockensubstanz. Nach weiteren 14 T'agen eine Gesamtgewichtsabnahme von 13 Pfd. Daraufbin wurde die Schilddrüsentherapie abgebrochen, da Patient eine längere Auslandsreise antreten musste. Nach 2 Monaten hatte das Körpergewicht um $8 \mathrm{Pfd}$. wieder zugenommen. Kine nocbmalige Salvarsanbehandlung von $1,5 \mathrm{~g}$ NeoSalvarsan im Laufe von 4 Wochen hatte auf das Gewicht keinen Einfluss. Dagegen sank es nach daran sich anschliessender Schilddrüsenbehandlung (Degrasin), 4 bis 6 Tabletten pro Tag, im Laufe von 14 Tagen um $5 \mathrm{~kg}$. Hier setzen die beiden Respirationsversuche ein. Infoige beruflicher Reisen musste die weitere Behandlung und Beobachtung abgebrochen worden.

\section{B. Der Grundumsatz.}

Die beiden angestellten Respirationsversuche zeigen cinen beträchtlich erhöhten Grundumsatz nach längerer starker Thyreoidinverabreichung. Sie verlieren allerdings an Wert, da die Beobachtung des dazugehörigen Normalgrundumsatzes fehlt. 
T a -

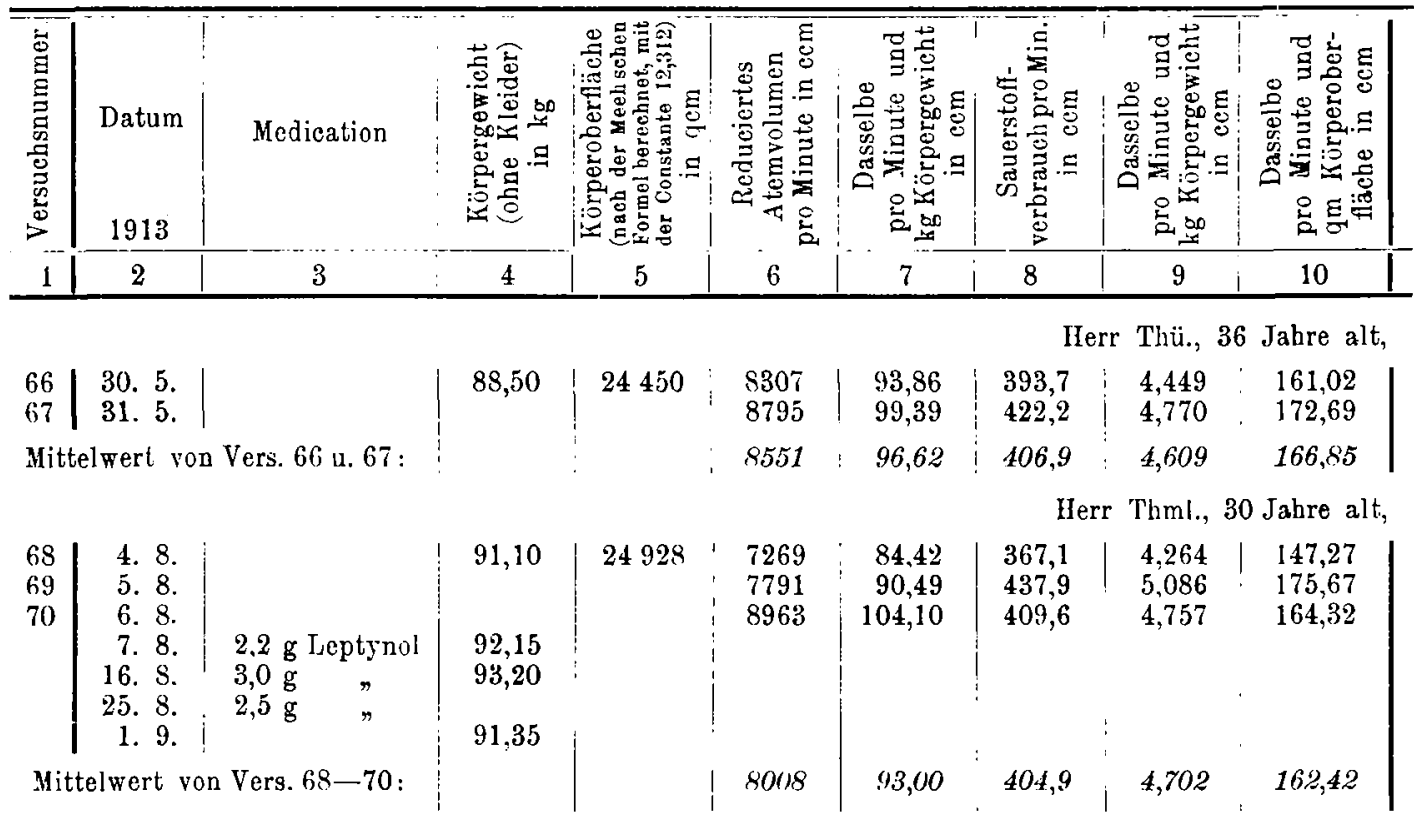

6. Fall. (Thml.)

(Vgl. Tabelle VIII, Versuch 68-70.)

A. Krankengeschichte. (4. 8. 1913.)

Patient: Thml, berufslos, früber Student, 30 Jahre alt, $1,72 \mathrm{~m}$ gross.

Diagnose: Exogene Fettsucht (Mastfettsucht auf alkobolischer Basis).

Anamnese: Familienanamnese ergibt Neigung zur Fettsucht. Patient gibt an, seit Jahren nicht zu Frühstück und nicht zu Mittag zu essen rausser einer Flascbe Wein. " Seine IJauptmahlzeit sei abends. Im Anschluss daran regelmässig sehr reichlicher Alkobolgenuss (Bier und Wein).

Status: Sebr kräftiger, fettreicher Mann. Fettverteilung gleichmässig. Besonders beteiligt Nacken und Bauchdecken. Gesioht etwas gedunsen. Mässige Erweiterung der Lidspalte. Speicheldrüsen und Genitalien: o. B.

Innere Organe: ohne Befund.

Urin: kein Zucker, kein Eiweiss.

Wassermannsche Reaction: negativ.

Blutbild: 0 . B.

\section{B. Der Grundumsatz.}

In diesem Falle finden wir einen für normale Verhältnisse hochgradig gesteigerten Grundumsatz. Im Hinblick auf die Anamnese ist es allerdings fraglich, ob die Versuche wirklich Nüchternwerte im üblichen Sinne darstellen. Sie wurden alle nach 10 Uhr vormittags, ohne vorhergehondes Frühstück gemessen. Der auffallend niedrige R.-Q. lässt die Beteiligung des Alkohols an der Verbrennung noch deutlich erkennen; er ist am niedrigsten beim höchsten Umsatzwert. Schon die kolossale Schwankung von $70 \mathrm{ccm} \mathrm{O}_{2}$ pro Minute von einem 'Tag auf den andern ist ein Zeichen dafür, dass wir es hier nicht immer mit gleichwertigen Zuständen des L'msatzes zu tun haben. 
be 11 e VIII.

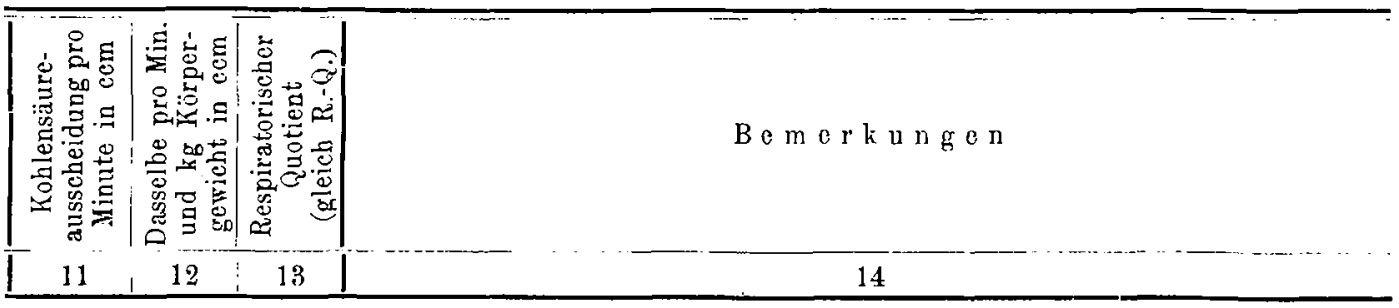

Grüsse $168 \mathrm{~cm}$.

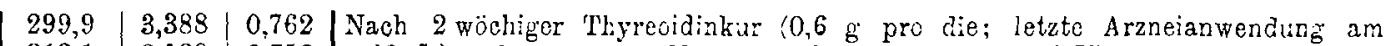
313,1 3,538;0,752 28.5.) aufgenommene Nüchternruhewerte, morgens 8 Uhr. (iewichtsahnahme \begin{tabular}{ll|l|l|l}
306,5 & 3.463 & 0,757 & während der Bchandlung $2,5 \mathrm{~kg}$.
\end{tabular}

Grösse $172 \mathrm{ccm}$.

\begin{tabular}{|c|c|c|c|}
\hline 301,7 & 3,504 & 0,822 & Ad Vorsuch $68-70$ : Normalnüchternrubewerte, vormittags 10 Uhr aufgenommen. \\
\hline 321,0 & 3,728 & 0.733 & Das Gewicht ist immer ohne $A b z u g$ der Kleider angegeben; für die Berechnung \\
\hline 315,5 & 3,664 & 0,770 & $\begin{array}{l}\text { wird } 5 \mathrm{~kg} \text { abgezogen. - Es sei benerkt, dass Pat. sich sehr unregelmässic er- } \\
\text { nährt und teilwreise am Abend vor dem Versuch reichliche Mengen alkoholisehe }\end{array}$ \\
\hline & & & $\begin{array}{l}\text { Getränke zu sich genommen hat. Hierdurch lassen sieh die grossen Schwankungen } \\
\text { der Einzelwerie erklären. Bei den Versuchen wird regelmässig Alkoholgeruch } \\
\text { des Atems wahrgenommen. }\end{array}$ \\
\hline $312, \%$ & 3,632 & $0,7 \approx 5$ & $\begin{array}{l}\text { Ad } 7-25 \text {. 8.: Ijeptynol wird in das Fettpolster der Bauchdecken injiciert. } \\
\text { Nachmittag desselben Tages Muskelarbeit mit Hanteln ausgeführt. }\end{array}$ \\
\hline
\end{tabular}

Man ist versucht, hier wirklich von einem Luxusenergieverbrauch zu reden. Ob die reichliche Alkoholernährung bei gleichbleibender Fettsparung auch den Umsatz erhöht, muss unentschieden bleiben.

7. Fall. (Kind G. B.)

(Vgl. Tabolle IX, Versuch 71 und 72.) ${ }^{1}$ )

A. Krankengeschichte. (6.10.1913.)

Patient: G. B., Schülerin, 10 Jahre alt.

Diagnose: Endogene Fettsucht (Status thymolymphaticus).

Anamnese: Adoptivkind. Ueber Familie nichts zu erheben. Früber Masern und Diphtherie überstanden. Wird rom Schularzt jetzt wegen Bleichsucht hergeschickt. Hat öfter Schmerzen im Kopf und im Loib, klagt über Uebelkeit. Stuhlgang regelmässig. Appetit nicht besonders gut. - In letzter Zeit hat sich Patient immer matt und unlustig zur Arboit gefühlt, kommt auch in der Schule nicht besonders vorwärts.

Körpergrösse: $1,41 \mathrm{~m}$. Gewicht $38,0 \mathrm{~kg}$.

Status: Für sein $A l t e r$ sehr entwickeltes Kind, muskulös, Fettpolster reichlich. Femininer Fottverteilungstypus mit Fettablagerung, besonders an den Hüften, Nates, Schamgegend. Breites, beträchtlich für das Alter entwickeltes Becken. Breite Michaelissche Raute. Lordose der Lendenwirbelsäule. Gesicht blass, pastös. Lymphknotenschwellungen an Hals, Achselhöhlen, Leistenbeugen. Parotis nicht geschwollen, wohl aber die beiderseitige Submaxillardrüse. Schilddrüse nicht vergrössert. Am Jugulum ist hinter der Incisur deutlich eine schwammige Masse zu fühlen. Dämpfung ïber dem Manubrium sterni, namentlich nach links. Gaumenmandeln rergrössert, von aussen durchzufühlen.

1) Die nunmehr folgenden Fälle sind von Herrn Professor Dr. Mohr untersucht und mir zar Veröffentlichung an dieser Stelle überlassen worden. 


\begin{tabular}{|c|c|c|c|c|c|c|c|c|c|c|}
\hline 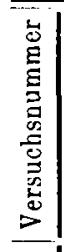 & Datum & $\begin{array}{c}\text { Versuchs } \\
\text { dauer }\end{array}$ & Medication. & 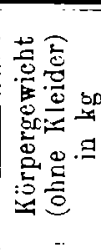 & 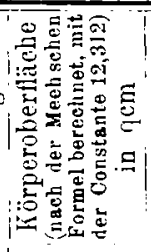 & 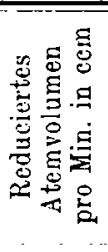 & 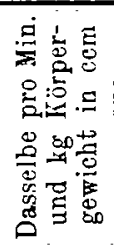 & 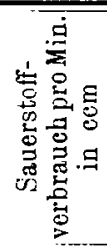 & 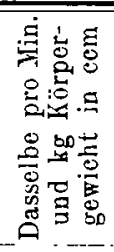 & 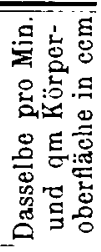 \\
\hline 1 & 2 & 3 & 4 & 5 & 6 & 7 & 8 & 9 & 10 & 11 \\
\hline 71 & 10. 10 . & $25 \mathrm{Min}$. & Normalnüchtern & $38,($ & 13916 & 5460 & 143,68 & 215,6 & 5,674 & 154 \\
\hline \multirow[t]{2}{*}{72} & & & & & $\mathrm{C7}$ & 1600 & 121,50 & 207,2 & 5,600 & 151,5 \\
\hline & & & Durchschnitt: & & & 5030 & 132,59 & 211,4 & $5,6: 37$ & 153,25 \\
\hline \multirow[t]{2}{*}{$\begin{array}{l}73 \\
74\end{array}$} & 24.10. & $\begin{array}{l}25 \text { Min. ! } \\
20 \% \text { । }\end{array}$ & $\begin{array}{c}\text { Normalnüchtern } \\
\end{array}$ & $\begin{array}{l}64,0 \\
64,0\end{array}$ & $\begin{array}{l}19700 \\
19700\end{array}$ & $\begin{array}{l}4700 \\
4900\end{array}$ & $\begin{array}{l}73,44 \\
76,56\end{array}$ & $\begin{array}{l}232,2 \\
236,6\end{array}$ & $\begin{array}{l}3,628 \\
3,697\end{array}$ & $\begin{array}{l}117,87 \\
120,11\end{array}$ \\
\hline & & & Durchsehr & & & 4800 & 75,00 & 234,4 & 3,662 & 118,99 \\
\hline 5 & 25.10. & 20 Min. & Normalnüchtern & 83, & 23520 & 5500 & 64,67 & 274,3 & 3,2 & 116,62 \\
\hline 77 & & $15 \%$ & & s. & 77 & 75 & 120.97 & 353,3 & 58 & \\
\hline 77 & $\begin{array}{r}20.12 . \\
1914\end{array}$ & $15 \pi$ & m & 115,5 & 29200 & 8700 & 75,32 & 400,2 & 3,465 & 137,06 \\
\hline 78 & 17.2. & $25 n$ & $\pi$ & 67,5 & 19492 & 6100 & 90,33 & 301,34 & 4,464 & 154,60 \\
\hline
\end{tabular}

Lungen: 0. . B.

Herz: Spitzenstoss im 5. Interkostalraum in der Mamillarlinie.

$A$ bdomen: sehr fettreich. Leber, Milz nicht fühlbar.

Nervensystem: 0 . B.

Im Röntgenschirm erscheint das Herz etwas nach links verbreitert. Thymusschatten nicht deutlich. Skelott grazil.

Blutbild: Hämoglobin (Sahli) 62 pCt., Erythrocyten 2680000, Leukocyten 18200, davon: grosse Lymphocyten 4 pCt., kleine Lymphocyten 30 pCt., neutrophile Leukocyten 64 pCt., eosinophile Leukocyten $2 \mathrm{pCt}$.

\section{B. Der Grundumsatz.}

Hier haben wir einen Umsatz (siehe Tabelle 1X, Versuch 71 und 72), der mit seiner absoluten Grösse $-211,4 \mathrm{ccm} \mathrm{O}_{2}$ pro Minute und mit seiner relativen Grösse $-5,6 \mathrm{ccm} \mathrm{O}_{2}$ pro Minute und Kilogramm Körpergewicht - an der oberen Grenze der kindlichen Normalwerte steht im lehrreichen Gegensatz zu Fall III (Kind Kl., Tabelle VI).

8. Fall. (Erl. M. K.)

(Vgl. Tabolle IX, Versuch 73 und 74.)

Krankengeschichte. (9.10.1913.)

Patient: M. K., Dienstmädchen, 18 Jahre alt.

Diagnose: Dysgenitale Fettsucht.

Anamnese: Familienanamnese ohne Belang. Patientin hatte als Kind Rachitis, lernte erst mit 3 Jahren laufen. Mit 15 Jahren wurden ihr die vergrösserten Gaumenmandeln entfernt. Patientin hat noch niemals menstruiert. Klagte über Gedächtnisschwäche. Isst angeblich sebr viel.

Status: Auffallend klein $(144 \mathrm{~cm}$ !). Gewicht $64,0 \mathrm{~kg}$, überreichliche Fettpolster. Protrusio bulbi. Geringes Myxödem der Stirnhaut. Lymphatisches Gewebe am Rachenring und weichen Gaumen. Submaxillaris beiderseits birnengross, Sublinguales geschwollen. Parotis nicht vergrössert. Schilddrüse etwas vorgrössert.

Innere Organe: 0 . B.

Urin: von Eiweiss und Zucker frei. 
b e 11 e IX.

\begin{tabular}{|c|c|c|c|}
\hline 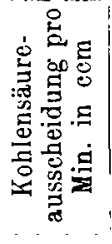 & 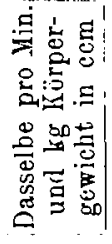 & 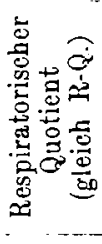 & B e merkug gen \\
\hline 12 & 13 & 14 & 15 \\
\hline $\begin{array}{l}170,9 \\
180,3\end{array}$ & $\begin{array}{l}4,496 \\
4,873\end{array}$ & $\begin{array}{l}0,792 \\
0,870\end{array}$ & $\begin{array}{l}\text { Sämtliche Versuche sind Normalnüch ternruhewerte, welche morgens zwischen } \\
9 \text { und } 10 \text { Uhr aufgenommen wurden. Sie sind aus einer grösseren Anzahl von } \\
\text { Versuchen als die zuverlässigsten und einwandfreisten ausgewählt worden }\end{array}$ \\
\hline $\begin{array}{l}175,6 \\
185,2\end{array}$ & $\begin{array}{l}1,684 \\
2,89+\end{array}$ & 0,841 & Ad 71 und 72 : Versuchsperson: Mädchen G. B., 10 Jahre alt, (irösse: $141 \mathrm{~cm}$. \\
\hline 188,6 & 2,947 & 0,798 & Nr. 71 ist der 3., Nr. 72 ist der 4. an Pat. ausgefübrte Respirationsversuch. \\
\hline 186,9 & 2,920 & 0,798 & $\begin{array}{l}\text { An } \\
\text { Nr. } 74 \text {. ist der } 5 \text {. an Pat. ausgefühte Respirationsversuch. }\end{array}$ \\
\hline $\begin{array}{l}202,5 \\
270,0 \\
319,1\end{array}$ & $\begin{array}{l}2,425 \\
4,355 \\
2,763\end{array}$ & $\begin{array}{l}0,738 \\
0,764 \\
0,797\end{array}$ & $\begin{array}{l}\text { Ad } 75 \text { : Versuchsperson: Frau Ho., } 34 \text { Jahre alt. Grösse: } 154 \mathrm{~cm} \text {. } \\
\text { Ad } 76 \text { : Versuchsperson: Frau M. N., } 38 \text { Jahre alt. Grösse: } 154 \mathrm{~cm} \text {. (1.Versuch.) } \\
\text { Ad } 77 \text { : Versuchsperson: Russe, } 21 \mathrm{~J} \text { ahre alt. Grösse: } 183 \mathrm{~cm} \text {. }\end{array}$ \\
\hline $223,87^{\prime}$ & 3,394 & 0,7 & Ad 78: Versuchsperson: Mädchen M. I, 14 Jahre alt. Grösse: $151 \mathrm{~cm}$. \\
\hline
\end{tabular}

Blutbild: Hämoglohin (Sahli) 75 pCt., Erythrocyten 4240000 , Leukocyten 9600 , davon: aeutrophile $79 \mathrm{pCt}$., Uebergangsformen $3 \mathrm{pCt}$., Iymphocyten $18 \mathrm{pCt}$.

Gynäkologische Diagnose: Ilypoplasie der Ovarien.

9. Fall. (Frau H. O.)

(Vgl. Tabelle IX, Versuch 75.)

\section{Krankengesehichte.}

Patient: Frau H. O., Zimmermannsfrau, 34 Jahre alt.

Diagnose: Endogene Fettsucht (Mikulicz-Syndrom).

An amnese: Seit einem Jahr Schmerzen im Unterleib - rechte Seite - beim Bücken. Stuhlgang angehalten. Patientin leidet viel an Kopfschmerz, besonders 14 Tage vor der Menstruation. Dann bekommt sie unerträgliches Hitzegefühl und Blutwallungen zum Kopf. Sie fühlt sich häıfig sehr matt. Seit 3 Jahren ist die Periode unregelmässig, manchmal nur alle $7-8$ Wochen. Keine Fehlgeburt; zwei Geburten. Trotz lebhaften Wunsches seit 10 Jahren keine Geburt mehr. Mann gesund. Eltern gesund, Vater corpulent. Patientin selbst vor 2 Jahren gelbsüchtig, sonst immer gesund.

Status: Grösse $154 \mathrm{~cm}$, Gewicht $83,5 \mathrm{~kg}$. Sehr corpulente Frau von gesundem Ausseben. Wangen gerötet. Stirn in der Mitte stark pigmentiert mit ziemlich scbarfer Abgrenzung. Graziler Knochenbau. Speicholdrüsen beiderseits vergrössert, so dass die Ohrläppchen abgehoben sind. Isthmus der Schilddrüse ist bypertrophisch, ebenso der rechte Seitenlappen, der druokempfindlich ist. Submaxillardrüse links vergrössert, ebenso beide Sublinguales. Lymphadenoider Rachenring geschwollen, ebenso die Papillae circumvallatae, sonst keine Drüsenschwellungen.

Herz: Spitzenstoss im 5. Interkostalraum, einwärts der Mamillarlinie, von normaler Stärke. Herzgrenzen sind durch die starken Fettpolster hindurch nicht zu percutieren. Ausgesprochene Dämpfung über dem Manubrium sterni, die das Sternum nach beiden Seiten otwas überschreitet, nach rechts unten schräg auswärts verläuft. Herzaction beschleunigt. Herztöne rein.

Puls: yon mittlerer Spannung und Füllung.

Abdomen: Milz nicht mit Sicherheit zu fühlen. Percossorisch nicht vergrössert. Sebr reichliche Fettablagerungen an den typischen Prädilectionsstellen, ror 
allew in der Bauchhaut, die sich geradezu infiltriert anfühlt. Kund un den Brustliorb herum, etwas oberhalb des Rippenbogens, läuft eine breite Fettfalte. Diese, wie die woiter abwärts folgenden Partien sind rechterseits druckschmerzhaft. Die Natesfettpolster sind mächtig entwickelt, ebenso dio P'olster an den Oberschenkclseiten, den Deltamuskeln and don Schultorblättern. Relativ weniger stark entwickelt sind die Mammafettpolster; rechte Mamma stärker entwickelt als dio linke. Sehr starke Fettablagerungen an den Waden. Nirgends über den infiltrierten Stellon aufallendo vasomotorische Veränderung. Schädelumfang $51 \frac{1}{2} \mathrm{~cm}$, Mento-occipitaldurchmesser $17 \mathrm{~cm}$, Fronto-occipitaldurchmesser $16,3 \mathrm{~cm}$, Bitemporaldurchmesser $13,6 \mathrm{~cm}, \mathrm{Bi}-$ parietaldurchmesser $14,0 \mathrm{~cm}$. Patellarreflexo lebhaft. Pupillon gleichweit. Augenbewegung frei. Geruch und Geschmack intact.

Urin: ron Eiweiss frei, von Zucker frei.

Blutbild: Hämoglobin (Sabli) $70 \mathrm{pCt.,}$ Erythrocyten 5584000, Leukocyten 7800, davon: Lymphocyten: grosse 2 pCt., kleine is pCt., Leukocyten: noutrophile 68 pCt., cosinophilo 4 pCt., Uobergangsformen 8 pCt.

10. Fall. (Frau N. N.)

(Vgl. Tabelle IX, Versuch 76.)

Krankengeschichte.

Patient: Firau M. N., 38 Jahre alt.

Diagnose: Endogene (hypophysäre) Fettsucht. 'Thymuspersistenz.

An amnese: Ausser Masern früher immer gesund gewesen, hat 6 Kinder, die ebenfalls alle gesund sind. Seit 6 Jahren hat Patientin keine Periode mehr gehabt. Seit dieser Zeit Körpergewichtszunahme. Im Anschluss an eine Schmierkur bekanı Patientin angeblich Haarausfall und Augenbeschwerden. Keine erbliche Belastung.

Status: Grösse $154 \mathrm{~cm}$, Gewicht 62,0 kg. Blass, mittlerer Knochenbau, sebr stark entwickelte Fottpolster an Bauch und IIüften; stark entwickolte Brüste. Schilddrüse vergrössert; Isthmus und rechter Seitenlappen schwer nach unten abgrenzbar, auch bei stark gestrecktem und gebeugtem Kopf nicht. Dümpfung über dem Brustbein nach rechts einen Querfinger ïber das Sternoclaviculargelenk reichend, von da in einem nach aussen convexen Bogen, der die 2. Rippe ungefähr 3 (querfinger von der Mittellinie entfernt trifft, nach unten in die Herzdämpfung übergehend. Linke Begrenzungslinie nach innen convex, $21 / 2-3 \mathrm{~cm}$ von der Mittellinie entfernt und nach unten in die Herzdämpfung übergehend. Lieine Drüsenschwellungen, Speicheldrüsen: o. B. Mangelhafte Behaarung in Achselböhlen und Schamgegend. Ceber dem Herzen findet sich ein systolisehes Geräusch an der Spitze, über der Aorta, im 2. r. Kippenzwischenraum und im opigastrischen Winkel. Augen: 0. B. Milz nicht fühlbar, unterer Leberrand handbreit unterhalb des Rippenbogens, Leberoberfläclie nicht verändert. Rellexe: 0. B.

Lrin: 0. B.

Blutbild: Hämoglobin 60 pCt., Erythrocyten 3856000 , Leukocyten 7500 .

Im Röntgenbild sieht man eine seiner lage und Form nach als Thymus anzusprechende Verdunkelung oberhalb der Aorta. Ferner ergibl die Röntgenaufnahme des Schädels eine Verbreiternng und Ausbuchtung der Sella turoica.

\section{Fall.}

(Vgl. Tabelle IX, Versuch $7 \pi$.)

\section{Krankengeschichte.}

Patient: Russe, Student, 21 Jahre alt.

Diagnose: Endogene lettsucht, Speicheldrüsenschwellung, l'hymuspersistenz.

Anamnese: Von Kind auf Neigung zur Fettsucht, ebenso wie bei allen kamiliengliedern. 
Status: Grösse $183 \mathrm{~cm}$, Gewicht $115,5 \mathrm{~kg}$. Breitschultriger, blass aussehender Mann mit sehr beträchtlicher Fettentwicklung an Bauch, Hüfte und Nacken. Beide Ohrspeicheldrüsen fühlbar. Die übrigen Speicheldrüsen und Tränøndrüsen nicht veründert. Schilddrüse deutlich fühlbar, über dem Manubrium sterni deutliche Dämpfung. Mammae kolossal entwickelt. X-Beine. Hinter dem Jugulum fühlt man bei starker Exspiration eine weiche Masse (Thymus). $\Lambda$ uch bei der Röntgenuntersuchung scheint über dem Aortenbogen ein bei schräger Durchleuchtung deutlich abgrenzbarer Schatten zu sitzen.

Genitalorgane: 0 . B.

Innere Organe: o. B.

Blutbild: Hämoglobin (Sahli) 100 pCt., Erythrocyten 6200000 , Leukocyten 6800. In mehreren Ausstrichpräparaten keine Lymphocyten zu sehen.

12. Fall. (Mädehen M. L.)

(Vgl. Tabelle IX, Versuch 78.)

\section{d. Krankengeschichte.}

Patient: M. L., Mädchen, 14 Jahre alt.

Diagnose: Endogene Fettsucht; Schilddrüsenvergrösserung.

A namnese: Früher nie krank. Mutter (gestorben) war sehr fett, ebenso von 9 Gesehwistern 1 Bruder und 1 Schwester. Menstruationen sind seit 1 Jahr regelmässig.

Status: Grösse $151 \mathrm{~cm}$, Gewicht 67,5 lig. Kopfmasse: Distanz der Tub. frontalia $5 \mathrm{~cm}$, Distanz der äusseren Gehörgänge $12 \mathrm{~cm}$, Biparietaldurchmesser $141 / 2 \mathrm{~cm}$, Fronto-occipitald urchmesser $171 / 2 \mathrm{~cm}$, Submento-occipitaldurchmesser $20,0 \mathrm{~cm}$, Frontooccipitalumfang $54,4 \mathrm{~cm}$. Ausserordentlich fettes Kind. Das Fett bedeckt mebr diffus, nicht in einzelnen Lagern den ganzen Körper; ist besonders reich an den Brüsten und den Oberschenkeln vorhanden. Ilaut bläulich, nicht myxödematös. Schilddrüse deutlich beiderseits vergrössert. Zäpfchen gespalten. Gaumenmandeln nicht vergrössert.

Herz: Systolisches Geräusch über der Basis.

Puls: 120.

Lungen: o. B. Leber und Milz nicht vergrössert.

Blutbild: Hämoglobin $80 \mathrm{pCt}$., Leukocyten 10500, davon: neutrophile Leukocyten 60 pCt., eosinophile Leukocyten 5 pCt., Lymphocyten: grosse 14 pCt., kleine $20 \mathrm{pCt}$., Uebergangsformen $1 \mathrm{pCt}$.

Wassermann: negativ.

Röntgenbild: kein Thymusschatten. Herzdämpfung nicht verbreitert.

\section{B. Der Grundumsatz.}

Die Fälle 8 bis 12 zeigen, mit $\Lambda$ usnahme von Fall 10 (Versuch 76), Werte, welche in den Bereich des Normalen fallen und auch in der von Noordenschen Tabelle der bisher auf ihren Umsatz untersuchten Fettsüchtigen (vgl. Tabelle II) keine aussergewöhnliche Stellung einnehmen, trotadem nach dem klinischen Befunde es sich durchweg um endogene Fettsuchtsformen handelt.

Bei Fall 10 (Versuch 76) berechtigen die hohen Werte des Umsatzes nicht zu irgend welchen Schlüssen, da es sich um einen einzigen Versuch, und zwar um den ersten handelt, welcher erfahrungsgemäss meistens zu hohe Werte ergibt. Bei den äbrigen Kranken sind die Zahlen nach längerer Uebung an die Ventilatmung gewonnen. 


\section{Zusammenfassung der hauptsächlichsten Frgebnisse.}

1. Unter 12 Fällen von Fettsucht, in denen 10 von sicher endogener Natur sich befinden, können wir 3 hervorheben, die folgende Typen darstellen:

a) Endogene Fettsucht mit gesteigertem Grundumsatz.

b) Endogene Fettsucht (dysgenitale Form) mit periodischen Schwankungen des an der unteren Grenze des Normalen stehenden Grundumsatzes. Parallel diesen Schwankungen wird veränderte Thyreoidinempfindlichkeit beobachtet.

c) Endogene Fettsucht (thyreogene Form) mit einem Grundumsat/, der absolut niedriger ist als der kleinste Normalwert.

Hieraus und aus dem Umstande, dass die Mehrzahl der untersuchten Fälle von endogener Fettsucht von dem normalen Durchschnitt nicht abweichende Zahlen ergab, wird gefolgert, dass zum Begriff der endogenen Fettsucht nicht unbedingt ein dauernd niedriger Grundumsatz gehört, dass vielmehr der Begriff der endogenen Fettsucht sich auch mit einem erhöhten Grundumsatz vereinigen lässt. Eine Erklärung für letzteren muss gesucht werden in einer mangelhaften Function der Fettverbrennung.

a) Es kann dies führen zu secundärer Steigerung der Nahrungsaufnahme und compensatorisch vermehrter Verbrennung von Kohlehydraten.

b) Es ist denkbar, dass auch ohne secundär gesteigerte Nahrungsaufnahme ein durch vermehrte Kohlehydratverbrennung gesteigerter oder normal hoher Umsatz den notwendig folgenden Gewichtsverlust eine gewisse Zeit hindurch durch Wasserretention compensiert. Für eine Bevorzugung der Kohlehydratverbrennung in diesem Falle scheint die bei einer grösseren Anzahl von Fettsüchtigen vorhandene crhöhte Einstellung des R.-Q. zu sprechen.

2. Die umsatzsteigernde Wirkung des l'hyreoidins bei endogener Fettsucht ist an den jeweiligen Zustand der Tätigkeit der Schilddrüse gebunden, derart, dass eine verringerte Function eine höhere Steigerung des Umsatzes, eine erhöhte Function eine geringere oder fehlende Steigerung des Lmsatzes verursacht.

3. Der Nutzeffect bei Muskelarbeit stimmt bei endogener (1. Fall) und exogener Fettsucht überein mit der für normale Individuen gefundenen Grösse.

4. Die Steigerung des Umsatzes nach Nahrungsaufnahme bei endogener Fettsucht (1. Fall) ist nicht geringer als bei Normalen, aber der Kurvenabfall wahrscheinlich verlangsamt.

5. Die Injection von Leptynol hat bei endogener und exogener Fettsucht keine Wirkung:

a) auf das Körpergewicht,

b) die Höhe des Grundumsatzes, 
c) die Höhe des Muskeleffectes,

d) die Steigerung des Umsatzes nach Nahrungsaufnahme (letzteres nur bei einem Fall endogener Fettsucht festgestellt) ${ }^{\mathbf{1}}$ ).

Zum Schluss erfülle ich die angenehme Pflicht, Herrn Prof. Dr. Mohr zu danken für seine Anregung zu dieser Arbeit und für seine stets bereitwillige, weitgehende Unterstützung bei der Ausführung der ihr zu Grunde liegenden Versuche.

\section{Literaturangabe.}

1) Kauffmann, Die therapeutische Verwendung von colloidalem PalladiumHydroxydul (Leptynol). Münchener med. Woohenschr. 1913. S. 525. - Weitere Erfahrungen mit colloidalem Palladium-Hydroxydul. Ebendas. 1913. S. 1261.

2) E. $\Lambda$ bderhalden, Handbuch der biochemischen Untersuchungsmethoden. 1913.

3) L. Mohr, Mothodik der Stoffwechseluntersuchungen. 1912.

4) Landolt und Börnstein, Physikalisch-chemische Tabellen.

5) Kohlrausch, Lehrbuch der praktischen Physik. 1910.

6) L. Mohr, Ueber die innere Secretion der Speicheldrüsen und ihre Beziehung zu den Genitalorganen. Zeitschr. f. Geburtsh. u. Gynäk. Bd. 74. (Hier befindet sich die Krankengeschichte und ein Teil der Versuchsdaten des Falles Mädchen Kl. wieder. Herr Prof. Dr. Mohr batte die Freundlichkeit, mir diesen nicht von mir selbst untersuchten Fall zur ausführlichen Veröffentlichung zu überlassen. Die Untersuchung war unter seiner Leitung von Dr. med. H. Kuhn nach derselben Methodik ausgeführt worden.)

7) Dorselbe, Die Behandlung der Fettsucht. Balneologie und Balneotherapie. 1914. Fischer.

8) von Noorden, Die Fettsucht. 1910.

9) Meyer und Gottlieb, Experimentelle Pharmakologie. 1910.

10) von Noorden, Handbuch der Patbologie des Stoffwechsels, Abschnitt: Fettsucht, Diabetes melitus, Der Hunger und die chronische Unterernährung, Diø Ueberernährung.

11) Magnus-Levy, Ebendas., Abschnitt: Die Physiologie des Stofiwechsels. (Hier findet sich die genaue Literaturangabe der hier citierten Arbeiten von Jaquet und Svenson, Lüthje, Stäholin, Nehring, Stüve, Kraus, Wolpert.

12) von Bergmann, Der Stoff- und Energieumsatz bei infantilem Myxödem und bei Adipositas universalis. Zeitschr. f. exper. Path. u. Therapie. 1909.

13) Zuntz, Physiologie des Stoffwechsels. Abschnitt im Lebrbuch der Physiologie des Menschen ron Zuntz und Löwy. 1913.

1) Hier sei noch die bisherige Literatur über die Wirkung bzw. die Erfolge des Joptynols kurz gestreift. Ausser den beiden oben erwähnten Veröffentlichungen von Ka uffman selbst sind von Gohr und von Vogt (23) aus einer Privatklinik bzw. einer Anstalt für Geisteskranke rein klinisch gehaltene Beobachtungen über Erfolge von Leptynolinjection bei Fettsüchtigen publiciert worden. Beide wenden neben der Leptynolbehandlung die von Kauffmann als Unterstützung der Leptynolwirkung sehr empfohlene Nahrungsbeschränkungen in einem Grade an, der die Gewichtsabnahme allein erklären kann, und machen keine kritischen Parallelversuche ohne Leptynol.

Klinische Beobachtungen und Untersuchungen der Wirkung des Leptynols ron Rosenberg (Deutsche med. Wochenschr. 1914 - vorläufige Veröffentlichung) kommen zu einem negativen Resultat. 
478 H. Haussleiter, Ueber den Gaswechsel verschiedener Formen von Fettsucht.

14) Meeh, Oberflächenmessung des menschlichen Körpers. Zeitschr. f. Biologie. 1879.

15) E. Münzer, Ceber Polycythämie usw. Zoitschr. f. exper. Path. u. Ther. 1909.

16) L. Mohr, Ceber Polycythämie. Mänchener med. Wochenschr. 1913. S. 1739.

17) ron Borgmann und Castex, Beitrag zur Frage der Umsatzminderungen und - Mehrungen im ganzen Tagesversuch. Zeitschr. f, exper. Path. u. T'ber. 1912.

18) von Bergmann, Die Fettsucht in Handbuch der Biochenio. 1910. 13d. IV.

19) L. Mobr, Versuche über Diabetes melitus. Zeitschr. f. exper. Path. u. Ther. 1907.

20) Rubner, Beiträge zur Ernährung im Knabenalter. 1902. - Die Geselze des Energieverbrauchs bei der Ernährung. 1902.

21) Tigerstedt, Stoff- und Kraftwechsel. Wärmehaushalt. In Nag Is Handbuch der Physiologie des Menschen.

22) Gegenbaur-Fürbringer, Lehrbuch der Anatomie des Mensc!en. 1912.

23) Vogt, Die Behandlung der Adipositas universalis mit leptynol. Münchener med. Wochenschr. 1914. S. 1060. 